\title{
ANALYSIS OF A Pinus radiata SEED STOCK FIELD TRIAL IN THE NATIVE AÑO NUEVO STAND IN CALIFORNIA
}

\author{
A Thesis \\ presented to \\ the Faculty of California Polytechnic State University, \\ San Luis Obispo
}

\author{
In Partial Fulfillment \\ of the Requirements for the Degree \\ Master of Science in Forestry Sciences
}

by

Christina Brassey

December 2009 
(C) 2009

Christina Brassey

ALL RIGHTS RESERVED 
COMMITTEE MEMBERSHIP

TITLE:

\author{
ANALYSIS OF A Pinus radiata SEED STOCK FIELD \\ TRIAL IN THE NATIVE AÑO NUEVO STAND IN \\ CALIFORNIA
}

AUTHOR: $\quad$ Christina Brassey

DATE SUBMITED: $\quad$ December 2009

COMMITTEE CHAIR: $\quad$ Dr. Walter Mark, Professor

COMMITTEE MEMBER: $\quad$ Dr. Douglas Piirto, Professor, Department Head

COMMITTEE MEMBER: Dr. Scott Steinmaus, Professor 


\begin{abstract}
ANALYSIS OF A Pinus radiata SEED STOCK FIELD TRIAL IN THE NATIVE AÑO

NUEVO STAND IN CALIFORNIA
\end{abstract}

Christina Brassey

This study was a part of the international collaborative IMPACT project, which aims to address the potential threat that the pitch canker disease poses to the use of Pinus radiata D. Don in plantations in New Zealand, Australia, and Chile. A field trial of 264 seedstocks was planted adjacent to a native stand of pitch canker infected $P$. radiata on the central coast of California, and disease symptom development was recorded over a period of 3 years. The results did not correlate with a greenhouse study of the same seedstocks inoculated with Fusarium circinatum Nirenberg \& O'Donnell, the causal agent of pitch canker. Three main types of symptoms were identified (branch flagging, pitchy buds, and chlorotic tips), and preliminary isolation analyses suggest that the disease observed is actually caused by Diplodia pinea (Desm.) Kickx. Survival analysis showed that the effect of tree genetic origin was significant to its time to disease, and that spatial location in the plantation was also significant. Average nearest neighbor analysis showed disease distribution to be significantly clustered, which also suggests that the disease is not pitch canker, but diplodia blight. This experiment illustrates the difficulty in performing naturally infected field trials when another similar-looking fungal disease is also present. It also provides data on seedstock resistance to diplodia blight, another fungal disease important to $P$. radiata forest managers.

Keywords: Monterey pine, radiata pine, Fusarium circinatum, field trial, resistance trial, natural infection, diplodia blight, GIS, spatial analysis, survival analysis, California, plantation forestry, New Zealand, Australia, Chile, IMPACT, pitch canker 


\section{ACKNOWLEDGMENTS}

Most large documents are rarely the work of a single author. This thesis is no exception to that. I have been fortunate to have support in all aspects of this project, from people and organizations here in California, and all the way across the world in New Zealand and Australia. My involvement in the IMPACT project was made possible through my association with Cal Poly State University and Dr. Wally Mark, who took me on as a graduate student to work on the plantation field trial up at Swanton Pacific Ranch. Funding for my assistantship came from Cal Fire, CSIRO (Australia), and ENSIS (New Zealand), with grant matching through the CSU Agricultural Research Initiative (ARI). I also received generous support from the Harold G. Hull Graduate Assistantship (Cal Poly CAFES), and the CSU Graduate Equity Fellowship.

Dr. Colin Matheson of CSIRO and Toby Stovold of ENSIS provided invaluable insight into the project via thoughtful and productive email exchanges, making it possible for me to complete my portion of the project within a reasonable time period. I very much enjoyed our work and conversations up at Swanton.

I am greatly indebted to David Yun who, on several occasions stayed late into the evening to help me with my GIS analysis. With the help of Mr. Yun, Nikki Smith, and Nathan Smith, I was able to produce the final maps in this report.

Thanks to Dr. Scott Steinmaus, who always took the time to meet with me for discussions about statistical methods and interpretation, and provided thoughtful comments on my Methods and Results sections. Dr. Doug Piirto read and commented on a previous draft of this thesis, and tapped me to teach two courses in the department. That 
experience provided me with important personal and professional development that ended up defining my graduate experience.

I found indispensable moral and intellectual support among teachers, administrators, graduate students, and friends, among whom include Dr. Bill Kinney, Dr. Chip Appel, Dr. Tim Baker, Jason Cummings, Jon Large, Valerie Loe, and Ellen Calcagno: none of whom might expect to find their names in this section, but were important to my success as a graduate student over the last two years, and deserving of acknowledgment.

My family has consistently supported my endeavors, and I am grateful. And of course Eric, for always being there, made this happen. 


\section{TABLE OF CONTENTS}

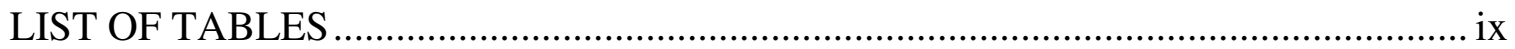

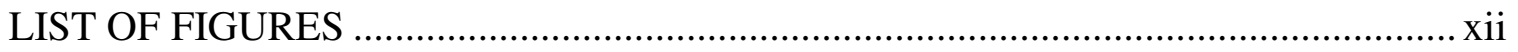

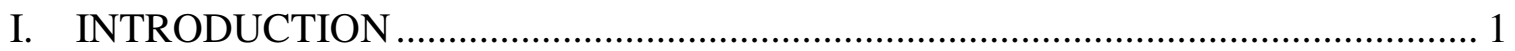

Background Information and Problem Statement.................................................. 1

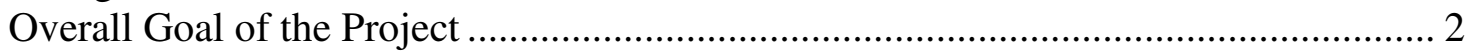

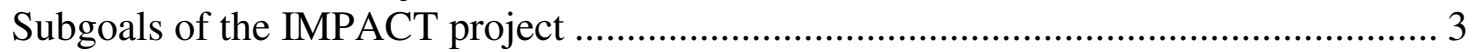

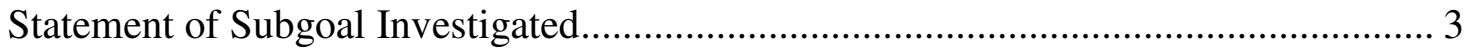

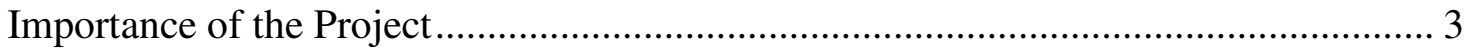

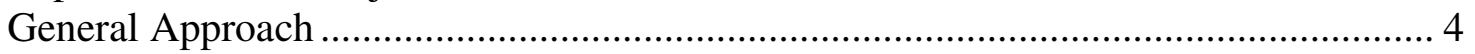

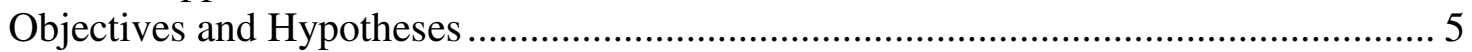

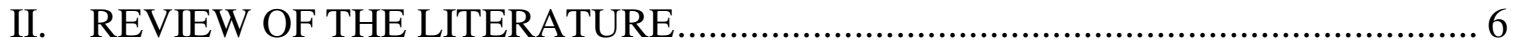

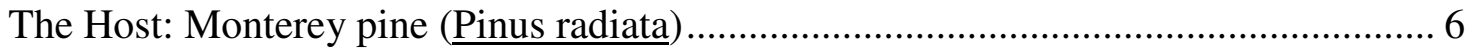

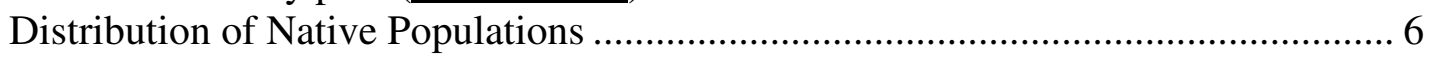

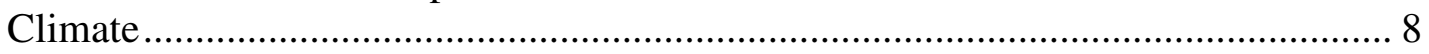

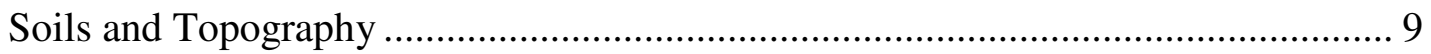

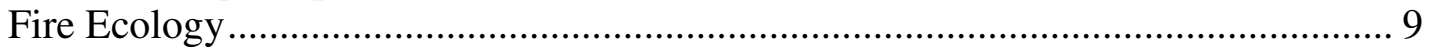

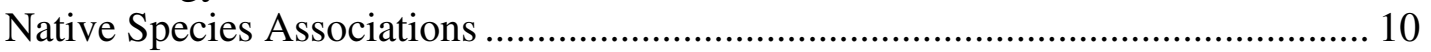

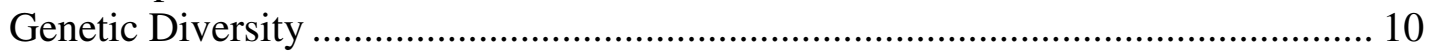

Monterey Pine as a Plantation Species ................................................................ 12

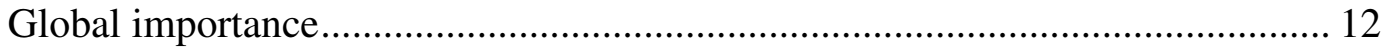

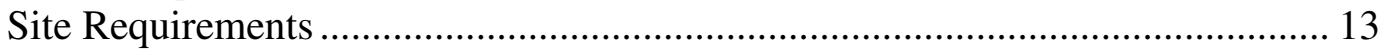

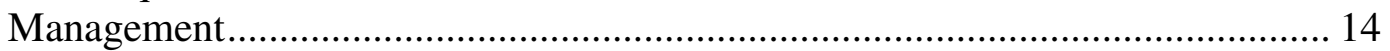

The Pathogen: Fusarium circinatum ............................................................................ 14

Symptoms of Pitch Canker ................................................................................. 15

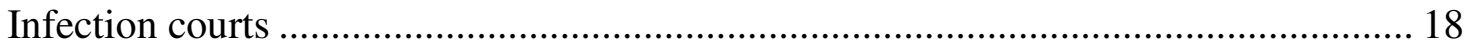

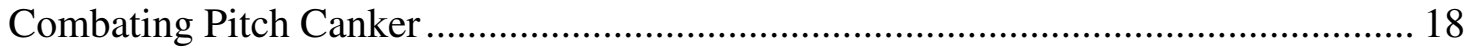

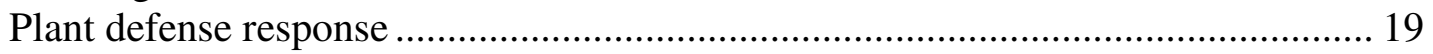

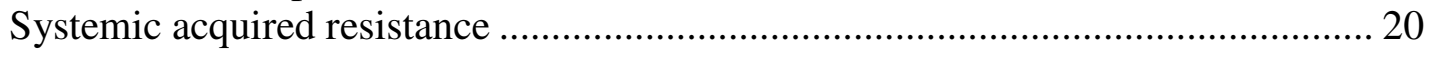

Genetic Resistance …………………………………................................. 21

Pitch Canker Resistance Trials ............................................................................. 23

Plantation Factors that May Affect Disease Incidence …………………...................... 25

Environmental Conditions and Silvicultural Practices ............................................. 26

Biological Factors ....................................................................................... 28

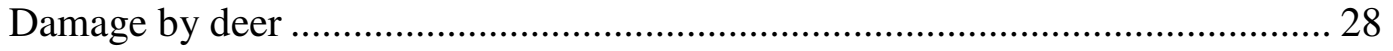

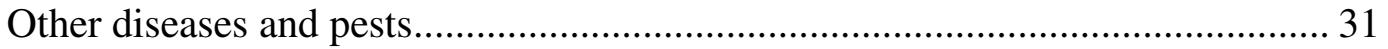

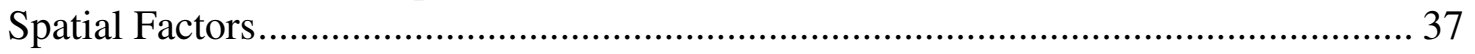




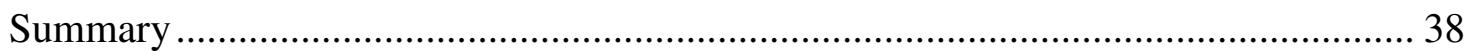

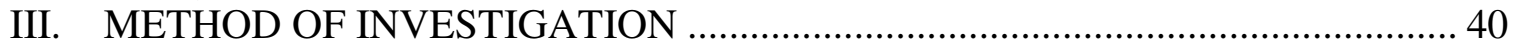

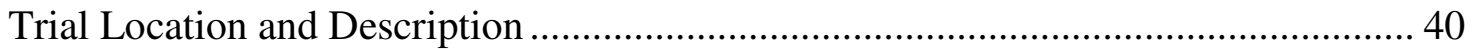

Time and Duration of Trial ................................................................................. 42

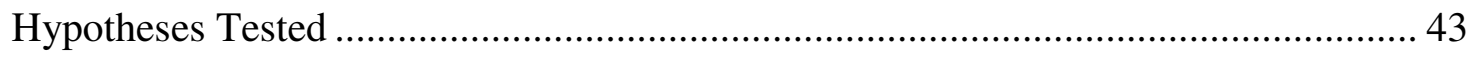

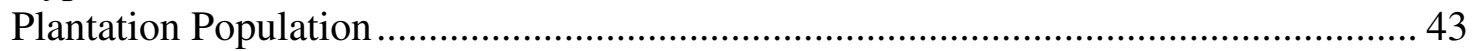

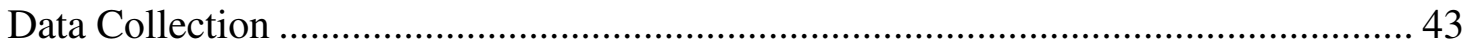

Experimental Design of Field Trial ..................................................................... 44

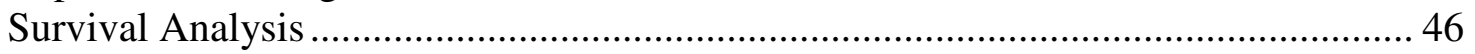

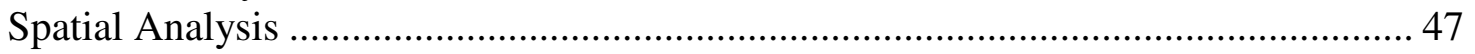

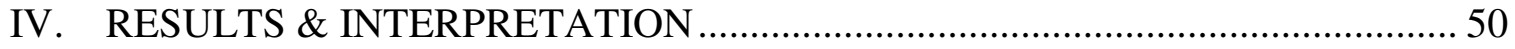

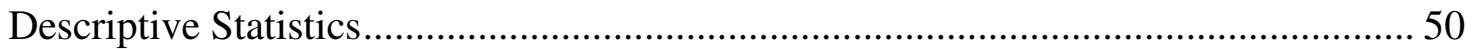

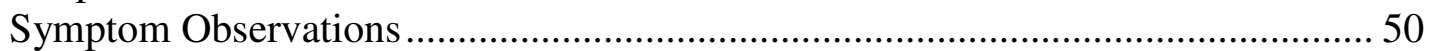

Other Pests Present in the Plantation ................................................................... 58

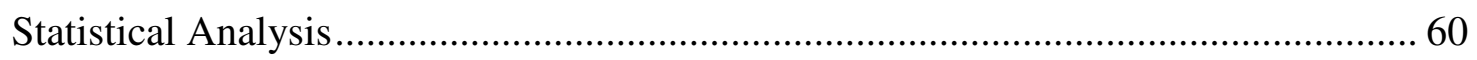

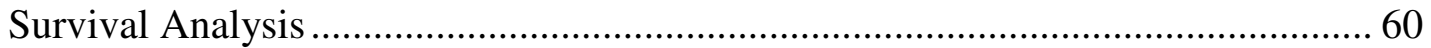

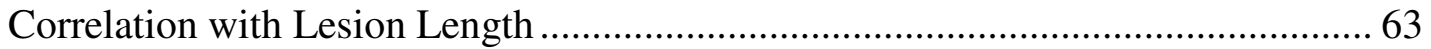

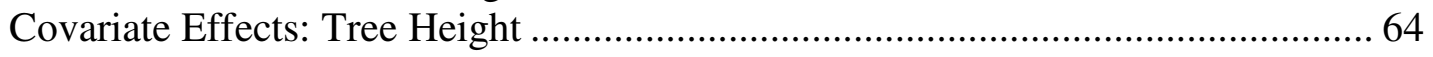

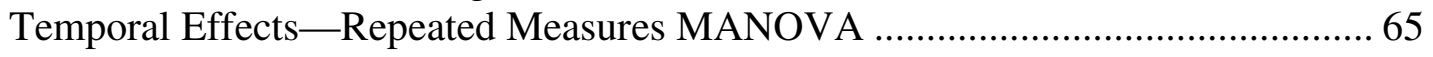

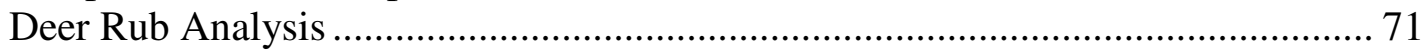

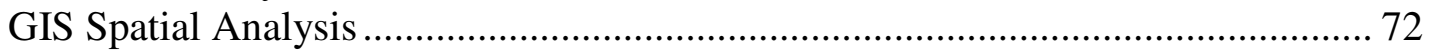

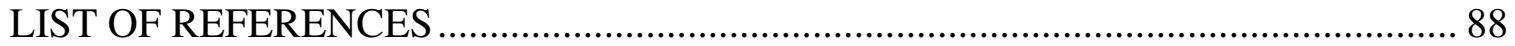

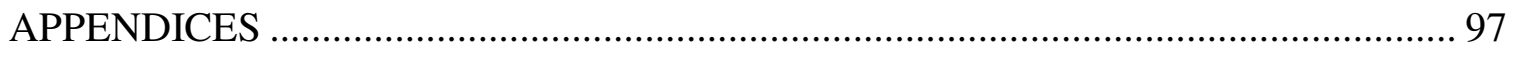

Appendix A: List of seedstock tested, by country origin and suborigin..................... 98

Appendix B: Mean number of symptoms observed on each seedstock, by country origin. Data is from 2009, with the most symptomatic stock listed first................... 100 


\section{LIST OF TABLES}

Table

Page

Table 1. Estimated land area used for Monterey pine plantations worldwide in 1999. Adapted from Balocchi, et al., 1999.

Table 2. Estimated Monterey pine wood use worldwide in 1999. Excerpted from Balocchi, et al., 1999.

Table 3. Variance components from fitting a diallel model to pitch canker resistance heritabilities observed in Monterey pine. General combining ability is observed in polygenic traits whereas specific combining ability is observed in monogenic traits. Adapted from Matheson, et al., 2006.

Table 4. Total number of trees observed to be alive or dead at each annual data collection.

Table 5. Total number of trees displaying presence or absence of flagging symptoms by year.

Table 6. Simple statistics for flagging symptom observations per tree.

Table 7. Number of trees observed with pitchy bud and/or chlorotic tip symptoms observed in the plantation each year.

Table 8 . Simple statistics for pitchy bud and chlorotic tip symptoms per tree.

Table 9. Stock observed to have the highest number of flagging or pitchy bud symptoms. No stock are listed for pitchy buds in 2007 because no more than 1 pitchy bud was observed per tree that year. Stock labeled C6XXX were not included in the greenhouse trial. A complete list of the symptoms observed for each stock is included in Appendix B. Aust=Australia, $\mathrm{NZ}=\mathrm{New}$ Zealand

Table 10. Stock with the longest mean lesion lengths from the greenhouse trial.

Table 11. Total number of trees observed with western gall rust infection or deer rub wounds in the entire plantation.

Table 12. Observations of new deer rub wounds on previously unwounded trees in the plantation by year.

Table 13. Tests for equality across strata. A $p$ value $<.05$ indicates that there is significant variation in time to flagging symptom development at the stock, suborigin, and/or country level.... 
Table 14. Tests for equality over strata within suborigins. Suborigin 11 (Forestal Mininco—Chile) showed significant differences among seedstock for flagging symptoms..

Table 15. Tests for equality across strata. A $p$ value $<.05$ indicates that there is significant variation in time to pitchy bud symptom development at the stock, suborigin, and/or country level.

Table 16. Tests for equality over strata for the Australian suborigins. C5/C6 showed significant differences among seedstock for pitchy bud symptoms.

Table 17. Tests for equality over strata for the New Zealand stock. A $p$ value of $<0.05$ indicates significant differences for pitchy bud symptoms.

Table 18. Tests for equality over strata for the Chilean suborigins. A $p$ value of $<0.05$ indicates significant differences among seedstock for pitchy bud symptoms...63

Table 19. Correlations between mean lesion lengths observed in the greenhouse trial and symptom data from the field trial. Trees were measured in 2007 $(n=3022), 2008(n=2938)$, and $2009(n=2891)$. $P$ values are for the null hypothesis of no correlation. flag=flagging, pbud=pitchy buds, ctip=chlorotic tips, $\mathrm{CC}=$ Pearson correlation coefficient .

Table 20. Analysis of the covariate effect of tree height on the development of flagging symptoms. ht= tree height in 2007, 2008, or 2009

Table 21. Analysis of the covariate effect of tree height on the development of pitchy bud symptoms.

Table 22. Results of a repeated measures MANOVA testing for an effect of time on the development of flagging symptoms. Interaction effects with time are included. r.g.r. = Roy's greatest root

Table 23. Polynomial contrasts for linear and quadratic components in flagging symptom development across replications and seedstock. A $p$ value of $<0.05$ indicates that at least one stock/rep had a significant linear/quadratic time component.

Table 24. Results of a repeated measures MANOVA testing for an effect of time on the development of pitchy bud symptoms. Interaction effects with time are included. r.g.r. $=$ Roy's greatest root

Table 25. Polynomial contrasts for linear and quadratic components in pitchy bud symptom development across replications and seedstock. A $p$ value of $<0.05$ indicates that at least one stock/rep had a significant linear/quadratic time component. 
Table 26. Results of means separation test showing the significance difference in flagging symptoms observed in each block from 2007-2009.

Table 27. Results of means separation test showing the significance difference in pitchy bud symptoms observed in each block from 2007-2009.

Table 28. MANOVA results for deer rub data in 2007, 2008, and 2009. .72

Table 29. Average nearest neighbor spatial statistics for three symptoms observed in the plantation. The nearest neighbor ratio is the observed mean distance divided by the expected mean distance, and the Z-score represents the standard deviation. 


\section{LIST OF FIGURES}

Figure

Page

Fig. 1. General location map of the 5 native populations of Monterey pine.

Excerpted from Rogers, 2002 ......

Fig. 2. Distribution of the three California mainland populations of $P$. radiata: Año Nuevo (upper left), Monterey (right), and Cambria (lower left). Excerpted from The Gymnosperm Database, 2009.

Fig. 3. Relative genetic diversity of Monterey pine (P. radiata) compared to western coniferous species. Diversity measure was percent polymorphic loci. Adapted from Rogers, 2002.

Fig. 4. A resin-soaked lesion on a Pinus radiata branch tip. Excerpted from Storer, et al. 1994 .16

Fig. 5. Resin flowing down the bole of a Monterey pine tree in response to pitch canker infection. Excerpted from Storer, et al. 1994.

Fig. 6. Branch flagging in response to pitch canker infection. Excerpted from Storer, et al. 1994.

Fig. 7. Aborted female cones in response to pitch canker infection. Excerpted from Storer, et al., 1994.

Fig. 8. Variation in mean lesion length in millimeters among trees that have been planted versus natural regeneration $(\mathrm{P}=0.011$; Mann-Whitney test). Tree rank indicates mean lesion length relative to the other trees measured. SE $<$ $0.5 \mathrm{~mm}$ Adapted from Storer, et al., 1999.

Fig. 9. Mechanical trunk wound on Pinus radiata likely due to rubbing by deer. Photo credit: Sarah Degasis.

Fig. 10. Gall on the main stem of a Pinus radiata sapling, caused by western gall rust. Photo credit: Sarah Degasis.

Fig. 11. Austrian pine shoot tip with developing symptoms of Diplodia blight. Excerpted from Peterson, 1981.

Fig. 12. Diplodia pinea pycnidia erupting from cone scales. Excerpted from Peterson \& Nicholls, 1989. 35

Fig. 13. Diplodia pinea pycnidia visible underneath needle fascicle. Excerpted from Peterson, 1981. 
Fig. 14. The sequoia pitch moth, Synanthedon sequoiae. Excerpted from Dreistadt, 2008 .

Fig. 15. Resin masses caused by feeding by Synanthedon sequoiae on Monterey pine. Excerpted from Dreistadt, 2008.

Fig. 16. General area map of trial location showing proximity to the Pacific Ocean, Highway 1, Ano Nuevo Island, and the town of Davenport, CA. Image credit: Google Earth http://earth.google.com.

Fig. 17. GIS Map showing trial location surrounded by native $P$. radiata forest. Trial area is highlighted in green.

Fig. 18. Aerial view of plantation. Image credit: Google Earth http://earth.google.com

Fig. 19. Trial layout design. Circles indicate individual trees, and colors represent blocking. 45

Fig. 20. Example graphical output of ArcView average nearest neighbor analysis.

Fig. 21. Observations by suborigin for two different types of symptoms present in the plantation in 2007. Suborigin identities may be found in Appendix A 53

Fig. 22. Observations by suborigin for two different types of symptoms present in the plantation in 2008. Suborigin identities may be found in Appendix A. 54

Fig. 23. Observations by suborigin for three different types of symptoms present in the plantation in 2009. Suborigin identities may be found in Appendix A. ...... 54

Fig. 24. Observations by replication for two different types of symptoms present in the plantation in 2007. 55

Fig. 25. Observations by replication for two different types of symptoms present in the plantation in 2008 . 56

Fig. 26. Observations by replication for three different types of symptoms present in the plantation in 2009 .

Fig. 27. Life table showing the development of pitchy bud symptoms over time by country of origin. A survival distribution function of 1.00 represents $100 \%$ survival.

Fig. 28. Development of flagging symptoms over the three year period. Suborigin identities may be found in the Appendix. 
Fig. 29. Development of pitchy bud symptoms over time by suborigin. Suborigin identities may be found in the appendix.

Fig. 30. Flagging symptom development over time by replication............................. 70

Fig. 31. Pitchy bud symptom development over time by replication. .......................... 71

Fig. 32. Distribution of trees with flagging symptoms in 2007. Circles symbolize symptomatic trees, and the color indicates relative number of symptoms per tree.

Fig. 33. Distribution of trees with flagging symptoms in 2008. Circles symbolize symptomatic trees, and the color indicates relative number of symptoms per tree.

Fig. 34. Distribution of trees with flagging symptoms in 2009. Circles symbolize symptomatic trees, and the color indicates relative number of symptoms per tree.

Fig. 35. Distribution of trees with pitchy bud symptoms in 2007. Circles symbolize symptomatic trees, and the color indicates relative number of symptoms per tree.

Fig. 36. Distribution of trees with pitchy bud symptoms in 2008. Circles symbolize symptomatic trees, and the color indicates relative number of symptoms per tree.

Fig. 37. Distribution of trees with pitchy bud symptoms in 2009. Circles symbolize symptomatic trees, and the color indicates relative number of symptoms per tree.

Fig. 38. Distribution of trees with pitchy bud symptoms in 2009. Circles symbolize symptomatic trees, and the color indicates relative number of symptoms per tree.

Fig. 39. Symptom distribution in 2007, combined for flagging and pitchy buds. Circles symbolize symptomatic trees, and the color indicates relative number of symptoms per tree.

Fig. 40. Symptom distribution in 2008, combined for flagging and pitchy buds. Circles symbolize symptomatic trees, and the color indicates relative number of symptoms per tree.

Fig. 41. Symptom distribution in 2009, combined for flagging and pitchy buds. Circles symbolize symptomatic trees, and the color indicates relative number of symptoms per tree 


\section{INTRODUCTION}

\section{Background Information and Problem Statement}

Pitch canker is a fungal disease of pines caused by the pathogen Fusarium circinatum Nirenberg \& O'Donnell. Some evidence suggests that $F$. circinatum is native to Mexico, though this has not been confirmed (Gordon, Storer, \& Wood, 2001). It was first described in the United States infecting Virginia pine (Pinus virginiana P. Mill.) trees in the southeast (Hepting \& Roth, 1946). In 1986 the disease was discovered in California, infecting native Monterey pine trees (Pinus radiata D. Don) (McCain, Koehler, \& Tjosvold, 1987). Globally, the disease has been observed in Chile (M.J. Wingfield, Jacobs, Coutinho, Ahumada, \& B.D. Wingfield, 2002), Italy (Carlucci, Colatruglio, \& Frisullo, 2007), South Korea (J.K. Lee, S.H. Lee, Yang, \& Y.W. Lee, 2000), Haiti, Japan, South Africa, Spain, and mainland Mexico (Dwinell, 1999). As of 2007, the disease has not been observed in Australia or New Zealand (Cook \& Matheson, 2008).

Monterey pine has a limited native distribution that has been impacted heavily by human activities, including development, fire suppression, and now the introduction of the pitch canker disease (Rogers, 2002). Currently there are five native populations remaining in the world: three on the Central California coast, and two island populations off the coast of Baja California in Mexico. As a native conifer species, Monterey pine plays an important ecological role in California and Mexico. Prior to the pitch canker 
epidemic in California, it was also important to the local nursery and Christmas tree industries (Owen \& Adams, 1999).

Abroad, Monterey pine accounts for over four million hectares of timber plantations, serving as an important timber species for many countries in the southern hemisphere, including New Zealand, Australia and Chile (Balocchi, Ahumada, \& Ramirez, 1999). In particular, New Zealand utilizes Monterey pine for close to $98 \%$ of the country's annual wood production. This has reduced the pressure to harvest in native forests, which has aided conservation efforts there (Sutton, 1995). The threat of pitch canker to Monterey pine is significant with respect to both ecological and economic perspectives, at local and global levels.

\section{Overall Goal of the Project}

The five native populations in North America represent the source of future genetic variability for plantations abroad, and the introduction of pitch canker has compromised the genetic diversity of these stands. This, along with the current ban on the importation of Monterey pine into Australia and New Zealand has raised concerns about the long-term viability of the species in forest product industries abroad. To address the threat of pitch canker to the future sustainability of $P$. radiata, a broad-based, international collaborative project known as the 'IMPACT project' was formed in 1998. The project is aimed at maintaining the genetic integrity and viability of $P$. radiata in its native range and as a major timber species in the rest of the world. 


\section{Subgoals of the IMPACT project}

- Perform pitch canker resistance trials on Monterey pine plantation stock already in use by countries in the Southern Hemisphere

- Conserve the genetic integrity of the 5 remaining native $P$. radiata populations

- Develop P. radiata trees that are genetically resistant to pitch canker

- Devise a method to transport resistant $P$. radiata plant materials to countries that have a ban on importation

\section{Statement of Subgoal Investigated}

The purpose of this thesis project is to address the need to test foreign plantation stock for genetic resistance to pitch canker. This will provide forest managers and researchers in Australia, New Zealand, and Chile with information about the performance of their seedstock in response to pitch canker infection in a field setting.

\section{Importance of the Project}

This project is important to the future sustainability of Monterey pine plantations in the Southern Hemisphere. Many countries rely on elite breeding material that has been developed to have superior growth characteristics, but that elite material does not necessarily exhibit pitch canker resistance. Disease resistance trials are especially 
important to commercial tree breeding programs because the genetic variability tends to be lower in these trees. This presents the risk that an accidental introduction of $F$. circinatum could devastate plantations and negatively impact the industries and economies based on $P$. radiata. This project will be of interest primarily to those involved in timber production in New Zealand, Australia, and Chile, whose breeding material is being tested in this trial. The results of the trial will identify pitch canker susceptible seedstock that should be phased out of use, as well as resistant stock that may be used as part of a resistance-breeding program.

\section{General Approach}

This was an applied research project, and the results will yield information directly applicable to $P$. radiata plantation managers. It is an empirical study of both genetic and plantation factors that will help managers prevent significant damage to plantations due to a fungal pathogen.

The project is a plantation field trial of 264 seedstock. The plantation has been in place since 2005, and exposed to fungal inoculum from an adjacent mature stand of native Monterey pine. The trees have been observed for the presence and development of disease symptoms over a period of 3 years. 


\section{Objectives and Hypotheses}

There were two main, related objectives of the resistance trial:

1. The assessment of resistance levels in Monterey pine seedstock that have been naturally infected with pitch canker in a field trial. This will test the hypothesis that there exists a variation in resistance levels among the 264 seedstock.

2. The comparison of results from the field trial with that of the greenhouse trial. This will test the hypothesis that the artificial inoculations and measurements of mean lesion length are reliable predictors of pitch canker resistance in the field. 


\section{REVIEW OF THE LITERATURE}

The Host: Monterey pine ( $\underline{\text { Pinus radiata) }}$

Monterey pine is a coniferous tree species with needles in bundles of 2 or 3 , with intermediate tolerance to shade, and generally considered a windfirm species (McDonald \& Laacke, 1990). The species is monecious, with male strobili occurring on side branches, and female cones occurring throughout the crown. It is not known to reproduce vegetatively by sprouts. Pollen is dispersed by wind. Cones are semi-serotinous, opening and closing in response to temperature and humidity. Seedlings develop best on moist mineral soil in full sunlight, free of competing vegetation, especially if disturbed by fire. In the first year, growth can reach $2 \mathrm{ft}$, and by year 5 have formed a lateral (rather than taproot) root system. It is one of the most rapidly growing conifers, reaching over 50 feet and 9 inches in diameter by age 15, though it is fairly average among pines in mature height (69-98 ft) and age (80-100 years). Specimens greater than 150 years are rare.

\section{Distribution of Native Populations}

The native range of Monterey pine is limited to 3 populations on the California Central Coast and 2 island populations off of Baja California (Figure 1). In California, the northernmost population is located east of Point Ano Nuevo in Santa Cruz County, the central population is in Monterey County and the southernmost exists in Cambria in San

Luis Obispo County (Figure 2). Bishop pine ( $P$. muricata D. Don) and knobcone pine $(P$. 
attenuata Lemmon) are closely related species whose distribution overlaps that of Monterey pine, and hybrids with $P$. radiata are known to occur (Critchfield, 1967). The two island populations occur off the coast of Baja California on Guadalupe Island and Cedros Island in Mexico. While each population is not entirely contiguous (most frequently due to urbanization), the 5 distinct populations are recognized as 1) Ano Nuevo, located in Santa Cruz County, 2) Monterey, 3) Cambria, 4) Cedros Island, an island on the continental shelf of the Baja California Peninsula and 5) Guadalupe Island, an island of volcanic origin located about 150 miles from the coast.

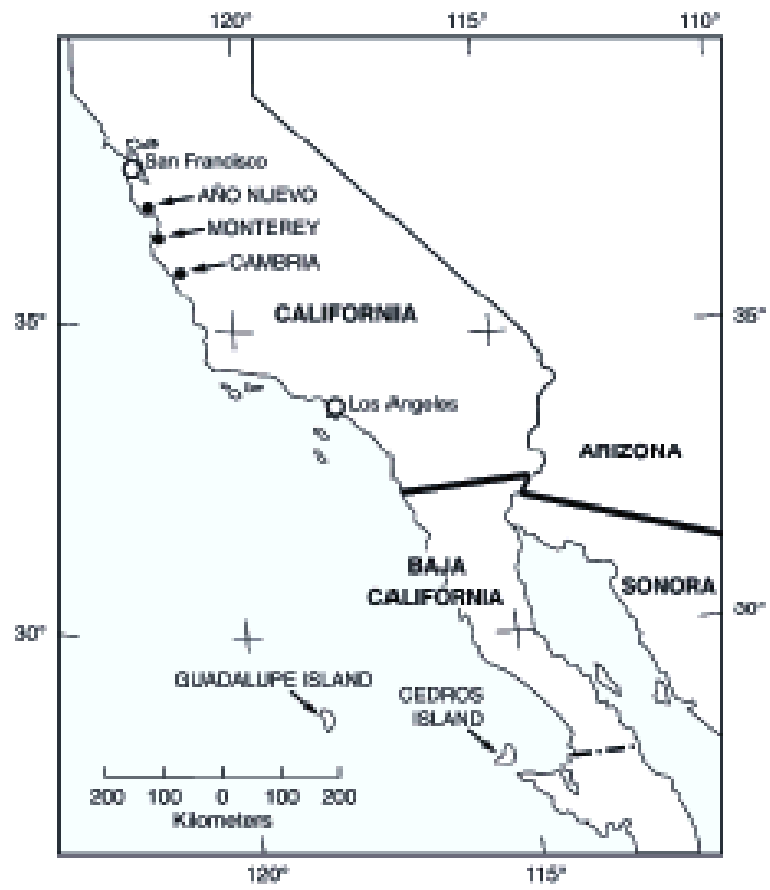

Fig. 1. General location map of the 5 native populations of Monterey pine. Excerpted from Rogers, 2002. 

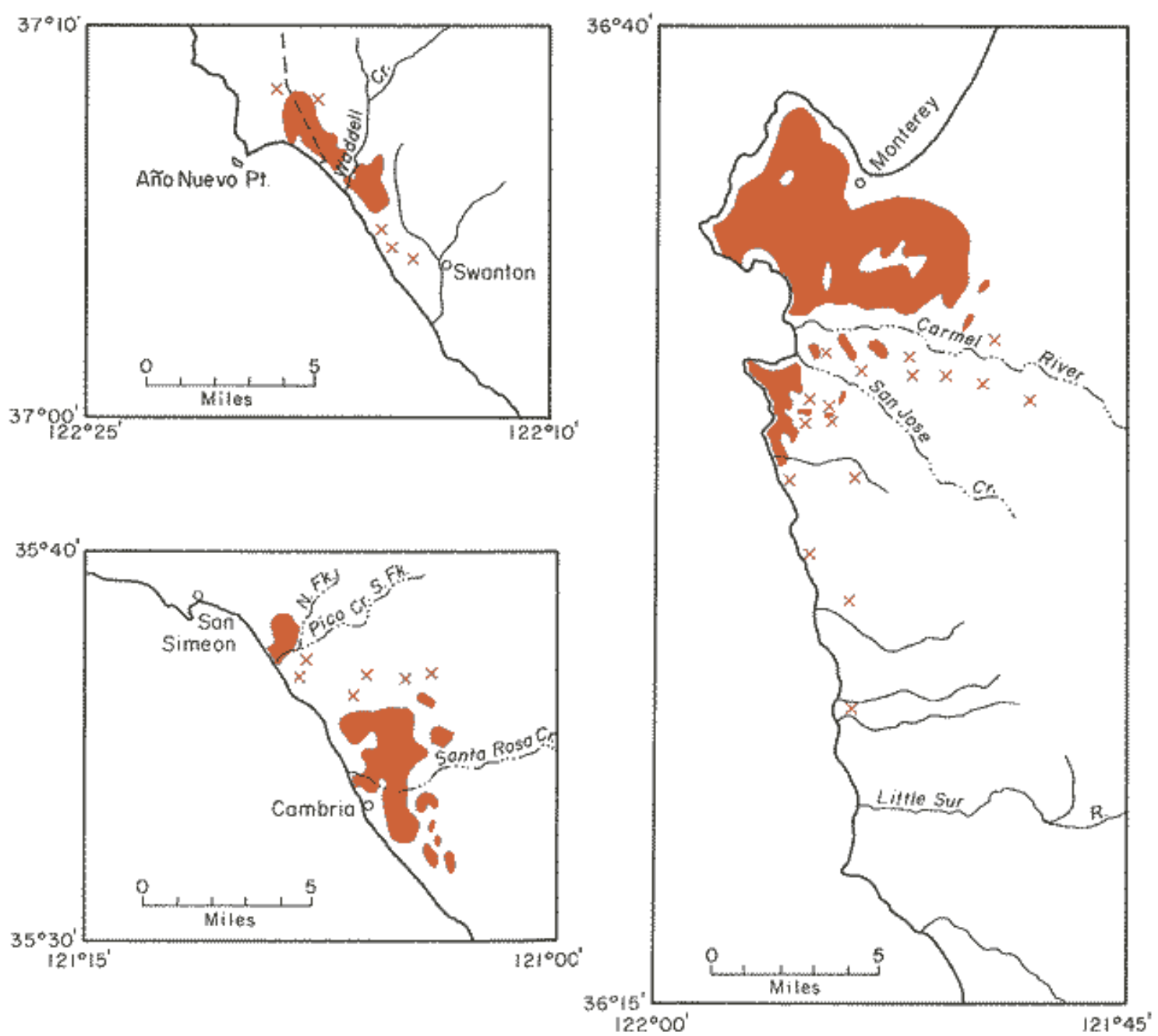

Fig. 2. Distribution of the three California mainland populations of $P$. radiata: Año Nuevo (upper left), Monterey (right), and Cambria (lower left). Excerpted from The Gymnosperm Database, 2009.

\section{Climate}

Monterey pine forests typically exist in the coastal fog zone with cool maritime temperatures that average above $50^{\circ} \mathrm{F}\left(10^{\circ} \mathrm{C}\right)$ year round (Rogers, 2002). Freezing temperatures and frost are rare in the native range of the populations. Currently, native populations of Monterey pine are generally not found further than about 7 miles from the 
coast (McDonald \& Laacke, 1990). This is related to the species' evolution within a maritime climate, characterized in particular by the presence of summer fog drip as a moisture source. Summer fog drip contributes a significant amount of water $(15 \mathrm{~mm} / \mathrm{wk})$, along with a higher relative humidity of $60-70 \%$. Precipitation requirements of the major plantations abroad are generally higher than the native populations, which could be due to the lack of summer fog and other factors related to plantation management.

\section{Soils and Topography}

Monterey pine can grow on a variety of parent material derivatives that range from shales, granite, limestone, sandstone and even volcanic rock on Guadalupe Island (Rogers, 2002). The soils are typically sandy loams with an underlying clay layer. The $\mathrm{pH}$ is acidic to very acidic. The topography is generally hilly and sloping (McDonald \& Laacke, 1990).

Fire Ecology

The semi-serotinous nature of the cones, as well as the cone morphology suggest that Monterey pine is a fire-adapted species (Linhart, 1978). Fire suppression policies, as well as the need for effective defensible space in the wildland-urban interface have likely impacted the natural regeneration of the species in two ways: by reducing the number of seeds released from the cones, and by harboring inoculum sources by not periodically removing diseased and dead trees from the stand. However, the quality and impact of fire 
historically is probably different from fires experienced today (Rogers, 2002), making it unclear that a reintroduction of fire into the habitat would be entirely effective. The proximity of the Monterey and Cambria populations to urban areas most likely precludes the decision to reintroduce fire into the landscape.

\section{Native Species Associations}

As a native conifer species in California, Monterey pine also plays an important ecological role. The species is known to provide important over-wintering sites for the Monarch butterfly Danaus plexippus Linnaeus, as well as form important biological associations with several threatened and endangered endemic plant species (Rogers, 2002). Coleman (1905) found that several mammals depend on the seed crops for food in California, including the Stellar jay, scrub jay, common crow, deer mice, chipmunks and ground squirrels (as cited in McDonald \& Laacke, 1990). A reduction in genetic diversity in the species has implications for the survival of the local ecosystem, as well as the continued viability of the 4 million ha managed abroad.

\section{Genetic Diversity}

Considerable differences in genetic diversity are observable among the 5 native populations (Rogers, 2002). Some of the observable differences include levels of disease resistance and cold hardiness, as well as phenotypic variations in cone size and number of needles per fascicle. However, even though there is genetic variation among the 5 native 
populations, the within-population genetic diversity is markedly lower than other species. Among western coniferous species, Monterey pine ranks below average in terms of within-population genetic diversity (Figure 3). This is notable because the Pinus genus typically has high adaptive potential resulting from genetic diversity. The lack of withinpopulation genetic diversity is important from a conservation standpoint, because each of the remaining native stands are experiencing considerable selection pressures. Over the last two decades, the FAO Panel of Experts on Forest Gene Resources has declared three of the populations to be 'endangered': the Guadalupe population due to intense grazing by feral goats, and the Monterey and Cambria populations due to urban encroachment and genetic contamination. The International Union of Conservation of Nature and Natural Resources (IUCN) has found the future of the three mainland populations to be 'conservation-dependent' and the two island populations to be classified as 'endangered'.

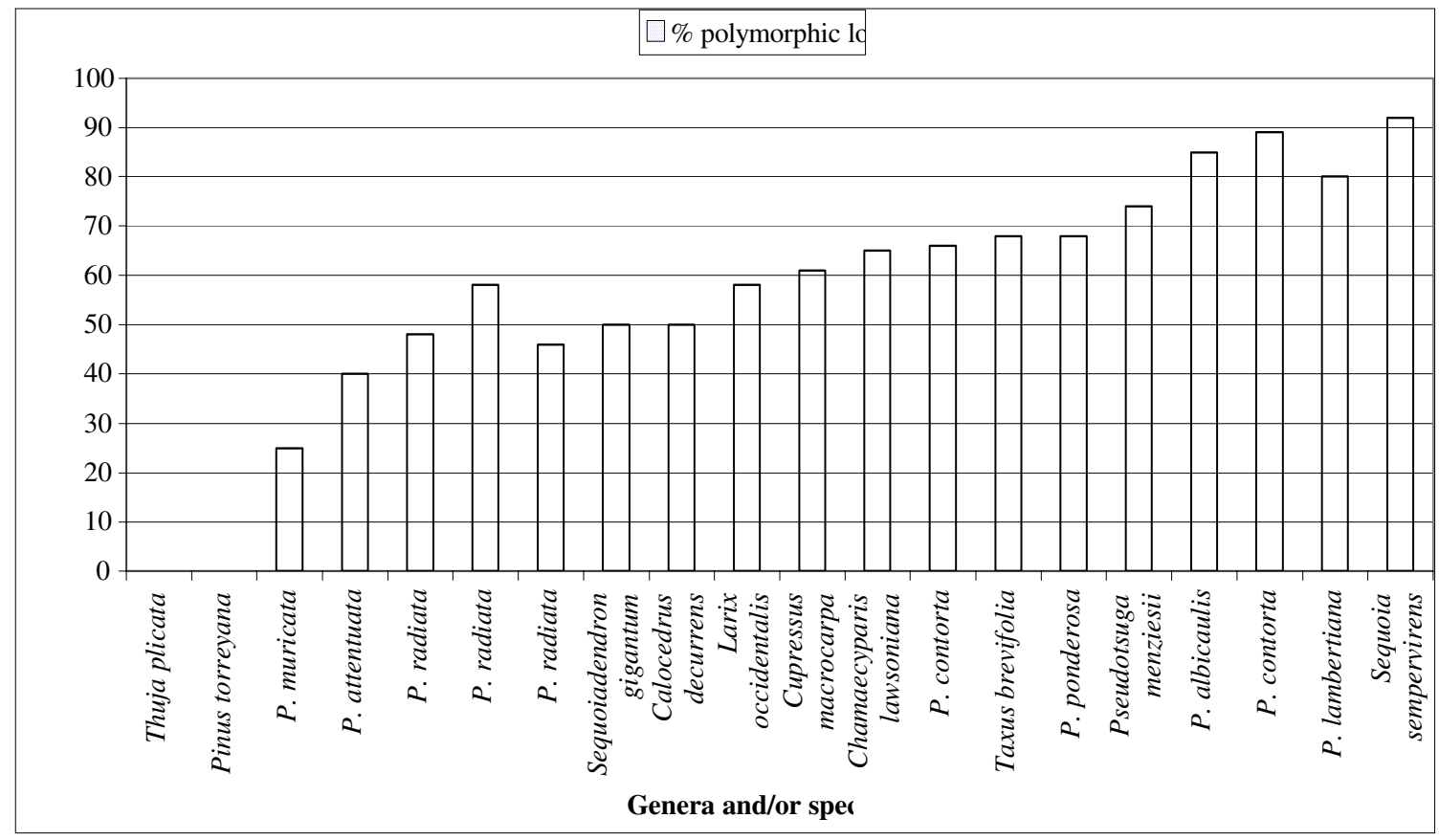

Fig. 3. Relative genetic diversity of Monterey pine (P. radiata) compared to western coniferous species. Diversity measure was percent polymorphic loci. Adapted from Rogers, 2002. 


\section{Monterey Pine as a Plantation Species}

\section{Global importance}

Monterey pine is grown in more places worldwide than any other exotic conifer. Around 3.8 million ha of plantations exist globally, primarily in Chile, New Zealand, Australia, Spain, and South Africa, and this total area increases by about 100,000 ha each year (Balocchi, et al., 1999). The species establishes most successfully in countries with Mediterranean climates and is particularly important to the countries of Chile, New Zealand, and Australia (Table 1).

Table 1. Estimated land area used for Monterey pine plantations worldwide in 1999. Adapted from Balocchi, et al., 1999.

\begin{tabular}{lcc}
\hline Country & Plantation area (ha) & $\begin{array}{c}\text { Wood Production } \\
\left(1000 \mathrm{~m}^{3} / \mathrm{yr}\right)\end{array}$ \\
\hline Chile & 1380 & 18548 \\
New Zealand & 1338 & 17000 \\
Australia & 642 & 10400 \\
Spain & 237 & 2000 \\
South Africa & 66 & 486 \\
Other countries combined & 100 & $\mathrm{n} / \mathrm{a}$ \\
\hline Total & 3763 & 48434 \\
\hline
\end{tabular}

Global Monterey pine wood production is almost $50000000 \mathrm{~m}^{3} / \mathrm{yr}$ and projected to double by the year 2036 (Balocchi, et al., 1999). The wood is mostly used for sawn timber, pulp/paper, and paneling (Table 2), and is generally of low durability. It generally has a pale yellow-brown color with a straight grain and distinct annual rings. Wood 
density increases with tree age, and observations in New Zealand suggest that environmental factors such as temperature and altitude can also affect density. These studies showed that wood produced at lower altitudes with warmer climates had a higher density than wood produced at higher altitudes with cooler temperatures (van de Hoef, 2003).

Table 2. Estimated Monterey pine wood use worldwide in 1999. Excerpted from Balocchi, et al., 1999.

\begin{tabular}{lcccc}
\hline Country & \multicolumn{4}{c}{ Wood use $(\%)$} \\
\hline Shile & Sawn timber & Pulp and paper & Panels & Other \\
Spain & 50 & 40 & 4 & 6 \\
South Africa & 82 & 45 & 0 & 0 \\
Australia & 45 & 0 & 1 & 17 (mostly poles) \\
New Zealand & 60 & 53 & 0 & 2 \\
\hline
\end{tabular}

\section{Site Requirements}

In plantations abroad, Monterey pine performs best at elevations below $900 \mathrm{~m}$ with precipitation levels of at least $750 \mathrm{~mm}$ (van de Hoef, 2003). Favorable temperatures are $25-27^{\circ} \mathrm{C}$ in the summer, and $2-5^{\circ} \mathrm{C}$ in the winter. No more than around 50 frosts per year are tolerable by the species. Monterey pine has a relatively fast growth rate, with rates of $18-30+\mathrm{m}^{3} / \mathrm{ha} / \mathrm{yr}$ being reported in Victoria, Australia, and greater than $50 \mathrm{~m}^{3} / \mathrm{ha} / \mathrm{yr}$ observed in New Zealand. 


\section{Management}

In Australia, Monterey pine is generally managed in two ways. The traditional approach is to manage high-density plantations of trees with multiple thinning operations over a rotation. Rotation ages range between 18 and 35 years. This method provides a constant, relatively small return while nurturing the quality of the final remaining crop of trees (van de Hoef, 2003). The other approach to management includes increasing the spacing between the trees, pruning them to produce more logs at a higher quality, and harvesting only at rotation. This method is common in New Zealand and is referred to as the 'clearwood' management regime. Common diseases and pests problems in Monterey pine plantations abroad include pine needle blight caused by Dothistroma septospora (Dorog.) M. Morelet, Diplodia canker caused by Diplodia pinea (Desm.) J. Kickx F., sirex wood wasp (Sirex noctilio Fabricius [Hymenoptera: Ibaliidae]), fivespined bark beetle (Ips grandicollis Wood \& Bright [Coleoptera:Scolytidae]), and the Monterey pine aphid (Essigella californica Essig. [Hemiptera: Aphididae]).

The Pathogen: Fusarium circinatum

Pitch canker is caused by the necrotrophic, ascomycete fungus $F$. circinatum (teleomorph $=$ Gibberella circinata Nirenberg \& O'Donnell). Though it is known to reproduce sexually in the southeastern U.S, it has only been observed to reproduce asexually in California. The growth of the fungus is optimal at $25^{\circ} \mathrm{C}$, with spore germination favored at $20^{\circ} \mathrm{C}$, and inhibited at temperatures below $10^{\circ} \mathrm{C}$ (Inman, 
Kirkpatrick, Gordon, \& Shaw, 2008). Thus, warm climates would likely favor the pathogen. Temporal variation in spore accumulation occurs throughout the year, with higher spore numbers observed during months with the highest recorded rainfall (Garbelotto, Smith, \& Schweigkofler, 2008).

Spores have been reported to be present in soil (Booth, 1971), and also can be dispersed by wind. Windborne spore dispersal has been observed to occur for distances longer than 200 meters (Garbelotto, et al., 2008). In California, the fungus has been observed on the bodies of several insect species associated with Monterey pine (Hoover, Wood, Fox, \& Bros, 1995), including twig beetles (Pityophthorus spp. [Coleoptera: Scolytidae]), cone beetle (Conophthorus radiatae Hopkins [Coleoptera:Scolytidae]), deathwatch beetle (Ernobius punctulatus LeConte [Coleoptera: Anobiidae]), spittle bug, (Aphrophora canadensis Walley [Homoptera:Cercopidae]) (Storer, Wood, Wikler, \& Gordon, 1998), and engraver beetles (Ips spp. [Coleoptera:Scolytidae]).

\section{Symptoms of Pitch Canker}

Pitch canker symptoms generally manifest once the pathogen enters a wound either on the bole of a tree, or within one or two whorls of the branch tip. It is generally believed that $F$. circinatum could not penetrate an unwounded tree. Once infection occurs, a lesion develops that usually becomes soaked with resin (Figure 4) (Storer, Gordon, Dallara, \& Wood, 1994; Dwinell, Kuhlman, \& Blakeslee, 1981). If the infection is on the bole, copious amounts of resin, "pitch" is often produced by the tree in response, 
and can be observed flowing down the trunk (Figure 5). Severe bole cankers can result in tree death.

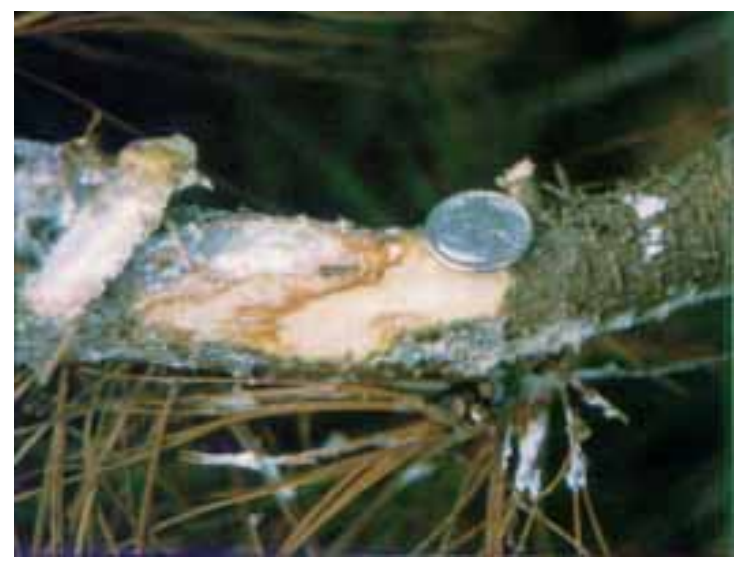

Fig. 4. A resin-soaked lesion on a Pinus radiata branch tip. Excerpted from Storer, et al. 1994.

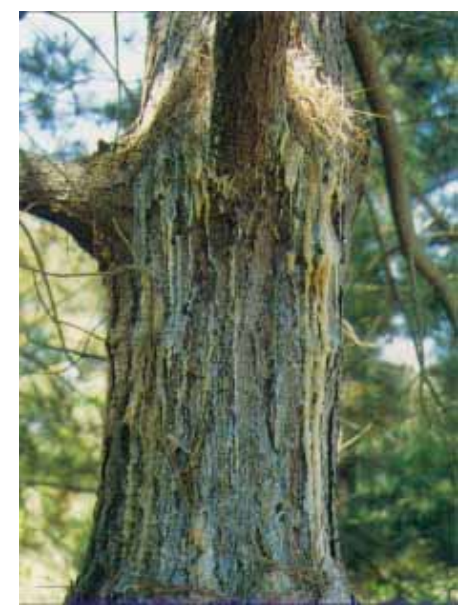

Fig. 5. Resin flowing down the bole of a Monterey pine tree in response to pitch canker infection. Excerpted from Storer, et al. 1994.

Lesions occurring on branch tips first result in localized needle browning, followed by dieback of the entire branch tip distal to the point of infection. Interestingly, the infection does not travel back toward to point of branch attachment, past a whorl or node. The resulting canopy symptoms are referred to as "flagging", and are identified as orange branch tips (Figure 6). The pitch canker fungus is also known to infect both the 
female flowers and cones of southern pines species (Dwinell, 1999) which, if also true for Monterey pine will further reduce regeneration rates (Figure 7).

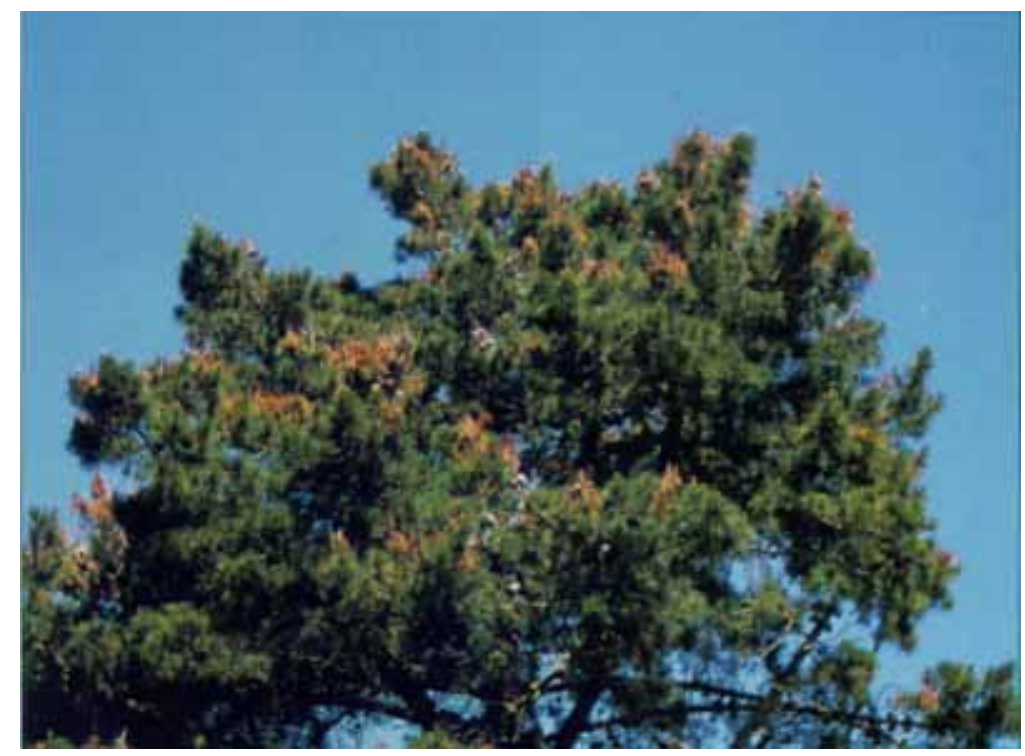

Fig. 6. Branch flagging in response to pitch canker infection. Excerpted from Storer, et al. 1994.

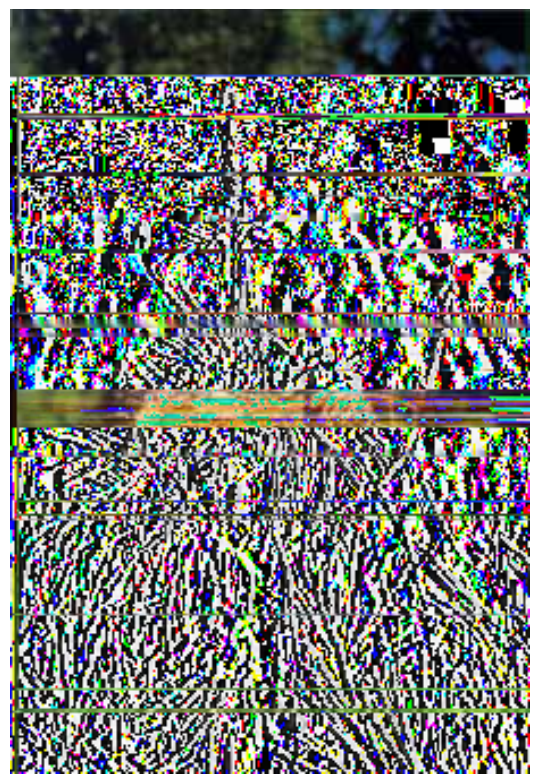

Fig. 7. Aborted female cones in response to pitch canker infection. Excerpted from Storer, et al., 1994. 


\section{Infection courts}

In Florida, pitch canker infections were associated with mechanical damage of slash pine ( $P$. elliottii Engelm.), with cone scars and broken branches becoming infected (Dwinell, et al., 1981). There is some dispute as to whether pitch canker is specifically vectored by insects on Monterey pine in California, or if the wounding caused by many insects merely provides an infection court. There have been several reports of $F$. circinatum spores found on insects in California (Storer, et al., 1998; Hoover, et al., 1995). However, the life histories of some of these insects conflict with the observed patterns of infection. For example, twig beetles are thought to be largely responsible for new branch tip infections on otherwise healthy Monterey pine trees. This conflicts with the current understanding that twig beetles tend to seek out suppressed and weakened branches to feed and breed, because suppressed branches are rarely observed to have infections (Gordon, Storer, \& Wood, 2001).

\section{Combating Pitch Canker}

Combating plant disease requires knowledge about the biology of the host and pathogen, and an understanding of the interaction between the two. An effective management strategy can be devised based on this information, and updated as new information becomes available through current research. The following section begins by outlining the plant resistance response to pitch canker and similar diseases, and concludes 
by discussing various pitch canker management strategies that utilize the resistance response, such as the development of resistant varieties.

\section{Plant defense response}

The plant response to infection by a foreign organism basically involves two types of defenses: constitutive and induced responses. Constitutive responses are always present in a plant and serve to repel potential disease agents. An example of a constitutive defense would be a phytochemical that is always present in leaves and is toxic to herbivorous insects or fungi. In contrast, induced responses are active only in the event of an invasion. An example of an induced response would be a gene that controls resin production being triggered by a chemical present on the pathogenic agent.

Resin production can counteract the invasion of pathogens and is both a constitutive and induced defense response in $P$. radiata. It is always present in the tree, and increased production can be induced in response to invasion. The most abundant phytochemicals in Monterey pine resin include several different terpenes, including mainly $\alpha$-pinene and $\beta$-pinene. Hybridizations of $P$. radiata with other native pines often occurs, and the result is varying levels of limonene, phellandrene, sabinene, and myrcene also being detected in the resin. Terpene production has been observed to be the highest in the resin ducts located in the needles (Cori, et al., 1968).

Inducible responses to invasion by $F$. circinatum have been demonstrated in several southern pine species, and could be similar to the mechanisms at work in Monterey pine. The histopathology of the pitch canker infection response of four other 
pine species was described by Barrows-Broaddus \& Dwinell (1983). The fungus attacked parenchyma cells, growing intercellularly and leaving empty pockets in the cortex when these cells were killed. In response to the presence of the disease, the plant formed inactive lesions surrounding the infection, and sloughed off killed cells. This was accomplished with the pith parenchyma cells accumulating lignin in their cell walls, and the xylem cells promoting the growth of adjacent regenerative parenchyma cells to take the place of killed cells. Infections seemed to be bound by the periderm in some species, possibly due to the presence of suberin in the cell walls. Xylem tracheids filled with resin and were not attacked by the fungus at all. Infections always stopped at nodes below the infection point, where the tracheids of emerging buds are concentrated. Also, the xylem tracheids located on the infection front were spatially oriented differently than other tracheids, apparently forming a physical barrier. So it seems that the fungus is unable to attack tracheids, and that their presence and formation are key to containing pitch canker infection. When selecting for and developing resistant varieties of plants, it is helpful and important to have an understanding of the cellular and biochemical mechanisms involved in disease resistance.

\section{Systemic acquired resistance}

Plants also can have inducible defenses that occur in response to subsequent infections. Different mechanisms and terminology exist for these responses, but will be referred to collectively as systemic acquired resistance (SAR) here. A few experiments have shown that repeated pitch canker infections in Monterey pine result in smaller 
lesions each time (Bonello, Gordon, \& Storer, 2001, Storer, Bonello, Gordon, \& Wood, 1999). This suggests that there may be an inducible resistance response over time with repeated infections.

Genetic Resistance

The rates of lesion development in infected trees have been measured as a way of quantifying the relative levels of resistance to the disease in different trees. By artificially inoculating and then measuring the lengths of the resulting pitch canker lesions in a stand of Monterey pine, Storer, et al., (1999) reported varying levels of resistance along a continuous gradient. In the same experiment, it was also shown that stands that are allowed to regenerate naturally following fires showed greater resistance to pitch canker than do stands that are replanted (Figure 8). This is likely due to the greater genetic variation in naturally regenerating stands, and suggests that 1) different levels of resistance exist in Monterey pine, and 2) pitch canker resistance is a heritable trait. 


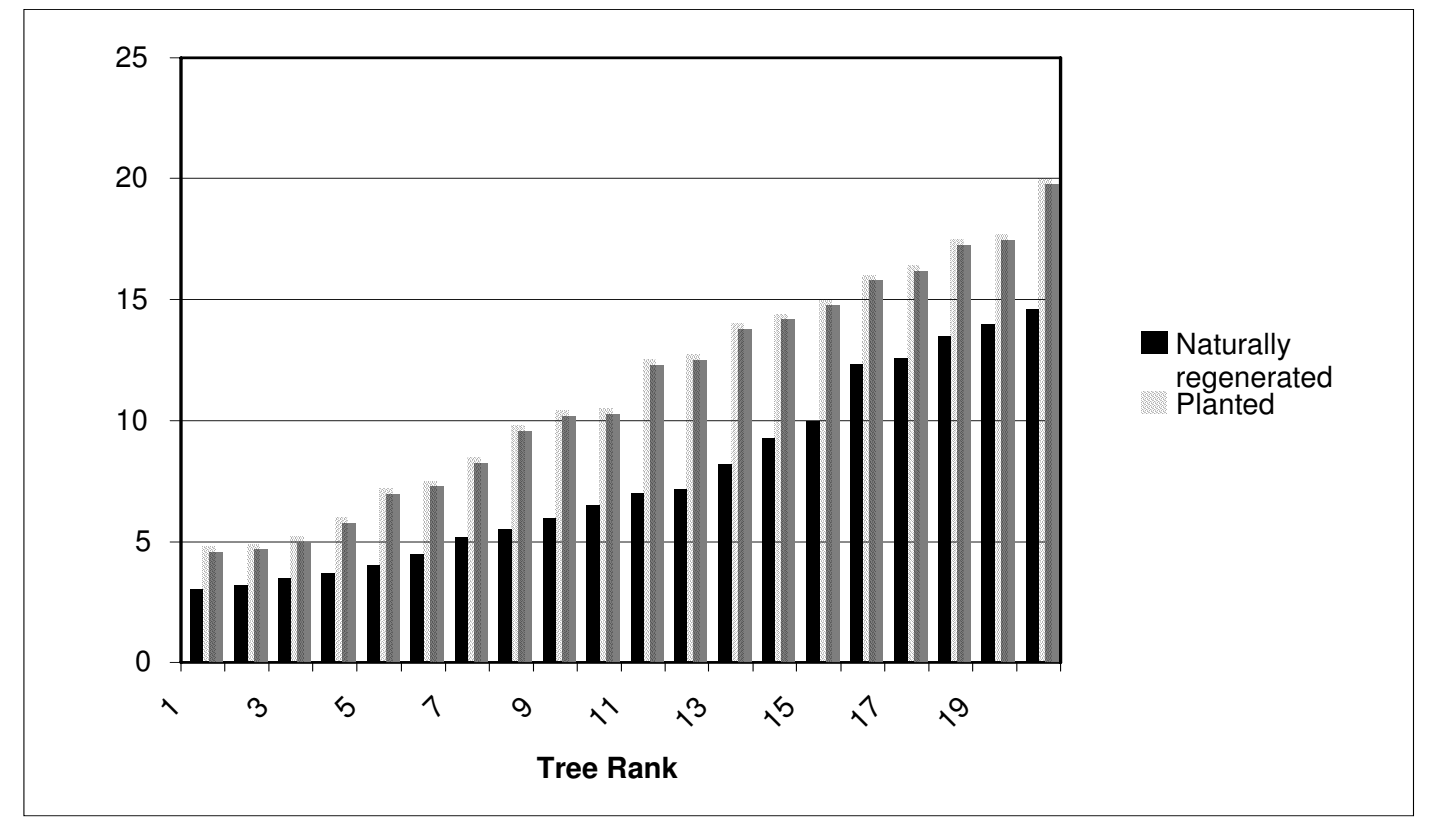

Fig. 8. Variation in mean lesion length in millimeters among trees that have been planted versus natural regeneration ( $P=0.011$; Mann-Whitney test). Tree rank indicates mean lesion length relative to the other trees measured. $\mathrm{SE}<0.5 \mathrm{~mm}$ Adapted from Storer, et al., 1999.

The observation that resistance occurs along a continuous gradient suggests that it is controlled by several genes (polygenic resistance). The heritability of a trait can be estimated if the genetic origin of one or both parents is known. The trait heritabilities for open pollinated families have one known parent and are treated as half sibs, whereas trees from closed pollinated families are treated as full sibs, as both parents are known. Matheson, et al., (2006) analyzed lesion length data on a plantation of known genetic origin to determine whether pitch canker resistance is controlled by one or many genes (monogenic or polygenic). A diallel model was used, which can estimate the ability of a gene to be inherited singularly or in combination with other genes (Table 3). This experiment confirmed that resistance was heritable and that it was polygenic in character. 
Table 3. Variance components from fitting a diallel model to pitch canker resistance heritabilities observed in Monterey pine. General combining ability is observed in polygenic traits whereas specific combining ability is observed in monogenic traits. Adapted from Matheson, et al., 2006.

\begin{tabular}{lcc}
\hline Term & Variance component & Standard error \\
\hline General combining ability & 4.59 & 2.98 \\
Specific combining ability & 25.19 & 5.96 \\
Residual & 164.75 & 4.58 \\
\hline
\end{tabular}

Polygenic resistance is more durable and stable than monogenic resistance, because it does not exert a strong selection pressure on the pathogen. Fungal species generally have shorter life-spans than trees and can evolve much faster. Therefore, it is important that the tree's disease resistance is not reliant on the inheritance of a single gene. Polygenic resistance ensures that a pathogen will not be able to easily overcome tree resistance by evolving. The observation that Monterey pine resistance to pitch canker appears to be a polygenic trait suggests that a tree breeding program for resistance could be very successful.

\section{Pitch Canker Resistance Trials}

Field trials for pitch canker resistance have been performed throughout the world on a variety of pine species, including Monterey pine. It is especially important to conduct disease resistance trials within commercial tree breeding programs, as the genetic variation tends to be lower in these trees. Many studies have been conducted in southern pine forests in the southeastern USA, where the pitch canker disease was first 
documented and is still prevalent. Field trials are most often infected by artificial inoculation, though natural infections have been studied in the southeastern USA. Experiments by Blakeslee \& Rockwood (1999) utilized natural infection by locating field trials "in areas with a history of significant pitch canker occurrence", though it is unclear how this significance was determined. The pitch canker symptom data collected was usually branch flagging during the late-spring to early-summer, when the disease is typically at its peak. In some trials, artificial inoculations were used to supplement natural infection, as a way to address escapes and the natural patterns of disease development that can occur in a plantation.

Pitch canker resistance in slash and loblolly pine has been shown to have genetic basis in both greenhouse and field trials (Blakeslee \& Rockwood, 1999). The heritability observed was high, with estimates exceeding 0.65 and 0.25 for family and individual heritability. Field trials that were both naturally and artificially inoculated were found to confirm greenhouse trials. The Cooperative Forest Genetics Research Program (CFGRP) through the University of Florida, and the North Carolina State Forest Tree Improvement Cooperative (NCSCTIP) have done extensive work on the genetics of pitch canker resistance, and have found no significant relationship between pitch canker resistance and traits like tree growth or rust resistance.

In response to the discovery of the disease in California in the early 1980's, research on pitch canker there has focused on the susceptibility of various landscape and native conifers, as well as the different resistance levels observed in Monterey pine seedlings and mature trees (Aegerter \& Gordon, 2006; Clark \& Gordon, 1999; Gordon, Okamoto, Storer, \& Wood, 1998; Sammon, Adams, Gordon, Frankel, \& Ringnes, 1999; 
Storer et al., 1999; and others). Resistance trials of Mexican and other Central American species of pines have also been performed, finding species more closely related to $P$. radiata (sub-section Patula) to be more susceptible, and those from sub-section Oocarpa to display significantly more resistance (Hodge, 1999; Hodge \& Dvorak, 2000).

Differences in resistance with respect to elevation have been noted, with pines growing at lower elevations showing higher resistance levels (Hodge \& Dvorak, 2007).

Other examples of international pitch canker resistance trials include those in South Africa, where researchers have addressed the variation in resistance among Pinus spp. by testing hybrids for their breeding programs. Reliable inoculation techniques have been developed for use in these types of trials (Roux et al., 2007). Developing trees resistant to pitch canker in South Africa is particularly challenging as $F$. circinatum has been found to undergo sexual reproduction there, which would render any host genetic resistance less durable. Finally, as examples of pitch canker resistance trials underway in Asia, South Korean researchers are testing Pinus spp. hybrids for use in plantations and seed orchards (Kim, Woo, Koo, \& Yeo, 2008). Another study found that wounding due to weather events provided the primary infection courts for F. circinatum (Woo, Y.J. Kim, T.S. Kim, \& Lee, 2005).

Plantation Factors that May Affect Disease Incidence

The presence and severity of forest diseases in plantations can be described as a function of the conditions known as the "disease triangle". The first and second requirements for disease presence are that a susceptible host is present, along with the 
causal agent, the pathogen. Thirdly, the environmental conditions must be such that favor host and pathogen survival. If all of these conditions are met in some proportion, then disease development is likely. A fourth, temporal component is sometimes added to include diseases that require a particular season or time period that may be requisite for development. Disease movement through a forest plantation requires an understanding of the spatial, biological and environmental conditions that make up the operational environment.

\section{Environmental Conditions and Silvicultural Practices}

The abiotic factors that have the greatest influence on the development of pitch canker are the availability of water and nutrients for the trees. Environmental stress factors can predispose trees to disease infection, by diverting resource allocation from defense mechanisms. For example, a tree that is experiencing water stress might allocate its resources (e.g. energy, nutrients) toward the production of additional fine roots to increase water absorption. If the tree were subsequently attacked by a fungal pathogen, there would be fewer resources available for the production of the phytochemicals necessary to mount an effective defense response.

Water stress has the additional effect of disrupting metabolic processes in plants by changing intracellular conditions such as solute concentration and distribution, turgor and temperature, in addition to being directly involved in many reactions. If the tree is not metabolizing properly, it is unlikely to be able to induce an effective disease response. Also, excessive heat in a plant cell can cause the hydrolysis of proteins into 
amino acids (Smith, 1970), which are a favorable source of nitrogen for fungal pathogens. Fire suppression in California has resulted in overstocked stands of Monterey pine, and the resulting waters stress probably exacerbates the disease (Ganley, 2006). It would follow that thinning out the stands would decrease competition for moisture and reduce plant stress and disease incidence. The use of irrigation could also be beneficial.

Fertilization has been found to increase pitch canker disease severity, and so should be avoided if possible (Ganley, 2006). In particular, high levels of nitrogen have been linked to pitch canker disease severity in slash pine in Florida (Lopez-Zamora, et al., 2007). High potassium levels have also been positively correlated with pitch canker disease severity. Fungi require nitrogen for many cellular components and thus require it to survive. However, the nitrogen must be in a form that the particular fungus can utilize. Most fungi can easily utilize free amino acids and/or salts that contain nitrate $\left(\mathrm{NO}_{3}{ }^{-}\right)$, nitrite $\left(\mathrm{NO}_{2}{ }^{-}\right)$, or ammonium $\left(\mathrm{NH}_{4}{ }^{+}\right)($Smith, 1970). Fertilization causes a flush of new growth that is rich in free amino acids in the plant, and the fertilizers themselves are made up of nitrogenous salts that would be easily tapped by a fungus growing within the vascular tissues of a plant. Fungi also require potassium (in the form of phosphate) in high amounts and thus benefit from the addition of this element through fertilization as well.

As chemical or biological controls for diseases in a forested environment are typically impractical and expensive, forest and plantation managers have either tried various silvicultural practices or simply chosen not to plant Monterey pine. As research on the heritability of pitch canker resistance advances, the use of resistant varieties will hopefully become an effective management strategy. Pitch canker can be removed from 
a tree by pruning out infected branches, and this may slow disease spread through a forest by removing inoculum sources (Gordon, et al., 2001). However, pruning will not prevent future infections from occurring, so the practice has limited practicality. Also, it remains to be demonstrated whether pruning wounds could serve as possible infection courts. When entire trees are diseased and removal is necessary, it is currently recommended to keep all diseased material on-site, in an effort to prevent spread of the disease to new areas. Dead material should be chipped to reduce insect breeding sites. High temperatures will kill the fungus, so the chips should be tarped or composted.

\section{Biological Factors}

\section{Damage by deer}

While it may or may not influence fungal disease severity, it is often overlooked that large herbivores are present in plantations, and can create additional stress on trees by wounding them. For example, young seedlings and the new growth of trees are commonly browsed by species such as the black-tailed deer (Odocoileus hemionus spp. columbianas Richardson) in California. Conifers are browsed the most intensely during the winter, though exceptions occur. The fertility of the site, seedling height, tree species, and even the variety of tree within species can influence tree selection by deer (Gill, 1992). Trees that were browsed within the last year are likely to be browsed again. Hood \& Libby (1980) studied deer browsing in a plantation of Monterey pine seedlings from the Año Nuevo, Monterey, and Cambria native populations, finding significant 
differences among the three populations for deer browsing incidence. Seedlings from Año Nuevo were browsed the heaviest, followed by Monterey and then Cambria. Bark stripping occurs when deer remove bark by chewing on it and eating it. Welch et al. (1987) observed red deer (Cervus elaphus Linnaeus) in a Sitka spruce (Picea sitchensis (Bong.) Carr.) forest in western Scotland, finding that damage most often occurred in the winter. Tree age and size were important factors in tree selection by deer for stripping, with the most damage occurring in pole-stage forests. The spatial distribution of bark stripping by red deer tended not to be random, but clustered, according to a nearest neighbor analysis. Trees selected for stripping were likely to be selected multiple times. The average wound was $12 \mathrm{~cm}$ in length and 5-6 cm in width, and located on the bole between 50-100 $\mathrm{cm}$ above ground (Welch et al., 1988). Tree species and branch morphology are also important factors in tree selection by deer for stripping (Gill,1992).

Bark rubbing occurs when bark is removed from the due to the rubbing of antlers against the trunk. Evidence of buck presence in plantations is visible in the form of large mechanical trunk wounds and broken branches resulting from the antler rubbing (Figure 9). 


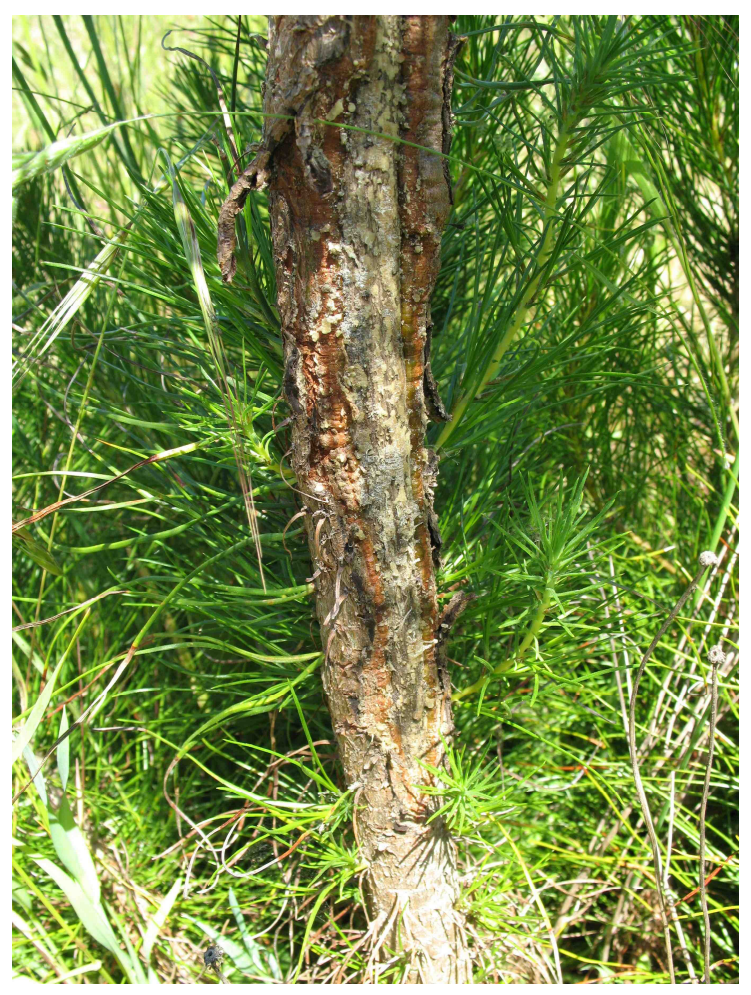

Fig. 9. Mechanical trunk wound on Pinus radiata likely due to rubbing by deer. Photo credit: Sarah Degasis.

Deer rubbing is usually associated with mating behavior, with such functions as signaling rival males, marking territory, or leaving scent. Rubbing is also performed to remove velvet from antlers, though this is less common (Gill, 1992). Blacktailed deer bucks have deciduous antlers that develop between April and August (Blood, 2000). During this time the antlers are covered in a soft velvet layer that functions to supply the antler with nutrients. When antler development is complete, the velvet dries up and is rubbed off when the buck rubs his antlers against hard surfaces, often trees. This prepares the buck for the breeding season, which occurs in late fall, after which time the antlers are shed. Studies on red and roe (Capreolus capreolus Linnaeus) deer showed a preference for particular tree species and diameters, as well as spatial location in the plantation. For pine trees, red deer tended to select diameters between 7-10 cm, whereas the smaller roe 
deer selected diameters between 3-5 cm (Ramos, Bugalho, Cortez, \& Iason, 2006). Red deer also preferred to rub trees on the edges of plantations whereas roe deer selected trees within the plantation.

\section{Other diseases and pests}

As in 'natural' forest ecosystems, plantations are usually populated with several types of disease-causing bacteria and fungi, which together contribute to the overall vigor and relative disease resistance levels of the trees. In addition to pitch canker, two notable fungal diseases of Monterey pine include western gall rust and Diplodia blight.

Western gall rust. The fungal pathogen Endocronartium harknessii (J.P. Moore) Y. Hiratsuka causes the disease known as western gall rust. The fungus is an autoecious basidiomycete, producing aeciospores that effectively function as teliospores. Aecial hosts include the 2- and 3-needled Pinus species. There are no teliospores or telial hosts. The current confirmed range of the disease includes Canada and the USA, with infections reported on jack pine ( $P$. banksiana Lamb.), lodgepole pine ( $P$. contorta Dougl. ex

Loud.), western yellow pine (P. ponderosa P. \& C. Lawson), knobcone pine, bishop pine and Monterey pine. European species planted in North America have reportedly become infected, including Scots pine (P. sylvestris L.), Aleppo pine (P. halepensis P. Mill.), mountain pine (P. mugo Turra), and Austrian pine (P. nigra Arnold) (CABI/EPPO, n.d.). Woody, globose galls on the main stem or branches typically form in the spring, between 1-4 years after infection (Figure 10). These galls produce spores in the spring, which are 
carried by wind and can directly infect other Pinus spp. in the area. Yellow or orange aecia can be visible when the bark sloughs off in scales.

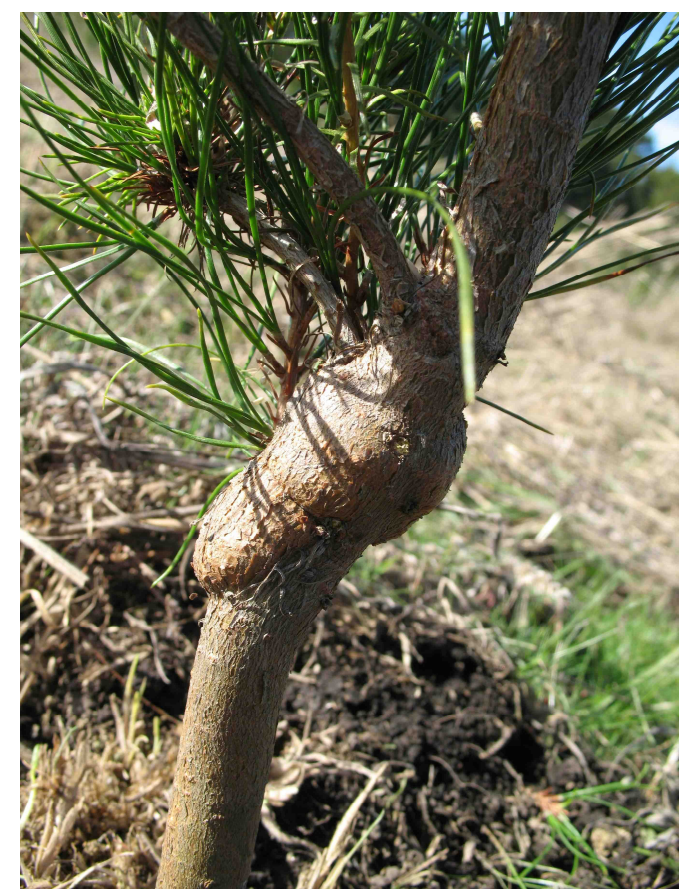

Fig. 10. Gall on the main stem of a Pinus radiata sapling, caused by western gall rust. Photo credit: Sarah Degasis.

The effects of western gall rust are mainly growth deformation in individual trees. Stem galls can cause tree death, but the disease is not known to cause widespread mortality at the stand level. Control of the disease requires an emphasis on sanitation and quarantine. In lodgepole pine, infections were not observed higher than $2 \mathrm{~m}$ from the ground in trees (Van der Kamp, 1994), so infected trees may be pruned or removed to reduce disease spread. Nurseries should be located far away from infected sites. In the U.S., the disease is commonly introduced into new areas via resting spores on infected nursery stock. It is not known to spread via infected seeds or pollen (CABI/EPPO, n.d.). The fungus Scytalidium uredinicola Kuhlman, J.W. Carmich. \& T. Mill. is known to act 
as a biological control and inhibits spore germination of Endocronartium harknessii (Cunningham \& Pickard, 1985).

Genetic resistance to western gall rust has been demonstrated in Monterey pine, and appears to be an additive genetic trait (Old, Libby, \& Russell, 1986). Relative genetic resistance levels also appear to be related to the developmental stage of the plant. By manipulating the ontogenetic age of cloned $P$. radiata trees through hedging, Zagory \& Libby (1985) were able to show differences in western gall rust resistance levels between trees in a juvenile growth stage versus those at a more mature stage, and other experiments have suggested this may be the case (Vogler \& Kinlock 1999). This has management implications for the use of selected seedstock in reducing disease impacts in plantation forestry. Analysis by Kayihan et al. (2005) of the genetic basis for pitch canker and fusiform rust resistance in loblolly pine showed the mechanisms to be independent. It is possible that the genetic mechanisms are similar in $P$. radiata and that resistance to western gall rust and pitch canker are also independent traits that need to be individually selected for.

Diplodia blight. Diplodia blight (also known as Sphaeropsis blight) is a disease caused by the deuteromycete fungus Diplodia pinea (syn. Sphaeropsis sapinea, Sphaeropsis ellisii). Hosts typically include two- and three-needled pines in temperate regions throughout the world. Damage is usually the most severe in species planted outside their natural range, and disease is uncommon in natural forests. In North America, commonly impacted species include Austrian, ponderosa, and Scots pine. In the Southern Hemisphere, plantations of loblolly, Monterey, and slash pines become infected (Sinclair, Lyon, \& Johnson, 1987). 
Symptoms of Diplodia blight include dieback of shoot tips, resinous cankers on the bole or branches, sapwood stain, and the death of cones, seedlings, and sometimes mature trees. Infections begin in the springtime on newly developing buds, shoots and needles. The fungus enters through leaf stomata, and pycnidia can penetrate killed needles, cone scales, needle fascicle sheaths, and bark starting in the summer following infection (Sinclair, Lyon, \& Johnson, 1987). Infected shoots and needles halt growth and may turn yellow and exude resin (Figure 11). Black pycnidia are often easily visible on cone scales or needle bases underneath the fascicle (Figures 12 and 13). Conidia spread via rain-splash from spring to fall. Cone scales are a source of abundant numbers of spores, and are important to the spread and severity of the disease in forests or plantations.

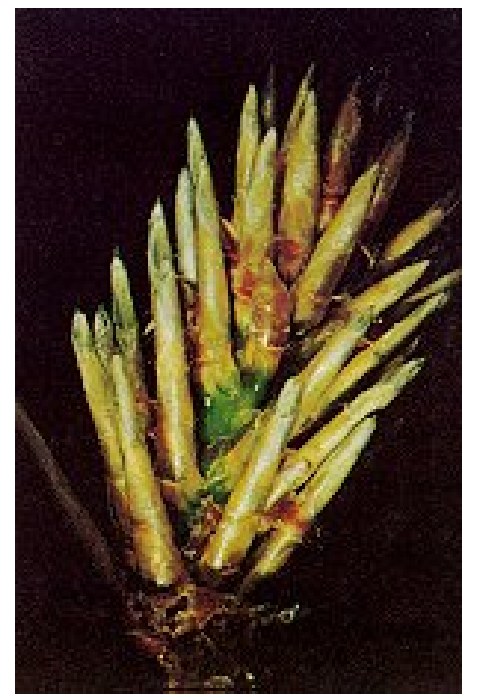

Fig. 11. Austrian pine shoot tip with developing symptoms of Diplodia blight. Excerpted from Peterson, 1981. 


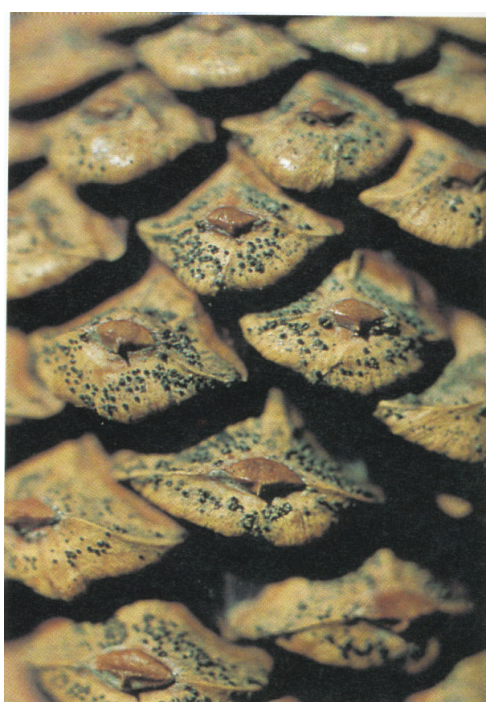

Fig. 12. Diplodia pinea pycnidia erupting from cone scales. Excerpted from Peterson \& Nicholls, 1989.

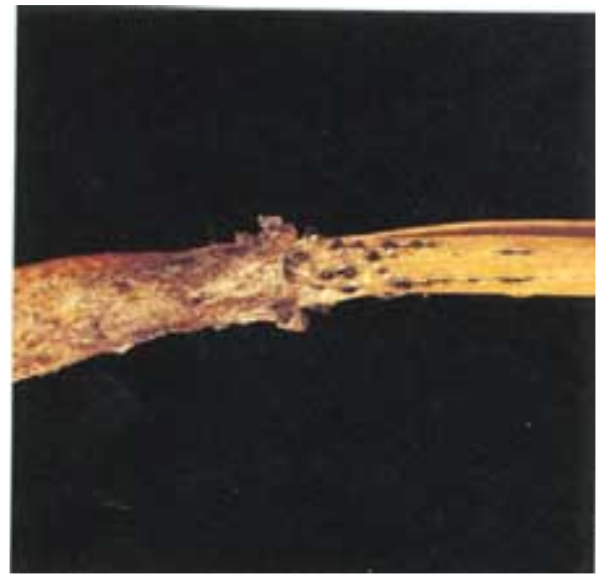

Fig. 13. Diplodia pinea pycnidia visible underneath needle fascicle. Excerpted from Peterson, 1981.

With favorable environmental conditions, trees under physiological stress will be pre-disposed to an epidemic of Diplodia blight. Drought stress is particularly important to disease predisposition. Wet spring weather with temperatures between $12-36^{\circ} \mathrm{C}$ favor spore germination, and fungus growth is optimal at around $28^{\circ} \mathrm{C}$ (Sinclair, Lyon, \& Johnson, 1987. 
Sequoia Pitch Moth. The sequoia pitch moth Synanthedon sequoiae (Hy. Edwards) [Lepidoptera:Sesiidae], is an herbivorous clearwing moth common to coastal regions in northern California (Figure 14). It occurs as far south as the Monterey Bay region and north to British Columbia. The larvae feed on conifers including Douglas-fir (Pseudotsuga menziezii (Mirb.) Franco) and spruce, but primarily Pinus spp. in California. Adult moths emerge between May and early September, with moths in coastal regions emerging toward the later part of this range (Dreistadt \& Svihra, 2008). They live for only a few days before mating and laying eggs on the bark of susceptible tree species. Eggs hatch after around two weeks, and proceed to feed as larva for several months to over a year. The pupal stage lasts about one month. The complete lifecycle from egg to adult can last 1-2 years.

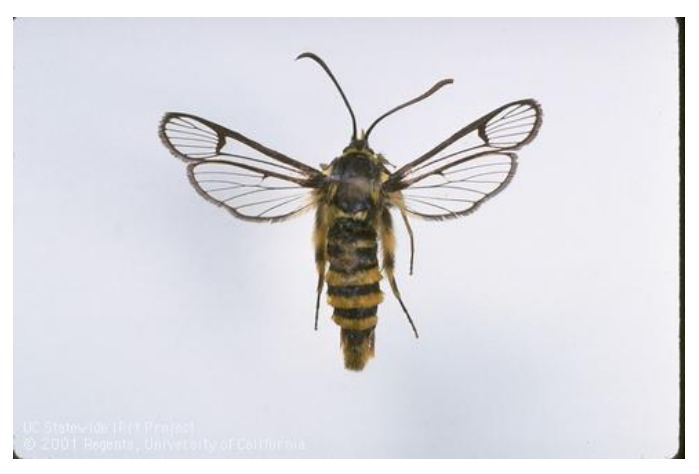

Fig. 14. The sequoia pitch moth, Synanthedon sequoiae. Excerpted from Dreistadt, 2008.

The feeding damage rarely affects the health of the tree in any significant way, but infestations are unsightly, with larvae feeding underneath round masses of white to pinkish pitch (Figure 15) (Driestadt \& Svihra, 2008). Infestations of sequoia pitch moth are common on trees that have been wounded or on planted trees in the landscape. The most effective way to avoid damage due to sequoia pitch moth includes cultural controls 
that maximize the vigor of the tree. This may include maintaining proper water and sunlight requirements, planting tolerant species, and avoiding practices that wound trees.

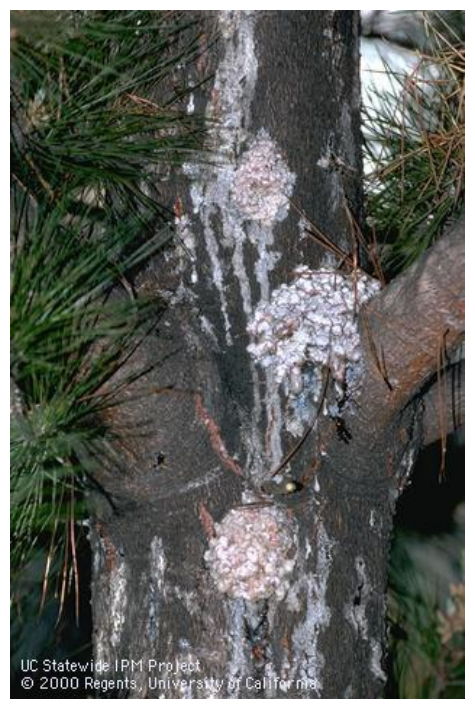

Fig. 15. Resin masses caused by feeding by Synanthedon sequoiae on Monterey pine. Excerpted from Dreistadt, 2008.

Spatial Factors

Given that the movement of a fungal pathogen through a plantation can be influenced by countless environmental factors (e.g. insect behavior and population density, microclimatic conditions, wind, the proximity and abundance of inoculum sources, etc.), it would follow that a spatial pattern of infection would be visible depending on the unique combination of these factors present in the plantation. Nearest neighbor analysis is one method by which spatial patterns can be examined and visualized. This method can statistically quantify spatial interactions based on the distances between nearby points (neighbors). Shaw, Chen, Freeman, \& Braun (2005) used nearest neighbor analysis to understand the spatial pattern of western hemlock dwarf 
mistletoe (Arceuthobium tsugense (Rosendahl) G.N. Jones subsp. tsugense) infection in an old-growth Douglas-fir—western hemlock (Tsuga heterophylla (Raf.) Sarg.) forest. Their analysis showed the disease distribution and spread to be distinctly clustered, centered around heavily infected trees. Nearest neighbor analysis is more useful than other spatial analysis methods when interactions are occurring among neighbors. This is because only the spatial relationships between neighboring points are used, rather than measuring the distance between all the points in the study area. The result is a more accurate representation of the degree of clustering or dispersion in the population (Williamson, McLafferty, Goldsmith, Mollenkopf, \& McGuire, 1999).

\section{Summary}

This literature review provided a background context to the current study, which is a field trial of foreign Monterey pine planting stock for resistance to pine pitch canker. The basic biology of Monterey pine and the F. circinatum was covered, as well as hostpathogen interactions as they related to conifer disease resistance. Resistance to pitch canker in Monterey pine appears to be a polygenic trait, which indicates that efforts to develop resistant varieties could be successful. This is worthwhile, given the global importance of the species. Pitch canker resistance trials are currently being performed on a variety of pine species worldwide, which highlights the perceived threat of the disease to plantation forest species. As opposed to greenhouse trials, field trials are subject to many more factors that are uncontrollable, including environmental and biological factors that can influence the severity of disease incidence. Special problems are also presented 
to the researcher that studies trees, as they are large and long-lived species. For this reason, spatial and temporal factors in the plantation also play important roles in studying forest disease. Nearest neighbor analysis can be used to statistically analyze spatial data when individuals interact with each other. In all, current research is making progress toward developing pitch canker resistant varieties of Monterey pine. Field trials are helping by confirming the presence of resistance in key varieties, and identifying additional factors that need to be taken into account for future trials. 


\section{METHOD OF INVESTIGATION}

\section{Trial Location and Description}

The trial is a plantation of $P$. radiata trees, located on a former hay field on Swanton Pacific Ranch, a property owned and operated by the California Polytechnic State University Corporation, San Luis Obispo. The property is located in Santa Cruz County, CA about $60 \mathrm{~km}$ south of San Francisco, with Point Año Nuevo to the north, and the town of Davenport on Hwy 1 to the south. The geographic coordinates are $37^{\circ} 04^{\prime} 29.54^{\prime \prime} \mathrm{N}$ and $122^{\circ} 14^{\prime} 49.74^{\prime \prime} \mathrm{W}$ at an elevation of approximately $130 \mathrm{~m}$ above sea level (Figure 16).

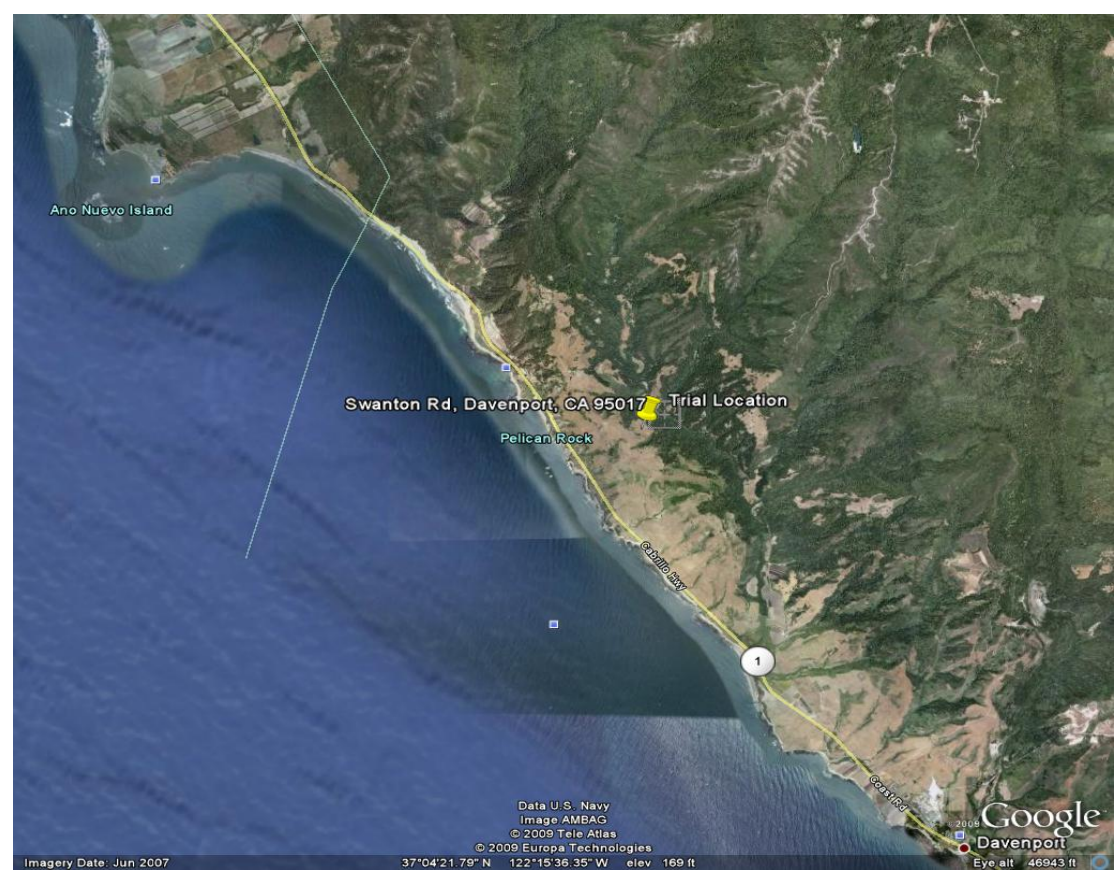

Fig. 16. General area map of trial location showing proximity to the Pacific Ocean, Highway 1, Ano Nuevo Island, and the town of Davenport, CA. Image credit: Google Earth http://earth.google.com 
The trial site was formerly a 3 ha hay meadow used for grazing. The area has been fenced off and is populated with fodder grasses and clover that require periodic mowing. The field is located on the southwest border of a native stand of $P$. radiata that is infected with $F$. circinatum, the causal agent of pitch canker (Figures 17 and 18).

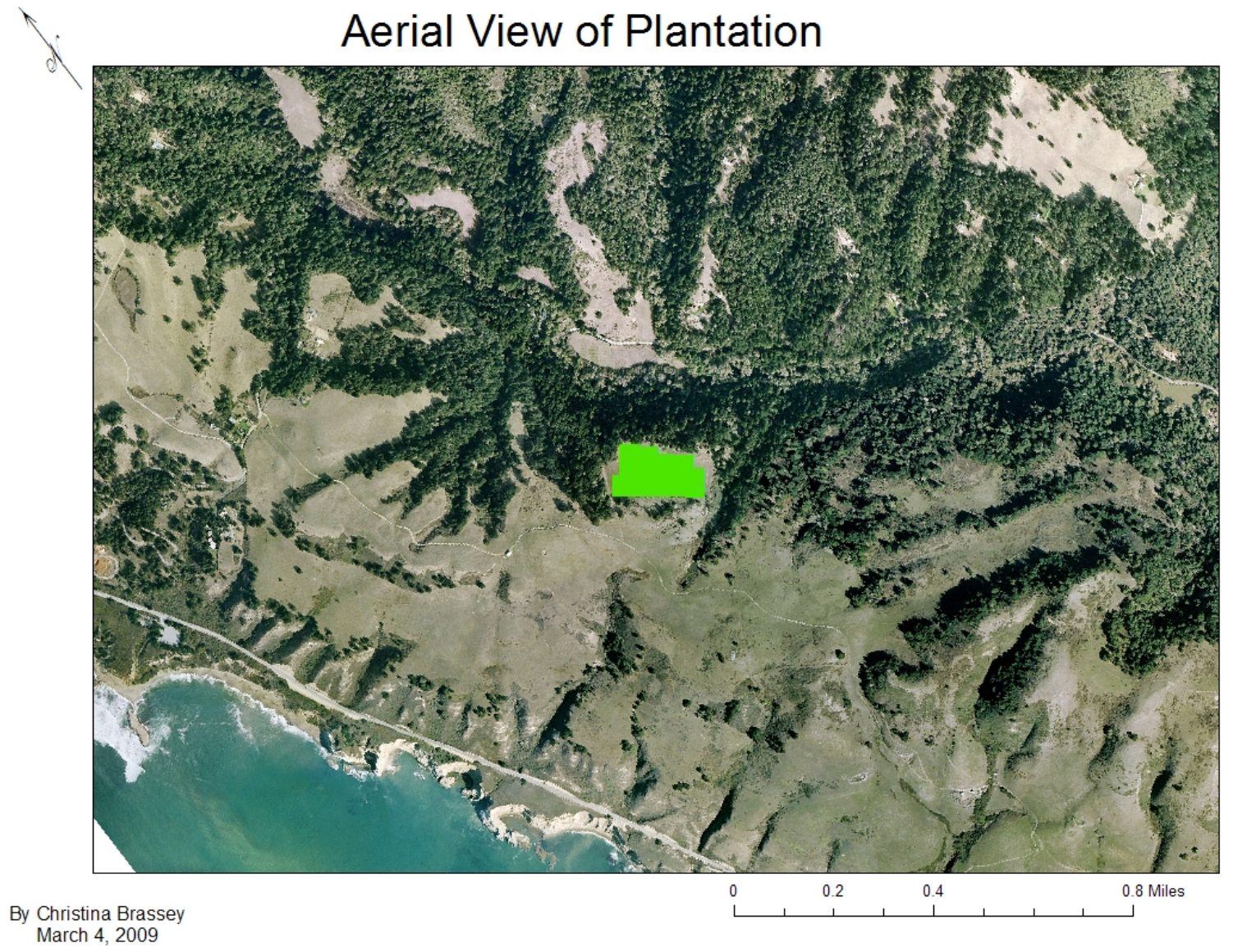

Fig. 17. GIS Map showing trial location surrounded by native $P$. radiata forest. Trial area is highlighted in green. 


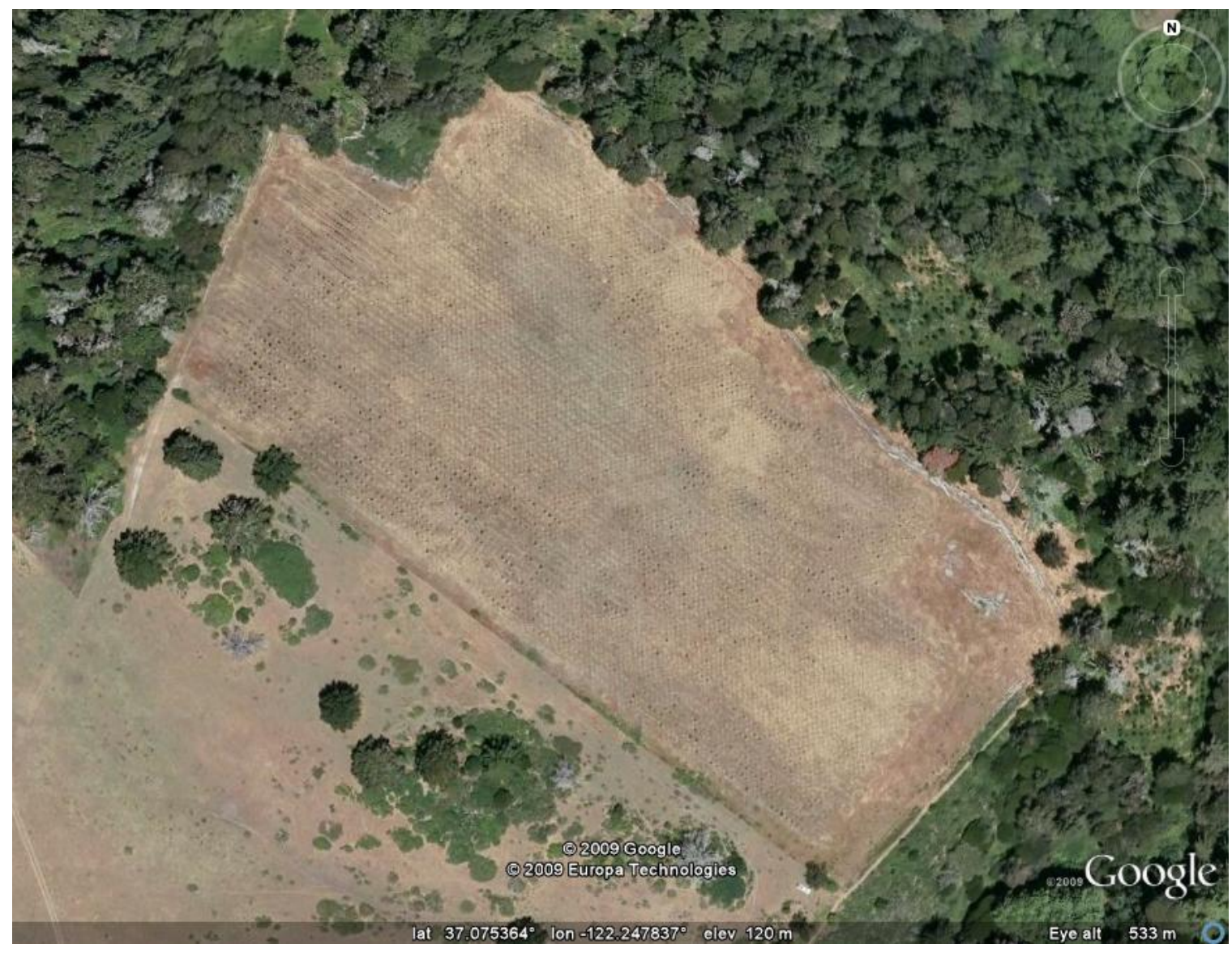

Fig. 18. Aerial view of plantation. Image credit: Google Earth http://earth.google.com

\section{Time and Duration of Trial}

Seedlings were planted in 2005 and again in 2006 to replace non-survivors.

Starting in 2007, symptom data was collected annually in the winter for a period of 3 years, after which the plantation will be removed to prevent genetic contamination of the adjacent native $P$. radiata stand. 


\section{Hypotheses Tested}

Two hypotheses were tested in this trial. The first was that the different levels of pitch canker resistance exist among the different seedstock. The second was that the resistance levels observed in the greenhouse trial would be consistent with the results of the field trial.

\section{Plantation Population}

The trial includes 264 seedstocks from 3 countries, for a total of 5280 trees. Of these seedstocks, 85 were from Chile, 82 from New Zealand, and 97 from Australia. Seedstocks were selected based on their performance in a preliminary greenhouse inoculation study. Additional seedstocks were added to the trial that were not tested in the greenhouse study. These are a part of an ongoing study of the genetics of disease resistance sponsored by CSIRO, Australia.

\section{Data Collection}

Annual observations of every tree were made during February. The number of symptoms observed on each individual tree was recorded. Dead branch tips (flags) were considered to be symptoms of pitch canker. Buds that were covered in pitch were not recognized as being symptoms of pitch canker, and were recorded separately for further 
analysis. Observations of western gall rust presence, damage due to animals, insects, or mowers were also recorded.

\section{Experimental Design of Field Trial}

Assessing disease resistance in plantation field trials can be difficult, due to the presence of a myriad of environmental factors that may influence relative disease severity in trees. For example, there is a slope gradient in the plantation, as well as differences in water drainage. The experimental design of this trial attempted to address the presence of environmental variation in the plantation. The layout of the plantation was designed by Colin Matheson of CSIRO, Australia. It is comprised of 5 replications in a 22 x 12 rowcolumn design. It is an incomplete block design that is resolvable, meaning that it can be analyzed as a randomized complete block design. The replications serve as five complete "super blocks" arranged to account for the environmental variation across the plantation (Figure 19). Each of these blocks was complete in that they contained representatives from each of the 264 seedstocks. Within each 'super block', the rows can be considered to be incomplete blocks, and can be analyzed to calculate the effect of being in a particular row. This design allows for blocking in two directions: one way from the 'super blocks' to account for slope, and then in the other direction by analyzing the rows separately. 


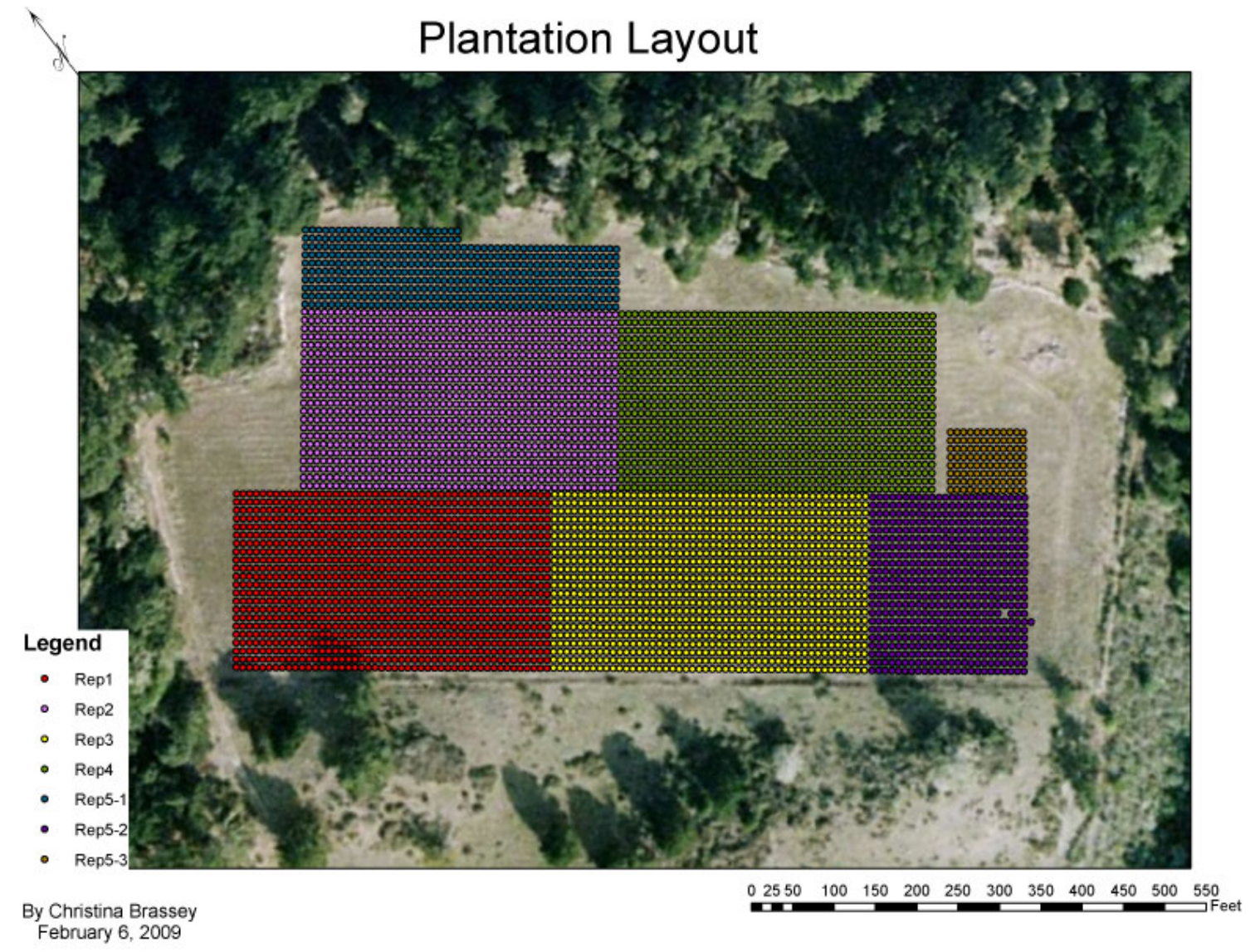

Fig. 19. Trial layout design. Circles indicate individual trees, and colors represent blocking.

The seedstocks within each super block were not simply randomized but arranged in a way that maximized the pair-wise comparisons. So, whereas a randomized design might put two different seedstocks next each other in more than one block, this arrangement ensured that seedstock pairs were not repeated.

Each seedstock was represented by a four tree line plot, meaning that each seedstock had four adjacent trees from the same seedstock. This was done so that a plot value could still be calculated even if a tree died for some reason. Also, a "between tree within plot" variance component can be calculated. The four tree line plot served as the experimental unit. 
Buffers were not planted because there was limited ground space for the trial, and they were not expected to make a difference in the relatively short duration of the study. It was not expected that an effect due to competition between trees would have been observable during this amount of time. Trees were planted $2.5 \mathrm{~m}$ apart and the rows were spaced $3 \mathrm{~m}$ apart.

During planting, it became apparent that the space was underestimated and as a result Rep 5 had to be split into parts, and placed on opposite ends of the field. This was not desirable, but necessary due to space limitations.

\section{Survival Analysis}

The seedstock tested in this trial were selected based on their performance in the greenhouse trial, rather than by random selection. The result was a population with characteristics that were not normally distributed. It was important to use a statistical analysis that did not require normally distributed data. The survival analysis procedures LIFETEST and LIFEREG in SAS 9.1 can analyze this type of data set.

Survival analysis is often used to compare the effects of different treatments on an individual's survival over time. Some examples of experiments that might utilize survival analysis include testing the effectiveness of pharmaceutical drugs on chronic illnesses, or in the current study, testing the effects of genetic origin on the susceptibility of trees to pitch canker. These kinds of experiments often involve lots of data that could obscure the true effects of the treatment, but still need to be taken into account. Examples of this kind of data include individuals who are removed from the experiment (died) for reasons other 
than the treatment in question, individuals who would have reacted to the treatment but the study ended too early to observe it, and/or individuals who did not and would never respond to the treatment even if the study was prolonged. All three of these situations result in a zero value input in the spreadsheet and should not be analyzed in the same way as all the other data. It would be incorrect to simply remove the data points from the study, especially in experiments where more individuals survive than die. Survival analysis deals with this by 'censoring' this type of data through the use of the product limit (Kaplan-Meier) estimator, which is a nonparametric estimate of survival time (SAS Institute, 2008). Significant differences in survival time are determined through the logrank and Wilcoxon tests. These tests compare the survival rates for individuals under the null and alternative hypothesis.

\section{Spatial Analysis}

The Average Nearest Neighbor spatial statistics tool in GIS calculates the statistical significance of spatial patterns in data. The analysis calculates the expected distance between spatial features that were distributed randomly, and compares that to the actual distance observed. The result is a 'nearest neighbor ratio' (NNR), which is the observed distance $\left(\mathrm{D}_{\mathrm{O}}\right)$ divided by the expected distance $\left(\mathrm{D}_{\mathrm{E}}\right)(\mathrm{ESRI}$, n.d.):

$$
N N R=\frac{\bar{D}_{O}}{\bar{D}_{E}}
$$

In this experiment, the observed distance is the average distance $\left(d_{s}\right)$ between a tree with disease symptoms $(s)$ and the next closest tree with disease symptoms, divided by the number of symptom observations $(n)$ : 


$$
\bar{D}_{O}=\frac{\sum_{s=1}^{n} d_{s}}{n}
$$

The expected mean distance predicts the average distance that would be observed if all the points were randomly distributed, with 'A' representing the total area of the trial:

$$
\bar{D}_{E}=\frac{0.5}{\sqrt{n / A}}
$$

The null hypothesis is that the spatial distribution is random, and this is represented as the 'expected distance' between similar points. Depending on the ratio, the spatial pattern is described as either being 'clustered', 'dispersed', or random. A ratio of less than one indicates that the spatial pattern is a clustering of points. A ratio of more than one indicates that points are scattered and spread out from one another. In the context of fungal plant pathogens, a clustered distribution of diseased trees might be more indicative of fungi with spores that tend be dispersed relatively short distances, such as by rain splash. Fungi with spores that tend to be dispersed over large distances, with the aid of air or water currents would show a more dispersed pattern of disease incidence. An example graphical output in ArcMap is shown in Figure 20. 


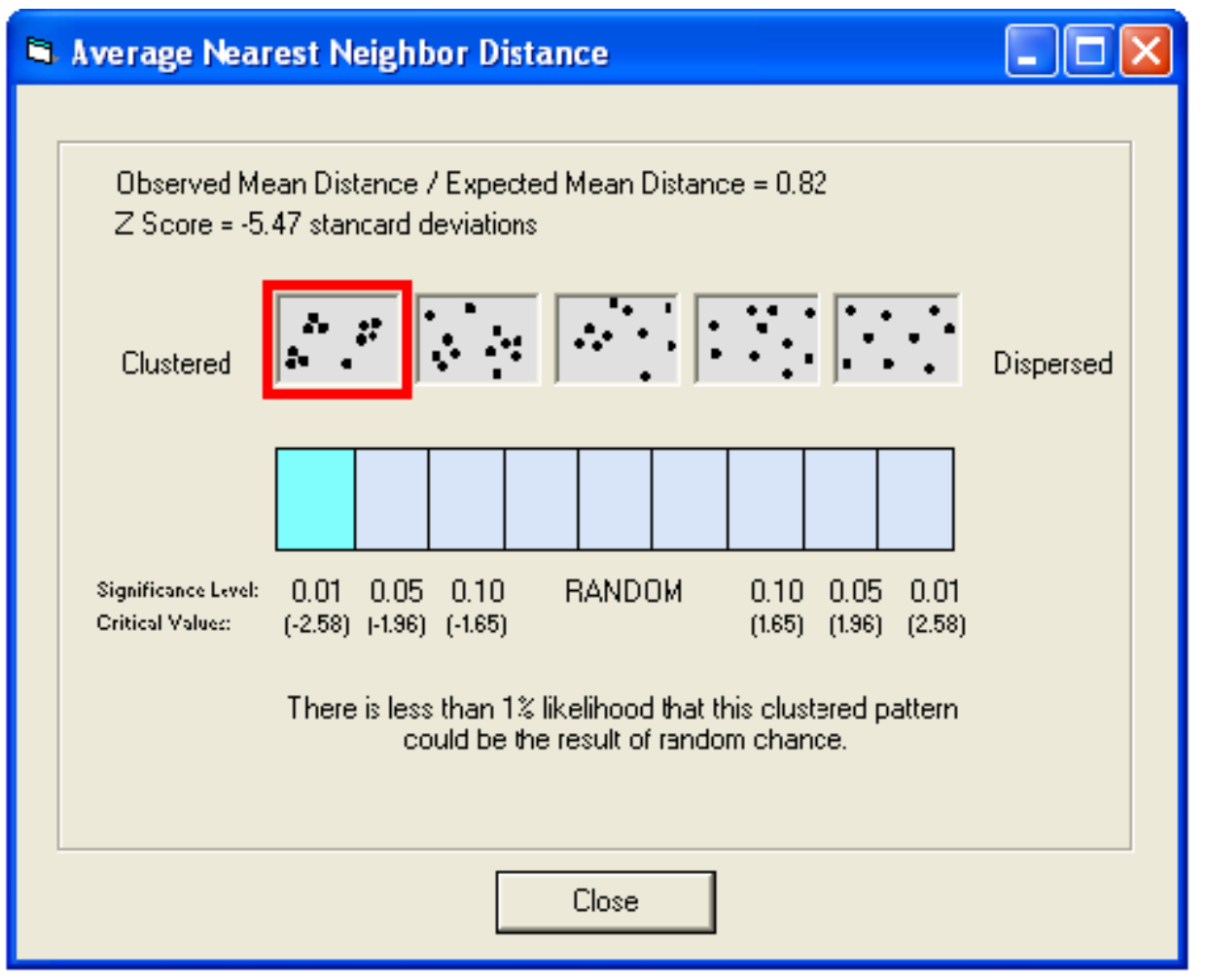

Fig. 20. Example graphical output of ArcView average nearest neighbor analysis.

The statistical significance is based on the standard deviation from the null hypothesis, and expressed as a Z-score. The difference between the observed and expected distances is divided by the standard error (ESRI, n.d.):

$$
\begin{gathered}
z_{N N R}=\frac{\bar{D}_{O}-\bar{D}_{E}}{S E} \\
S E=\frac{0.26136}{\sqrt{n^{2} / A}}
\end{gathered}
$$

Critical Z-scores of +/- 1.96 standard deviations represents the range between which the null hypothesis cannot be rejected, based on a 95\% confidence interval. Anything outside of that range can be considered statistically significant. 


\section{RESULTS \& INTERPRETATION}

At the time of data collection, it was unclear whether to interpret the flagging observations as definitive symptoms of pitch canker, diplodia blight, or even both. Though it seemed likely that the pitchy buds were symptoms of diplodia blight, there was not enough evidence at the time to assume that all flagging observations were symptoms of diplodia blight. For that reason, survival analyses were performed separately for flagging and pitchy buds. As of the writing of this document, isolations now strongly suggest that all of the symptoms observed between 2007-2009 resulted from infection by Diplodia pinea, and that pitch canker has only begun to manifest since the last data collection in February 2009. To address this, an additional analysis was performed combining the flagging and pitchy bud data for the spatial cluster analysis, and the corresponding maps are included.

\section{Descriptive Statistics}

Symptom Observations

There were originally 5280 trees planted in 2005, with one replanting of 1367 trees in 2006 to replace seedlings that failed to establish, and to address flooding mortality in Rep 2. Between 2007 and 2009, around 100 trees died each year (Table 4). The first disease assessment in 2007 showed that about $10 \%$ of the total population 
displayed flagging symptoms (Table 5). By 2008, symptomatic trees had increased to $13 \%$ of the plantation, and to almost $19 \%$ in 2009 .

Table 4. Total number of trees observed to be alive or dead at each annual data collection.

\begin{tabular}{llll}
\hline & 2007 & 2008 & 2009 \\
\hline Alive & 4100 & 3993 & 3929 \\
Dead & 1180 & 1287 & 1351 \\
\hline
\end{tabular}

Table 5. Total number of trees displaying presence or absence of flagging symptoms by year.

\begin{tabular}{cccc}
\hline & 2007 & 2008 & 2009 \\
\hline Flagging absent & 3687 & 3459 & 3196 \\
Percent of total plantation & $89.93 \%$ & $86.63 \%$ & $81.34 \%$ \\
\hline Flagging present & 413 & 534 & 733 \\
Percent of total plantation & $10.07 \%$ & $13.37 \%$ & $18.66 \%$ \\
\hline
\end{tabular}

Most trees were observed to have 0,1 , or 2 symptoms, though the most susceptible trees had up to 71 symptoms in 2009 (Table 6). The increase in the median symptom value from 1 to 2 by 2009 indicates a general increase in disease severity in the plantation.

Table 6. Simple statistics for flagging symptom observations per tree.

\begin{tabular}{cccc}
\hline & 2007 & 2008 & 2009 \\
\hline Symptom low value & 0 & 0 & 0 \\
Symptom high value & 11 & 28 & 71 \\
Symptom median value & 1 & 1 & 2 \\
Standard Deviation & 0.71 & 1.20 & 3.11 \\
\hline
\end{tabular}


Attempts to isolate the pitch canker fungus from the plantation in 2009 confirmed the presence of Diplodia pinea (syn. Sphaeropsis pinea) the causal agent of diplodia blight of pines in buds that were covered in pitch and in branch tips that had turned chlorotic. The number of trees displaying these "pitchy buds" more than doubled each year for the three years (Table 7). Branches with chlorotic tips were also considered to be likely symptoms of diplodia blight. Observations of chlorotic tips were only collected in 2009. Pitchy bud symptoms per tree have been increasing over the three years, with median values increasing from one to five between 2007 and 2009 (Table 8). High values of 102 pitchy buds and 107 chlorotic tips represent cases of extreme disease severity.

Table 7. Number of trees observed with pitchy bud and/or chlorotic tip symptoms observed in the plantation each year.

\begin{tabular}{cccc}
\hline & 2007 & 2008 & 2009 \\
\hline Pitchy buds present & 52 & 213 & 443 \\
Percent of total plantation & $1.27 \%$ & $5.33 \%$ & $11.28 \%$ \\
\hline Chlorotic tips present & -- & -- & 267 \\
Percent of total plantation & -- & -- & $6.80 \%$ \\
\hline
\end{tabular}

Table 8. Simple statistics for pitchy bud and chlorotic tip symptoms per tree.

\begin{tabular}{cccc}
\hline & 2007 & 2008 & 2009 \\
\hline Pitchy buds & & & \\
Low value & 0 & 0 & 0 \\
High value & 1 & 3 & 102 \\
Median value & 1 & 1.34 & 5.12 \\
Std. Dev. & 0.11 & & \\
Chlorotic tips & & -- & 0 \\
Low value & -- & -- & 67 \\
High value & -- & -- & 5.32 \\
Median value & -- & -- & \\
Std. Dev. & -- & & \\
\hline
\end{tabular}


The three annual data collection periods showed a distinct sequence in the types of symptoms that were predominant over time. Diseased trees in 2007 displayed mostly flagging symptoms, with relatively very few having pitchy buds (Figure 21). In 2008, trees with flagging symptoms increased only slightly, while trees with pitchy buds quadrupled (Figure 22). In 2009, flagging and pitchy bud symptom numbers increased, and chlorotic tips emerged as an important disease symptom in the plantation (Figure 23).

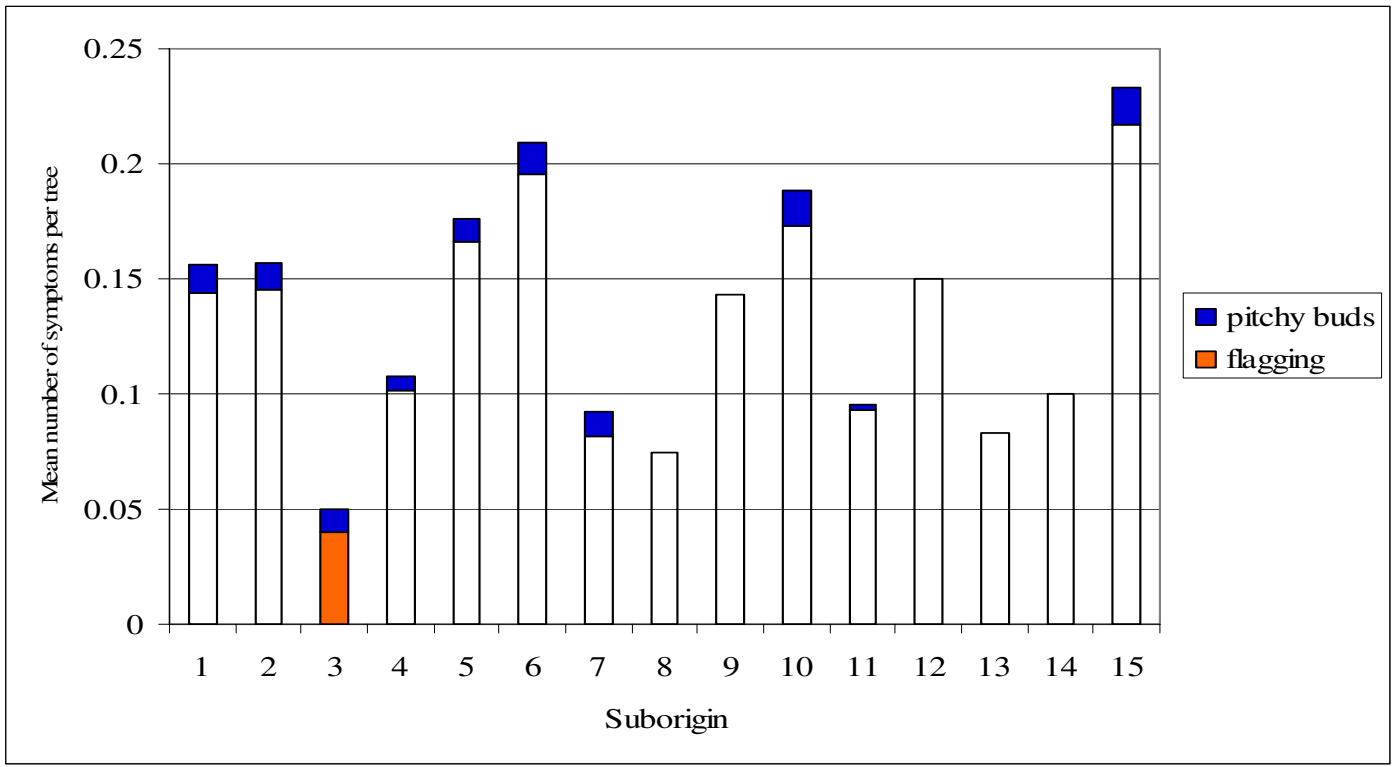

Fig. 21. Observations by suborigin for two different types of symptoms present in the plantation in 2007. Suborigin identities may be found in Appendix A. 


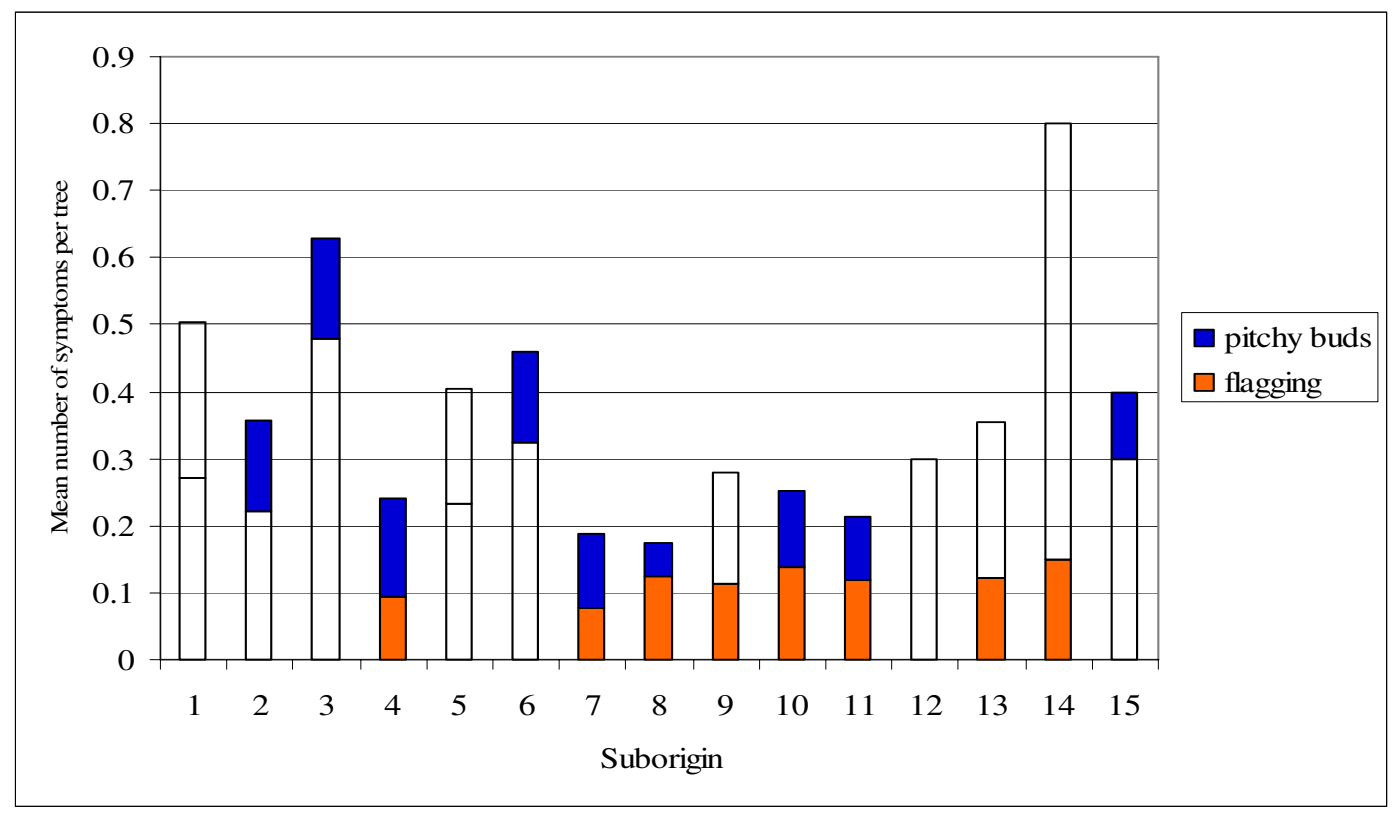

Fig. 22. Observations by suborigin for two different types of symptoms present in the plantation in 2008. Suborigin identities may be found in Appendix A.

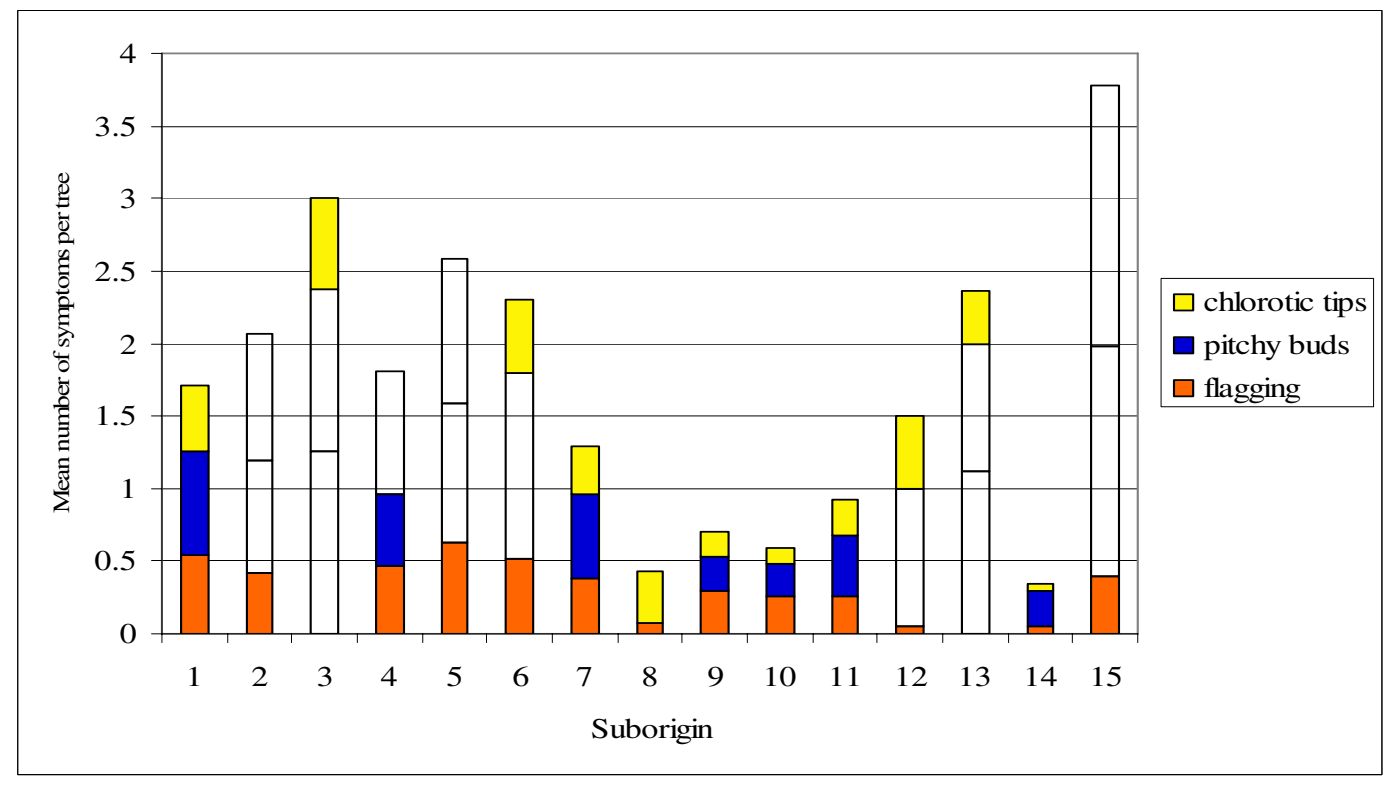

Fig. 23. Observations by suborigin for three different types of symptoms present in the plantation in 2009. Suborigin identities may be found in Appendix A.

An unusual feature of the disease development by suborigin is that suborigin 14 (Bosques de Chile) appeared to have the highest disease severity in 2008, and then had the lowest severity in 2009. This drastic change in status was largely because suborigin 
14 only contains a single stock (CPF 7), representing considerably fewer trees in the plantation than most of the other suborigins. The two highly diseased trees in 2008 were found to be symptomless in 2009 , and the two trees that experienced symptoms for the first time in 2009 had a low number of symptoms.

In addition to the effect of seedstock on disease development, a tree's location in the plantation also appeared to play a role, with some replications experiencing higher disease severity than others. The relative disease severity in each replication fluctuated over the three years, though symptoms were often among the lowest in Rep 2, and highest in Rep 4 (Figures 24, 25 and 26). Many of the trees in Rep 2 are among those replanted in 2006 to replace those killed by flooding in the plantation. The smaller size of the trees, as well as the shorter duration of exposure to inoculum may have contributed to the low numbers of symptoms in Replication 2. Replications 4 and 5 were situated the closest to the assumed sources of inoculum, which may have resulted in a higher probability of infection in these trees.

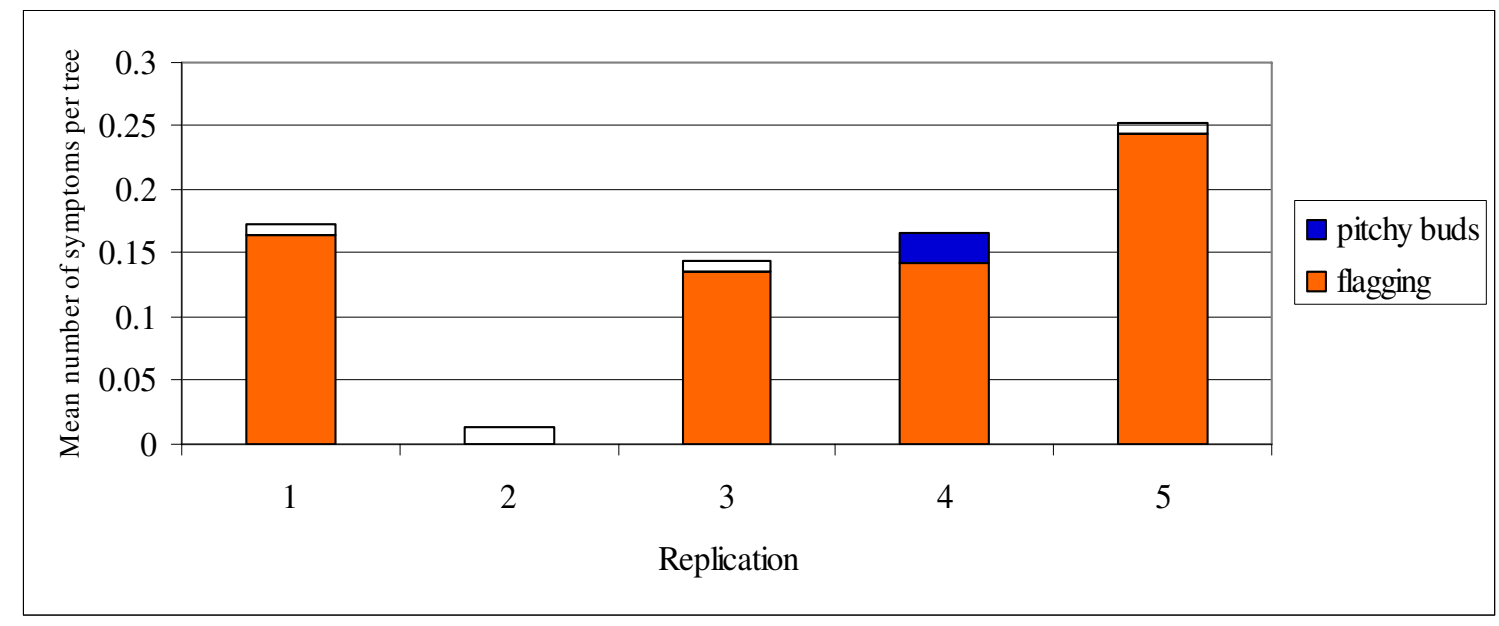

Fig. 24. Observations by replication for two different types of symptoms present in the plantation in 2007. 


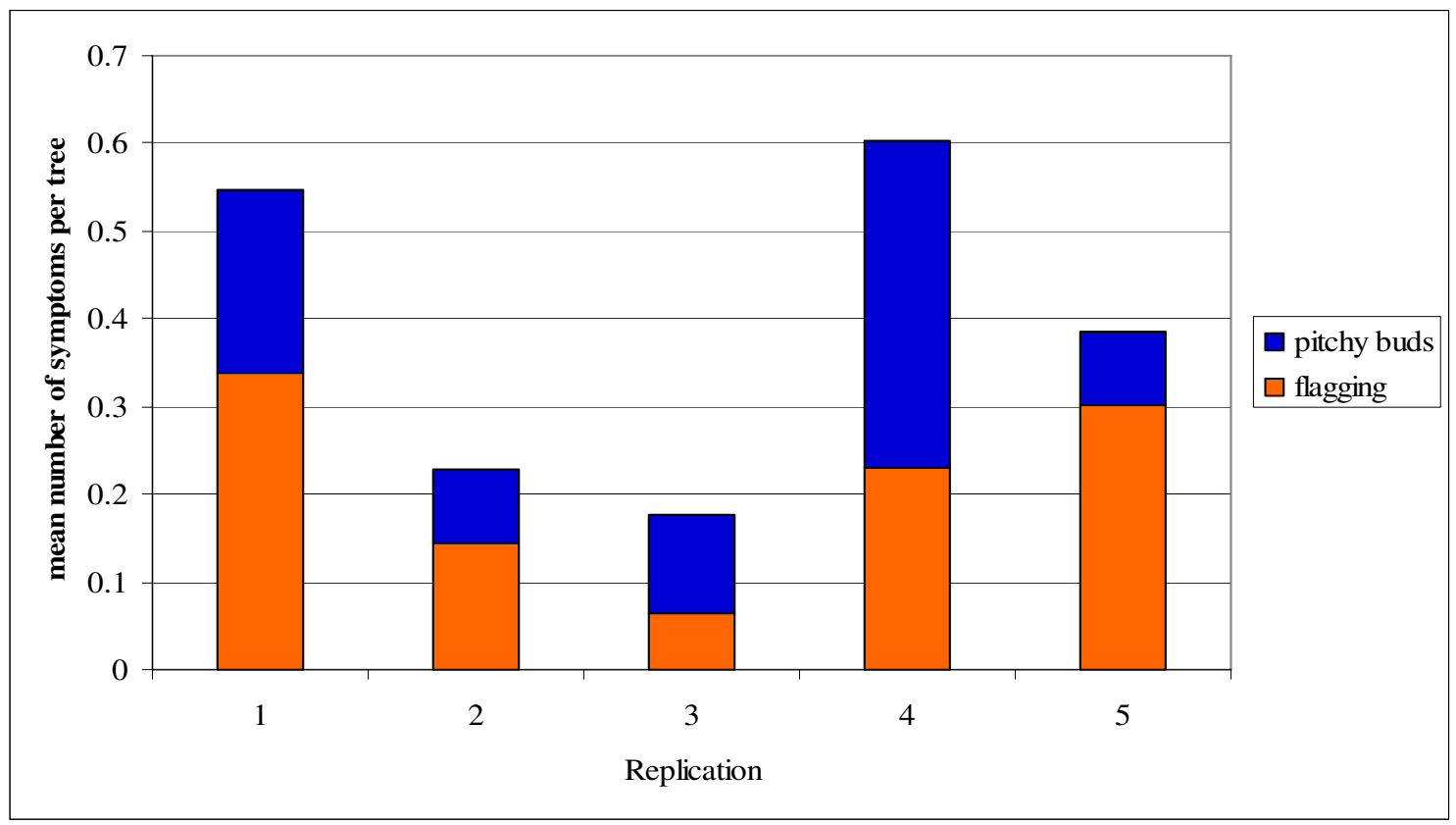

Fig. 25. Observations by replication for two different types of symptoms present in the plantation in 2008.

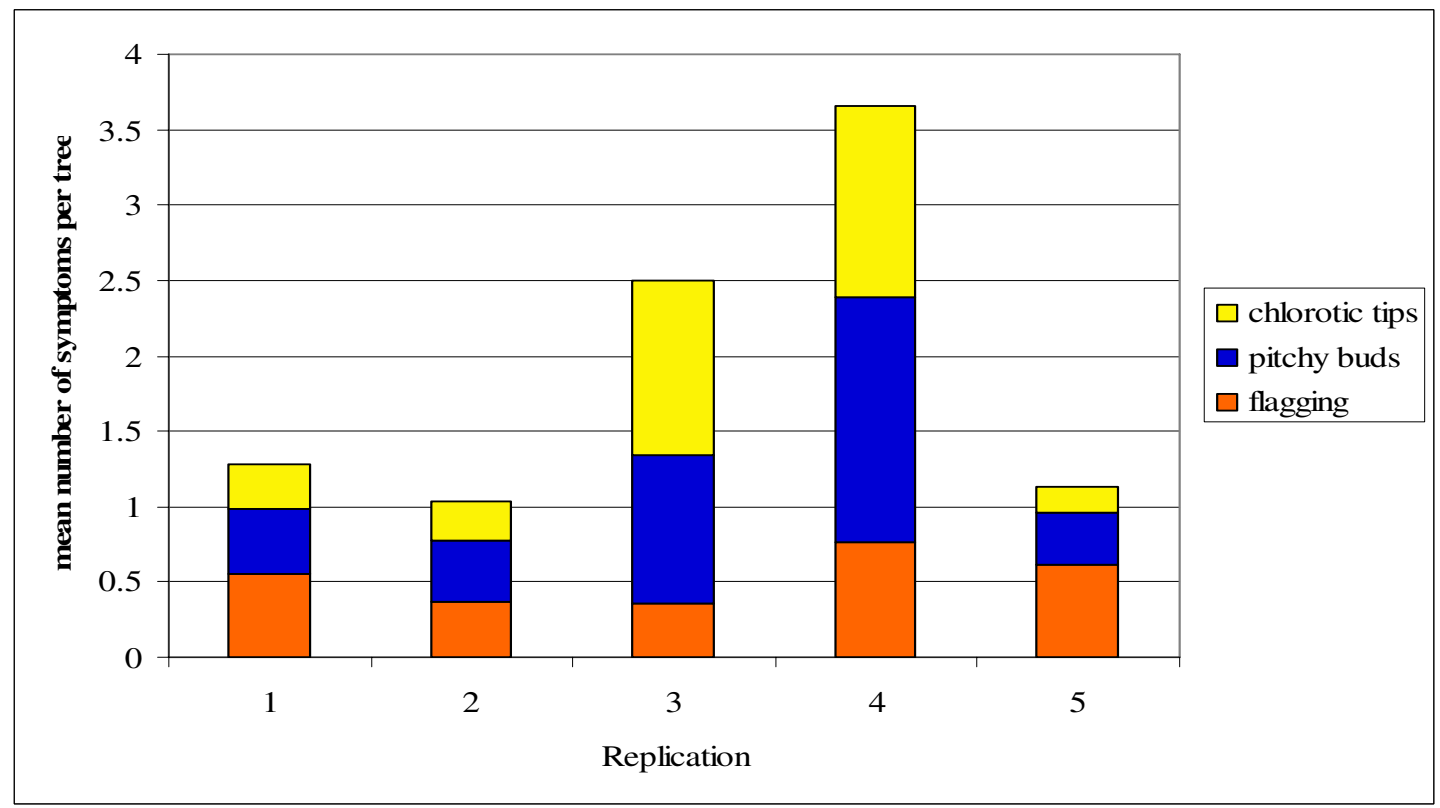

Fig. 26. Observations by replication for three different types of symptoms present in the plantation in 2009.

Of the 264 different genetic stock present in the plantation, the 5 with the highest disease severity were tabulated each year for both flagging and pitchy bud symptoms 
(Table 9). For flagging symptoms, 10 of the 15 most diseased trees were from Australia, 4 were from New Zealand, and 1 from Chile. The only stock that showed up more than once as having high severity were CFTT019 and C6176, both from Australia. For pitchy buds, the 10 most diseased included 5 from New Zealand and 2 from Australia, and 3 from Chile. Stock NZ39 and NZ106 showed up twice as having high disease severity. Mean lesion lengths from the greenhouse pitch canker inoculations are included in Table 10. The 5 least resistant stock were all from Chile. A complete list of mean symptom numbers in 2009 by seedstock is included in Appendix B. There was no overlap between stock that were susceptible to artificial inoculation as seedlings in the greenhouse, and those susceptible in the field trial. Stock labeled with codes beginning with C5 or C6 were Australian seedstock added for the purposes of the genetic trials and did not have corresponding lesion length data from the greenhouse. There were 1082 trees from these supplementary seedstocks in the plantation in 2009 (out of 3929 trees total). 
Table 9. Stock observed to have the highest number of flagging or pitchy bud symptoms. No stock are listed for pitchy buds in 2007 because no more than 1 pitchy bud was observed per tree that year. Stock labeled C6XXX were not included in the greenhouse trial. A complete list of the symptoms observed for each stock is included in Appendix B. Aust=Australia, NZ=New Zealand

\begin{tabular}{cllll}
\hline & \multicolumn{1}{c}{2007} & \multicolumn{1}{c}{2008} & \multicolumn{1}{c}{2009} \\
\hline Stock with & 1. CSIRO143 (Aust) & 1. C6244 (Aust) & 1. C6176 (Aust) \\
highest & 2. NZ131 (NZ) & 2. CFTT019 (Aust) & 2. CFTT019 (Aust) \\
numbers of & 3. NZ106 (NZ) & 3. C6159 (Aust) & 3. CPF162 (Aust) \\
flagging & 4. CPF3 (Chile) & 4. C6176 (Aust) & 4. CPF161 (Aust) \\
symptoms & 5. NZ100 (NZ) & 5. CFTT019 (Aust) & 5. NZ139 (NZ) \\
\hline Stock with & -- & 1. NZ106 (NZ) & 1. NZ79 (NZ) \\
highest & & 2. CPF12 (Chile) & 2. NZ39 (NZ) \\
numbers of & & 3. C6031 (Aust) & 3. CPF53 (Chile) \\
pitchy bud & & 4. NZ39 (NZ) & 4. C6003 (Aust) \\
symptoms & & 5. NZ106 (NZ) & 5. CPF6 (Chile) \\
\hline Stock with & & & & \\
highest & & - & 1. NZ139 (NZ) \\
numbers of & & & 2. NZ79 (NZ) \\
chlorotic tip & & & 4. CPZ139 (NZ) \\
symptoms & & & 5. NZ39 (NZ)
\end{tabular}

Table 10. Stock with the longest mean lesion lengths from the greenhouse trial.

\begin{tabular}{lll}
\hline \multicolumn{1}{c}{ Stock } & $\begin{array}{c}\text { Mean lesion } \\
\text { length }(\mathrm{mm})\end{array}$ \\
\hline 1. & CPF105 (Chile) & 39.14 \\
2. CPF147 (Chile) & 37.84 \\
3. CPF96 (Chile) & 36.60 \\
4. CPF152 (Chile) & 36.40 \\
5. CPF16 (Chile) & 35.87 \\
\hline
\end{tabular}

Other Pests Present in the Plantation

The trend for western gall rust incidence in the plantation is unclear, with the data showing that the number of infected trees decreased between 2008 and 2009 (Table 11). 
This is not possible with a biotrophic, gall-forming pathogen unless the fungus killed the trees, which was not the case. It is likely that many of the galls tabulated in 2008 were misidentified. The total number of trees with deer rub wounds in the plantation increased each year (Table 11). The number of new deer rub wounds on previously un-rubbed trees also increased each year (Table 12). It seems that many old wounds were not tabulated, and that the cumulative total number of rub wounds should be higher.

Table 11. Total number of trees observed with western gall rust infection or deer rub wounds in the entire plantation.

\begin{tabular}{cccc}
\hline & 2007 & 2008 & 2009 \\
\hline Western gall rust presence & 176 & 613 & 578 \\
Deer rub & 144 & 272 & 475 \\
\hline
\end{tabular}

Table 12. Observations of new deer rub wounds on previously unwounded trees in the plantation by year.

\begin{tabular}{cccc}
\hline & 2007 & 2008 & 2009 \\
\hline New deer rub & 144 & 242 & 329 \\
\hline
\end{tabular}

Trees were exposed to the fungal inoculum for western gall rust in two places: the greenhouse in Placerville during the seedling stage, and in the plantation at Swanton Pacific Ranch. Since the woody galls are only formed on new growth, and require at least one year for an infection to develop into a gall, it is possible to estimate the time period when infection took place by the location of the galls on the tree. During the data collection in February of 2009, it was determined that 297 of the existing galls on trees in the plantation were acquired during the seedling stage in Placerville, and 291 were acquired at a later time in the Swanton plantation. Trees with both Swanton and Placerville galls were counted twice. 
The presence of the sequoia pitch moth (Synanthedon sequoiae) was noted through observations of round, pinkish masses of resin on the boles of trees caused by larval feeding. This data was collected in 2008 and 2009, tabulating 67 sequoia pitch moth observations in 2008, and 129 observations in 2009.

\section{Statistical Analysis}

Survival Analysis

Symptom data was analyzed using the survival analysis procedures LIFETEST and LIFEREG in SAS 9.1. This type of analysis treats the duration of time before a tree develops a symptom as the 'survival time'. To see if there was a significant difference in survival time among the different countries, suborigins, or individual stock, a test of equality over strata was performed for both flagging symptoms and pitchy buds. For flagging symptoms, there was significant variation for time to disease development at the individual stock level, but not at the country or suborigin levels (Table 13). This means that no particular country or suborigin out-performed another, but that significant differences could be found among individual seedstocks. The variation among seedstocks within each suborigin was analyzed, and it was found that there was significant variation within Suborigin 11 (Forestal Mininco—Chile) for flagging (Table 14). 
Table 13. Tests for equality across strata. A $p$ value $<.05$ indicates that there is significant variation in time to flagging symptom development at the stock, suborigin, and/or country level.

\begin{tabular}{cccccccccc}
\hline & \multicolumn{3}{c}{ Country } & \multicolumn{3}{c}{ Suborigin } & \multicolumn{3}{c}{ Stock } \\
\hline Test & $\chi^{2}$ & $D F$ & $p>\chi^{2}$ & $\chi^{2}$ & $D F$ & $p>\chi^{2}$ & $\chi^{2}$ & $D F$ & $p>\chi^{2}$ \\
\hline Log-Rank & 1.32 & 2 & 0.5162 & 22.98 & 14 & 0.0606 & 305.13 & 258 & 0.0233 \\
Wilcoxon & 1.14 & 2 & 0.5661 & 22.94 & 14 & 0.0613 & 303.48 & 258 & 0.0272 \\
\hline
\end{tabular}

Table 14. Tests for equality over strata within suborigins. Suborigin 11 (Forestal Mininco-Chile) showed significant differences among seedstock for flagging symptoms.

\begin{tabular}{cccc}
\hline & \multicolumn{3}{c}{ Suborigin 11 } \\
\hline Test & $\chi^{2}$ & $D F$ & $p>\chi^{2}$ \\
\hline Log-Rank & 36.4818 & 20 & 0.0135 \\
Wilcoxon & 37.0736 & 20 & 0.0115 \\
\hline
\end{tabular}

Analysis of the pitchy bud data indicated that there was significant variation in time to disease at the country and individual stock levels, but not at the suborigin level (Table 15). The life table presented in Figure 27 is a graphical representation of seedstock survival each year for each country, where a survival distribution function of 1.00 represents $100 \%$ survival. These findings were similar to the analysis of the flagging symptoms in that there were significant differences among individual stock. However, the pitchy bud analysis showed that New Zealand seedstock had significantly better survival rates in 2009 with respect to pitchy buds than did Australia or Chile. Several suborigins had significant differences in pitchy bud numbers among their seedstock, including the C5 and C6 stock from Australia (Table 16), all of the New Zealand stock (Table 17), and three Chilean suborigins (Forestal Celco, Forestal Millalemu, and Forestal Mininco) (Table 18). 
Table 15. Tests for equality across strata. A $p$ value $<.05$ indicates that there is significant variation in time to pitchy bud symptom development at the stock, suborigin, and/or country level.

\begin{tabular}{lccccccccc}
\hline & \multicolumn{3}{c}{ Country } & \multicolumn{3}{c}{ Suborigin } & \multicolumn{3}{c}{ Stock } \\
\hline Test & $\chi^{2}$ & $D F$ & $p>\chi^{2}$ & $\chi^{2}$ & $D F$ & $p>\chi^{2}$ & $\chi^{2}$ & $D F$ & $p>\chi^{2}$ \\
\hline Log-Rank & 6.48 & 2 & 0.0391 & 19.27 & 14 & 0.1550 & 330.63 & 230 & $<.0001$ \\
Wilcoxon & 6.34 & 2 & 0.0419 & 18.98 & 14 & 0.1657 & 328.93 & 230 & $<.0001$ \\
\hline
\end{tabular}

Pitchy Bud Symptom Data by Country

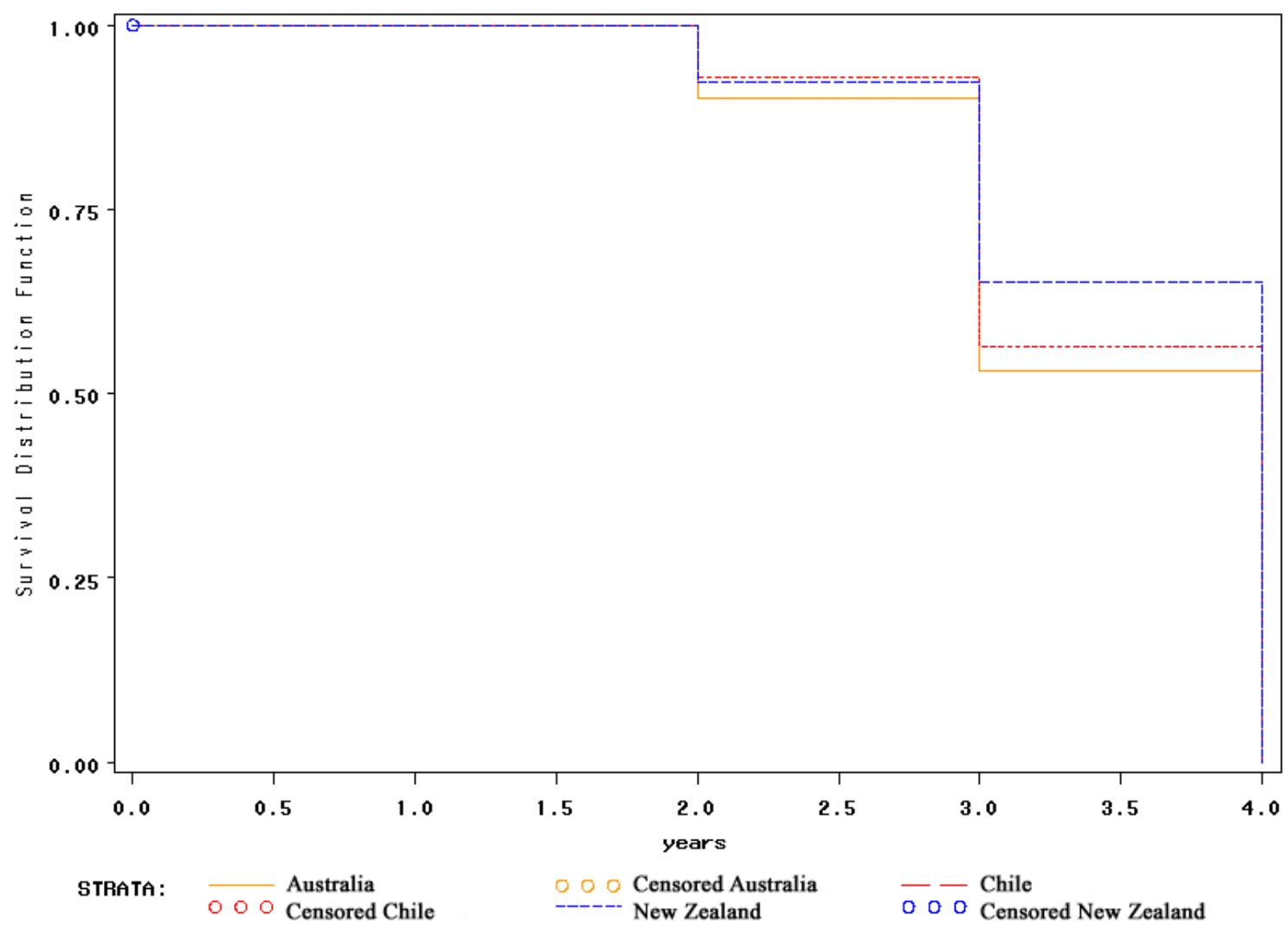

Fig. 27. Life table showing the development of pitchy bud symptoms over time by country of origin. A survival distribution function of 1.00 represents $100 \%$ survival. 
Table 16. Tests for equality over strata for the Australian suborigins. C5/C6 showed significant differences among seedstock for pitchy bud symptoms.

\begin{tabular}{lccc}
\hline & \multicolumn{3}{c}{ C5/C6 } \\
\hline Test & $\chi^{2}$ & $D F$ & $p>\chi^{2}$ \\
\hline Log-Rank & 84.4205 & 64 & 0.0446 \\
Wilcoxon & 84.3577 & 64 & 0.0450 \\
\hline
\end{tabular}

Table 17. Tests for equality over strata for the New Zealand stock. A $p$ value of $<0.05$ indicates significant differences for pitchy bud symptoms.

\begin{tabular}{lccc}
\hline & \multicolumn{3}{c}{ New Zealand } \\
\hline Test & $\chi^{2}$ & $D F$ & $p>\chi^{2}$ \\
\hline Log-Rank & 103.2952 & 74 & 0.0139 \\
Wilcoxon & 102.7367 & 74 & 0.0152 \\
\hline
\end{tabular}

Table 18. Tests for equality over strata for the Chilean suborigins. A $p$ value of $<0.05$ indicates significant differences among seedstock for pitchy bud symptoms.

\begin{tabular}{lccccccccc}
\hline & \multicolumn{2}{c}{$\begin{array}{c}\text { Suborigin } 7 \\
\text { (Forestal Celco) }\end{array}$} & \multicolumn{2}{c}{$\begin{array}{c}\text { Suborigin 10 } \\
\text { (Forestal Millalemu) }\end{array}$} & \multicolumn{3}{c}{$\begin{array}{c}\text { Suborigin 11 } \\
\text { (Forestal Mininco) }\end{array}$} \\
\hline Test & $\chi^{2}$ & $D F$ & $p>\chi^{2}$ & $\chi^{2}$ & $D F$ & $p>\chi^{2}$ & $\chi^{2}$ & $D F$ & $p>\chi^{2}$ \\
\hline Log-Rank & 29.5977 & 14 & 0.0087 & 16.4103 & 7 & 0.0216 & 47.3723 & 18 & 0.0002 \\
Wilcoxon & 29.2937 & 14 & 0.0095 & 15.6325 & 7 & 0.0287 & 47.2559 & 18 & 0.0002 \\
\hline
\end{tabular}

Correlation with Lesion Length

One of the primary objectives of this trial was to confirm or deny a relationship between the lesion length data from the greenhouse portion of the study with the symptom data collected in the plantation. Correlations between the greenhouse mean 
lesion lengths and the numbers of flagging, pitchy bud, and chlorotic tip symptoms from all three years were tested for. The resulting analysis showed that there was not a significant correlation between lesion length and any of the symptoms for any of the three data collection years (Table 19). The Pearson correlation coefficient is a parametric estimate of a linear relationship between two variables.

Table 19. Correlations between mean lesion lengths observed in the greenhouse trial and symptom data from the field trial. Trees were measured in $2007(\mathrm{n}=3022), 2008$ $(n=2938)$, and 2009 ( $n=2891)$. $P$ values are for the null hypothesis of no correlation. flag=flagging, pbud=pitchy buds, ctip=chlorotic tips, $\mathrm{CC}=$ Pearson correlation coefficient

\begin{tabular}{cccccccc}
\hline & flag07 & pbud07 & flag08 & pbud08 & flag09 & PBud09 & CTip \\
\hline CC & -0.02 & -0.02 & -0.02 & -0.00 & -0.03 & -0.02 & -0.03 \\
\hline$p$ & 0.1780 & 0.3074 & 0.3052 & 0.9886 & 0.1075 & 0.2673 & 0.1013 \\
\hline
\end{tabular}

Covariate Effects: Tree Height

The height of the trees was tested as a covariate effect, to test the hypothesis that the development of symptoms is a function of the size of the tree. The tests for covariate effects were performed using the procedure LIFEREG in SAS 9.1. For flagging symptoms, height had a significant covariate effect in 2007 (Table 20). For pitchy bud symptoms, height was significant in 2008 and 2009 (Table 21).

Table 20. Analysis of the covariate effect of tree height on the development of flagging symptoms. ht= tree height in 2007, 2008, or 2009

\begin{tabular}{|c|c|c|c|c|c|c|c|}
\hline Parameter & $D F$ & Estimate & $\begin{array}{l}\text { Standard } \\
\text { Error }\end{array}$ & \multicolumn{2}{|c|}{$\begin{array}{l}95 \% \text { Confidence } \\
\text { Limits }\end{array}$} & $\chi^{2}$ & $p>\chi^{2}$ \\
\hline Intercept & 1 & 1.129 & 0.034 & 1.061 & 1.196 & 1072.86 & $<.0001$ \\
\hline & 1 & -0.01 & 0.006 & -0.022 & -0.0 & 3.95 & 0.0469 \\
\hline ht08 & 1 & -0.002 & 0.004 & -0.011 & 0.006 & 0.22 & 0.6416 \\
\hline ht09 & 1 & 0.003 & 0.002 & -0.001 & 0.008 & 2.14 & 0.1440 \\
\hline
\end{tabular}


Table 21. Analysis of the covariate effect of tree height on the development of pitchy bud symptoms.

\begin{tabular}{ccrrrrrr}
\hline \multirow{2}{*}{ Parameter } & \multirow{2}{*}{ EF } & \multirow{2}{*}{ Estimate } & $\begin{array}{c}\text { Standard } \\
\text { Error }\end{array}$ & \multicolumn{2}{c}{ 95\% Confidence } & \multirow{2}{*}{$\chi^{2}$} & $p>\chi^{2}$ \\
\hline Intercept & 1 & 1.368 & 0.032 & 1.304 & 1.431 & 1771.42 & $<.0001$ \\
ht07 & 1 & 0.003 & 0.006 & -0.008 & 0.014 & 0.25 & 0.6194 \\
ht08 & 1 & -0.023 & 0.004 & -0.031 & -0.014 & 28.61 & $<.0001$ \\
ht09 & 1 & 0.004 & 0.002 & 0.000 & 0.008 & 4.67 & 0.0308 \\
\hline
\end{tabular}

Temporal Effects-Repeated Measures MANOVA

To test the importance of spatial factors such as location in the plantation, and temporal (year to year) factors, a repeated measures multivariate analysis of variance (MANOVA) was performed. The dependent variables modeled were the annual flagging and pitchy bud observations and the independent variables were the blocking factor (rep), and the seedstock identity. Seedstock effects were considered to be nested within the larger effect of suborigin. In SAS 9.1, a multivariate repeated measures analysis cannot be performed on data that has missing values for any of the measurements. So, only trees that were alive in 2009 were analyzed, which required eliminating trees that had observations recorded but died during 2008 or 2009 . There were 182 such trees deleted, of the 4103 trees with observations recorded.

The multivariate repeated measures analysis showed a significant time effect on flagging symptoms according to both the Wilks' $\Lambda$ and Roy's greatest root (r.g.r.) test statistics (Table 22). There were also significant interaction effects between time and 
stock $F(263,3653)=1.87, p<0.0001$ and time and replication $F(4,3653)=10.11, p<$ 0.0001 , indicating strong spatial and temporal effects in the plantation.

Table 22. Results of a repeated measures MANOVA testing for an effect of time on the development of flagging symptoms. Interaction effects with time are included. r.g.r. $=$ Roy's greatest root

\begin{tabular}{lcccccc}
\hline & \multicolumn{2}{c}{ Test Statistic } & \multirow{2}{*}{ F Value } & Num & Den & \multirow{2}{*}{ Pr $>$ F } \\
\cline { 2 - 3 } & Wilks' $\Lambda$ & r.g.r. & & DF & \\
\hline time & 0.97 & 0.03 & 61.53 & 2 & 3652 & $<.0001$ \\
\hline \multirow{2}{*}{ time * stock(suborigin) } & 0.83 & & 1.36 & 526 & 7304 & $<.0001$ \\
& & 0.12 & 1.36 & 526 & 3653 & $<.0001$ \\
\hline \multirow{2}{*}{ time * rep } & 0.99 & & 5.03 & 8 & 7304 & $<.0001$ \\
& & 0.01 & 7.25 & 4 & 3653 & $<.0001$ \\
\hline
\end{tabular}

Within the repeated measures analysis, a polynomial contrast was performed in order to further visualize symptom development over time. The were significant linear $F(1,3653)=122.68, p<0.0001$ and quadratic $F(1,3653)=46.33, p<0.0001$ time effects on symptom development. There was a significant linear time effect for at least one stock $F(263,3653)=1.62, p<0.0001$ and at least one replication $F(4,3653)=3.44$, $p<0.0001$. There was also a significant quadratic time effect for at least one of the replications (Table 23). So, flagging symptoms over time tended to develop in a linear fashion according to stock, but had a significant quadratic component, depending on the replication in which the tree was located (Figure 28). 
Table 23. Polynomial contrasts for linear and quadratic components in flagging symptom development across replications and seedstock. A $p$ value of $<0.05$ indicates that at least one stock/rep had a significant linear/quadratic time component.

\begin{tabular}{lrrr}
\hline & DF & F value & Pr $>$ F \\
\hline Linear component & 263 & 1.62 & $<.0001$ \\
Stock & 4 & 3.44 & 0.0082 \\
Rep & 3653 & & \\
Error & & & \\
\hline Quadratic component & 263 & 1.13 & 0.0813 \\
Stock & 4 & 3.71 & 0.0051 \\
Rep & 3653 & & \\
Error & & & \\
& &
\end{tabular}

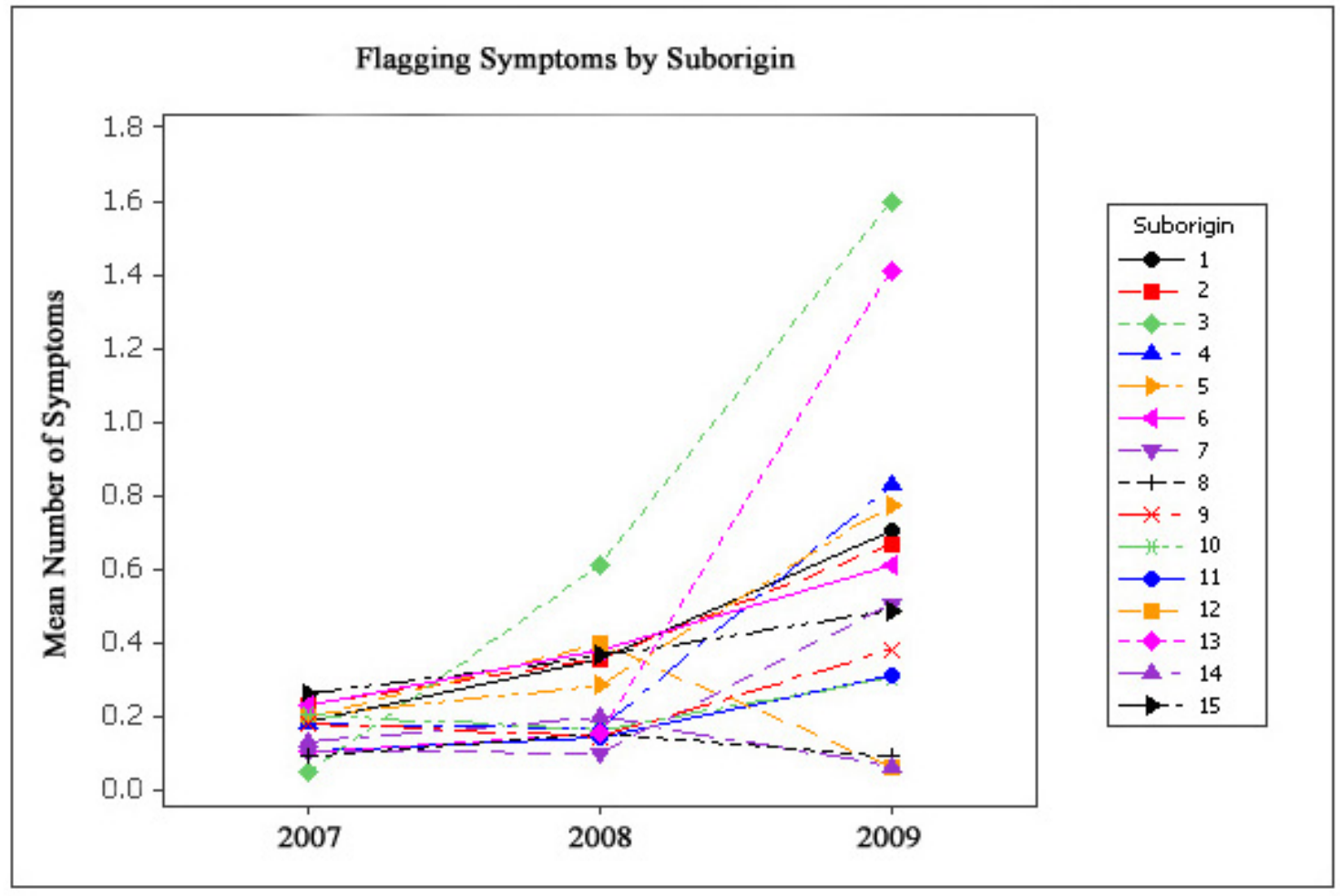

Fig. 28. Development of flagging symptoms over the three year period. Suborigin identities may be found in the Appendix.

The same analysis on the pitchy bud data yielded results similar to the flagging data. There was again a significant effect of time on symptom development, according to 
both Wilks' $\Lambda$ and r.g.r test statistics (Table 24). Significant interaction effects were also observed between time and stock $F(263,3653)=1.22, p<0.0001$ and time and replication $F(4,3653)=17.53, p<0.0001$.

Table 24. Results of a repeated measures MANOVA testing for an effect of time on the development of pitchy bud symptoms. Interaction effects with time are included. r.g.r. $=$ Roy's greatest root

\begin{tabular}{lcccccc}
\hline & \multicolumn{2}{c}{ Test Statistic } & \multirow{2}{*}{ F Value } & Num & Den & \multirow{2}{*}{ Pr $>$ F } \\
\cline { 2 - 3 } & Wilks' $\Lambda$ & r.g.r. & & DF & \\
\hline time & 0.95 & 0.05 & 97.80 & 2 & 3652 & $<.0001$ \\
\hline \multirow{2}{*}{ time * stock(suborigin) } & 0.83 & & 1.32 & 526 & 7304 & $<.0001$ \\
& & 0.10 & 1.32 & 526 & 3653 & $<.0001$ \\
\hline \multirow{2}{*}{ time * rep } & 0.98 & & 10.04 & 8 & 7304 & $<.0001$ \\
& & 0.02 & 16.97 & 4 & 3653 & $<.0001$ \\
\hline
\end{tabular}

A polynomial contrast of the pitchy bud symptoms indicated that there was also both a linear and quadratic relationship between time and symptom development $(\mathrm{P}<0.0001)$ (Table 25). This was due to a significant interaction effect between stock and replication, indicating an important spatial effect on disease development in the plantation (Figure 29).

Table 25. Polynomial contrasts for linear and quadratic components in pitchy bud symptom development across replications and seedstock. A $p$ value of $<0.05$ indicates that at least one stock/rep had a significant linear/quadratic time component.

\begin{tabular}{lrrr}
\hline & DF & F value & Pr $>$ F \\
\hline Linear component & & & \\
Stock & 263 & 1.20 & 0.0196 \\
Rep & 4 & 14.46 & $<.0001$ \\
Error & 3653 & & \\
\hline Quadratic component & & & \\
Stock & 263 & 1.25 & 0.0045 \\
Rep & 4 & 7.56 & $<0.0001$ \\
Error & 3653 & & \\
& & &
\end{tabular}




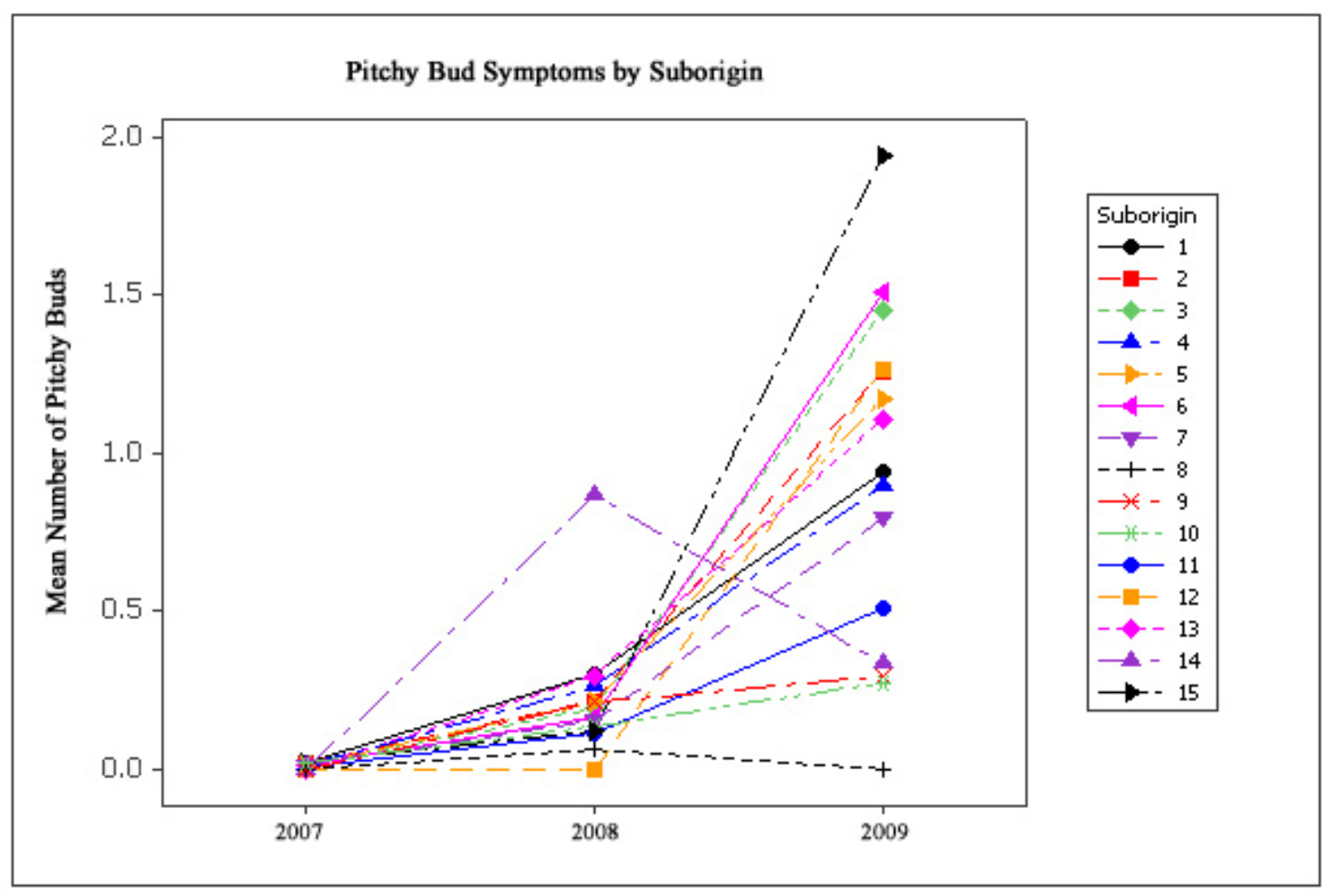

Fig. 29. Development of pitchy bud symptoms over time by suborigin. Suborigin identities may be found in the appendix.

To further understand the effect of location in the plantation, a means separation test was performed to compare symptoms in each of the five replications. This analysis showed that at least one replication experienced significantly different numbers of symptoms every year (Tables 26 and 27, Figures 30 and 31). This means that the particular rep in which the tree was located had an influence on its probability of developing disease symptoms. 
Table 26. Results of means separation test showing the significance difference in flagging symptoms observed in each block from 2007-2009.

\begin{tabular}{c|ccc}
\hline & \multicolumn{3}{|c}{ Duncan grouping } \\
REP & 2007 & 2008 & 2009 \\
\hline 1 & $\mathrm{~b}$ & $\mathrm{a}, \mathrm{b}$ & $\mathrm{b}, \mathrm{c}$ \\
2 & $\mathrm{c}$ & $\mathrm{c}, \mathrm{d}$ & $\mathrm{c}$ \\
3 & $\mathrm{~b}$ & $\mathrm{~d}$ & $\mathrm{c}$ \\
4 & $\mathrm{~b}$ & $\mathrm{~b}, \mathrm{c}$ & $\mathrm{a}$ \\
5 & $\mathrm{a}$ & $\mathrm{a}$ & $\mathrm{a}, \mathrm{b}$ \\
\hline
\end{tabular}

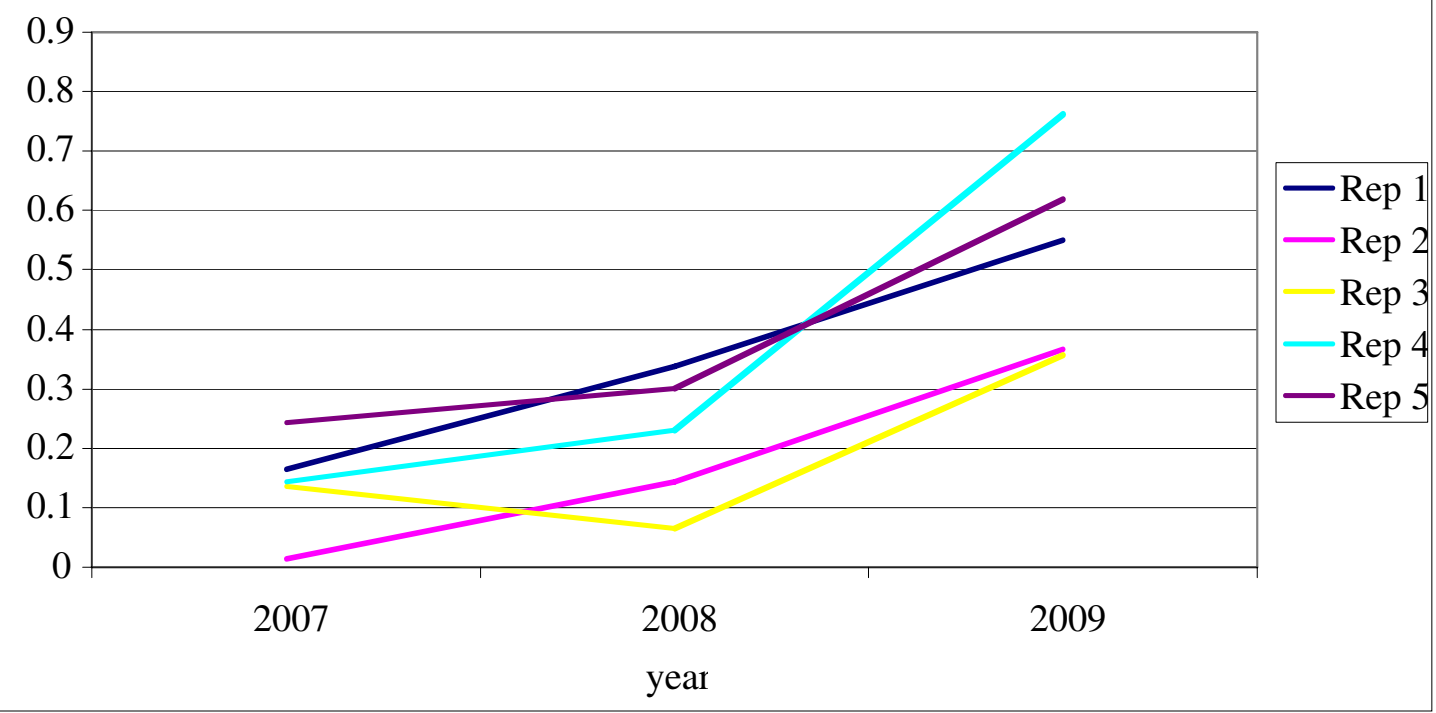

Figure 30. Flagging symptom development over time by replication.

Table 27. Results of means separation test showing the significance difference in pitchy bud symptoms observed in each block from 2007-2009.

\begin{tabular}{c|ccc}
\hline & \multicolumn{3}{|c}{ Duncan grouping } \\
REP & 2007 & 2008 & 2009 \\
\hline 1 & $\mathrm{~b}, \mathrm{c}$ & $\mathrm{b}$ & $\mathrm{c}$ \\
2 & $\mathrm{c}$ & $\mathrm{b}$ & $\mathrm{c}$ \\
3 & $\mathrm{~b}, \mathrm{c}$ & $\mathrm{b}$ & $\mathrm{b}$ \\
4 & $\mathrm{a}$ & $\mathrm{a}$ & $\mathrm{a}$ \\
5 & $\mathrm{~b}$ & $\mathrm{~b}$ & $\mathrm{c}$ \\
\hline
\end{tabular}




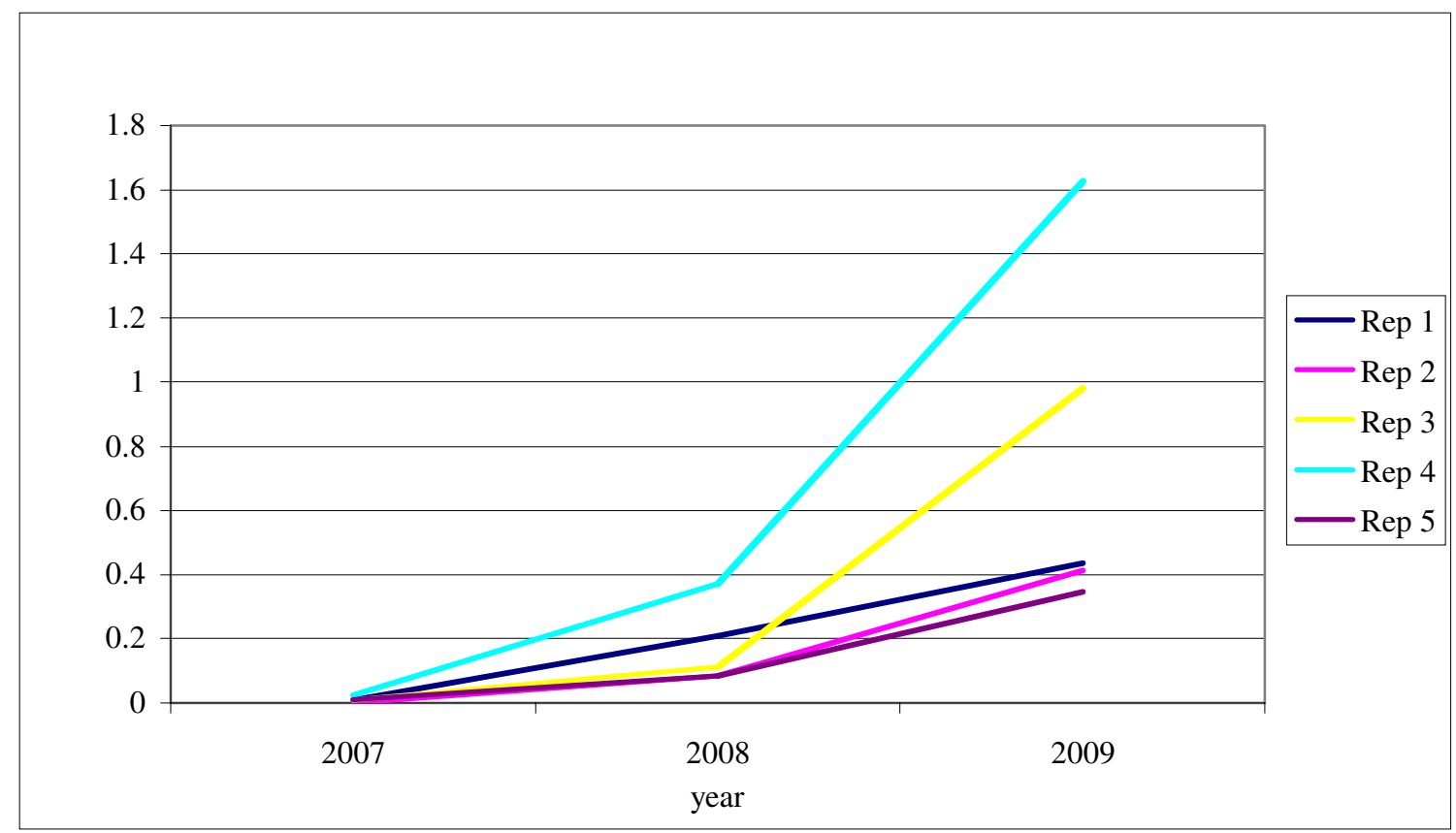

Figure 31. Pitchy bud symptom development over time by replication.

Deer Rub Analysis

The presence of trunk wounds due to deer rubbing in the plantation was also of interest and explored statistically. Wounds were observed on trees scattered throughout the plantation, and it was hypothesized that the selection of tree to rub might be related to any or all of three factors: the height of the tree, the genetic stock of the tree, or the location in the plantation. These factors, plus their interactions were tested with a MANOVA. In 2007, tree height and replication (location in the plantation) were significant with respect to the presence of deer rub wounds (Table 28). Also, there were significant interaction effects between height and replication, as well as between height, stock and replication. In 2008 only tree height was found to have a significant effect. In 2009, tree height, and the interactions between height and replication, and height, 
replication, and stock were significant. These results indicate that the height of the tree was significant to its probability of being rubbed by deer. The interaction effects show that seedstock only had a significant effect when combined with the effects of both height and replication. The interaction between height and replication probably occurred because differences in nutrient and water status existed throughout the plantation, resulting in some replications (such as Rep 1) having taller trees than others.

Table 28. MANOVA results for deer rub data in 2007, 2008, and 2009.

\begin{tabular}{lrrr}
\hline Source & $D F$ & F Value & $p>\mathrm{F}$ \\
\hline 2007 & & & \\
height & 1 & 41.38 & $<.0001$ \\
stock & 263 & 1.06 & 0.2691 \\
rep & 4 & 6.58 & $<.0001$ \\
height*rep & 4 & 3.56 & 0.0067 \\
ht07*stock*rep & 881 & 1.68 & $<.0001$ \\
\hline 2008 & & & \\
height & 1 & 9.47 & 0.0021 \\
stock & 263 & 0.78 & 0.9946 \\
rep & 4 & 2.02 & 0.0897 \\
height *rep & 4 & 1.30 & 0.2687 \\
height *stock*rep & 901 & 1.05 & 0.2079 \\
\hline 2009 & & & \\
height & 1 & 8.01 & 0.0047 \\
stock & 263 & 1.01 & 0.4533 \\
rep & 4 & 1.20 & 0.3111 \\
height *rep & 4 & 2.48 & 0.0423 \\
height *stock*rep & 900 & 1.14 & 0.0159 \\
\hline
\end{tabular}

GIS Spatial Analysis

Flagging symptoms on trees were found to have a significant clustered distribution in the plantation in 2007 and 2008 (Table 29). By 2009, flagging was more prevalent throughout the plantation, though was still nearly significantly clustered. Pitchy 
buds showed no significant spatial pattern in 2007, but was significantly clustered in both 2008 and 2009. Chlorotic tips had a highly significantly clustered distribution in 2009.

When the data for flagging and pitchy buds was combined, there was a significant cluster pattern in 2007 and 2008, but in 2009 the distribution was random, probably because the disease had become so prevalent in the plantation by then. Graphical display of the symptomatic tree distribution is presented in Figures 32-41. A clustered distribution of symptomatic trees would be consistent with conidia dispersal by splashing rain, which is a characteristic of Diplodia spp. The pitch canker fungus (Fusarium circinatum), on the other hand has conidia that are either dispersed via insects or aerially. This would probably result in a more random pattern throughout the plantation.

Table 29. Average nearest neighbor spatial statistics for three symptoms observed in the plantation. The nearest neighbor ratio is the observed mean distance divided by the expected mean distance, and the $Z$-score represents the standard deviation.

\begin{tabular}{ccccccc}
\hline & $\begin{array}{c}\text { Spatial } \\
\text { Pattern }\end{array}$ & $\begin{array}{c}\text { Observed } \\
\text { Mean } \\
\text { Distance }\end{array}$ & $\begin{array}{c}\text { Expected } \\
\text { Mean } \\
\text { Distance }\end{array}$ & $\begin{array}{c}\text { Nearest } \\
\text { Neighbor } \\
\text { Ratio }\end{array}$ & Z-score & P-value \\
\hline $\mathbf{2 0 0 7}$ & & & & & & \\
Flagging & Clustered & 15.79 & 17.38 & 0.91 & -3.56 & 0.0004 \\
Pitchy buds & Random & 45.83 & 46.68 & 0.98 & -0.25 & 0.8048 \\
Combined & Clustered & 15.79 & 17.38 & 0.90 & -3.56 & 0.0004 \\
\hline $\mathbf{2 0 0 8}$ & & & & & & \\
Flagging & Clustered & 14.07 & 15.44 & 0.91 & -3.90 & $<0.0001$ \\
Pitchy buds & Clustered & 20.49 & 23.48 & 0.87 & -3.55 & 0.0004 \\
Combined & Clustered & 13.02 & 13.79 & 0.94 & -2.76 & 0.0057 \\
\hline $\mathbf{2 0 0 9}$ & & & & & & \\
Flagging & Clustered & 12.64 & 13.12 & 0.96 & -1.89 & 0.0582 \\
Pitchy buds & Clustered & 14.63 & 15.68 & 0.93 & -2.69 & 0.0071 \\
Combined & Random & 11.50 & 11.46 & 1.00 & 0.22 & 0.8232 \\
Chlorotic tips & Clustered & 17.28 & 20.95 & 0.82 & -5.47 & $<0.0001$ \\
\hline
\end{tabular}




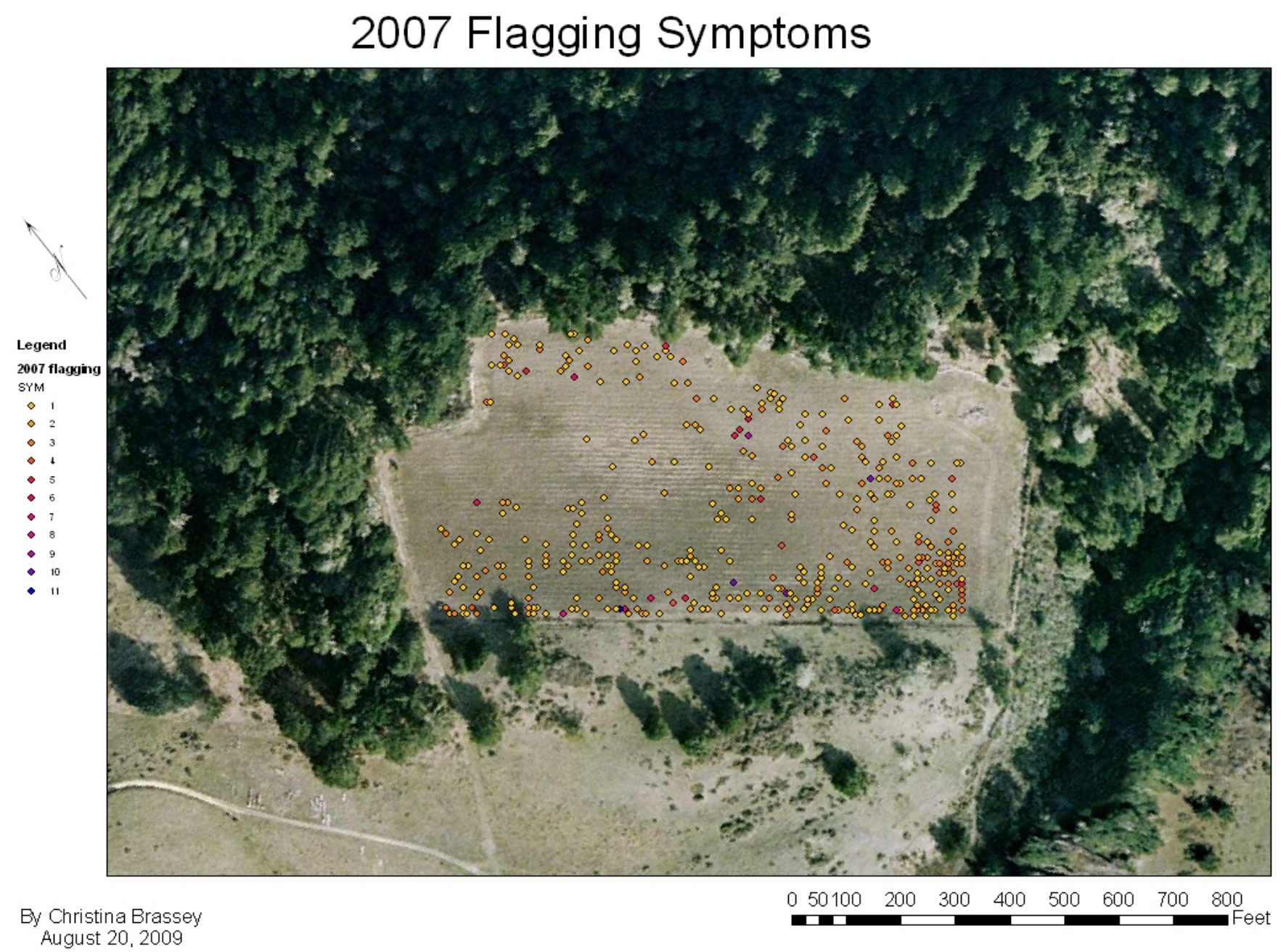

Fig. 32. Distribution of trees with flagging symptoms in 2007. Circles symbolize symptomatic trees, and the color indicates relative number of symptoms per tree. 


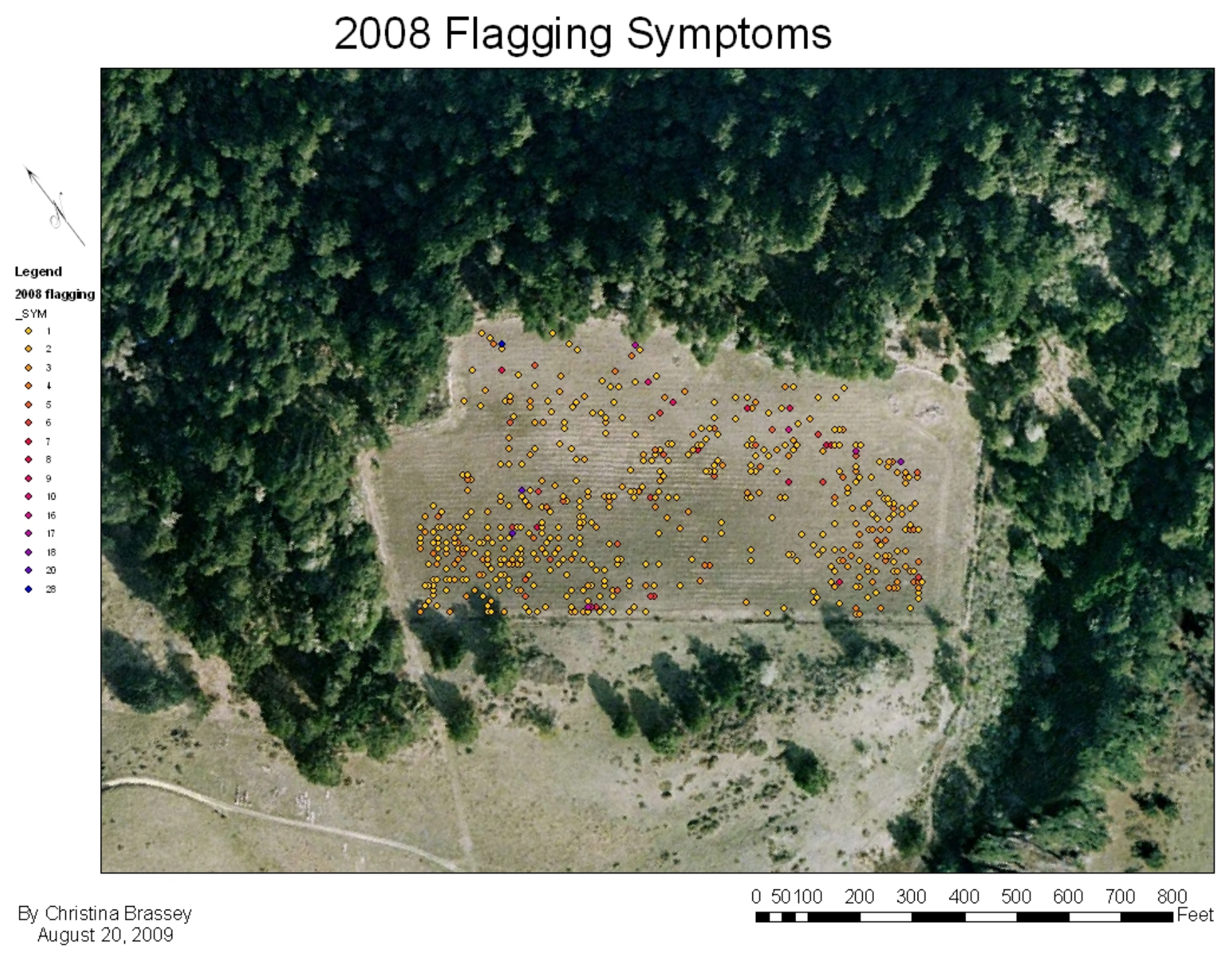

Fig. 33. Distribution of trees with flagging symptoms in 2008. Circles symbolize symptomatic trees, and the color indicates relative number of symptoms per tree. 


\section{Flagging Symptoms}

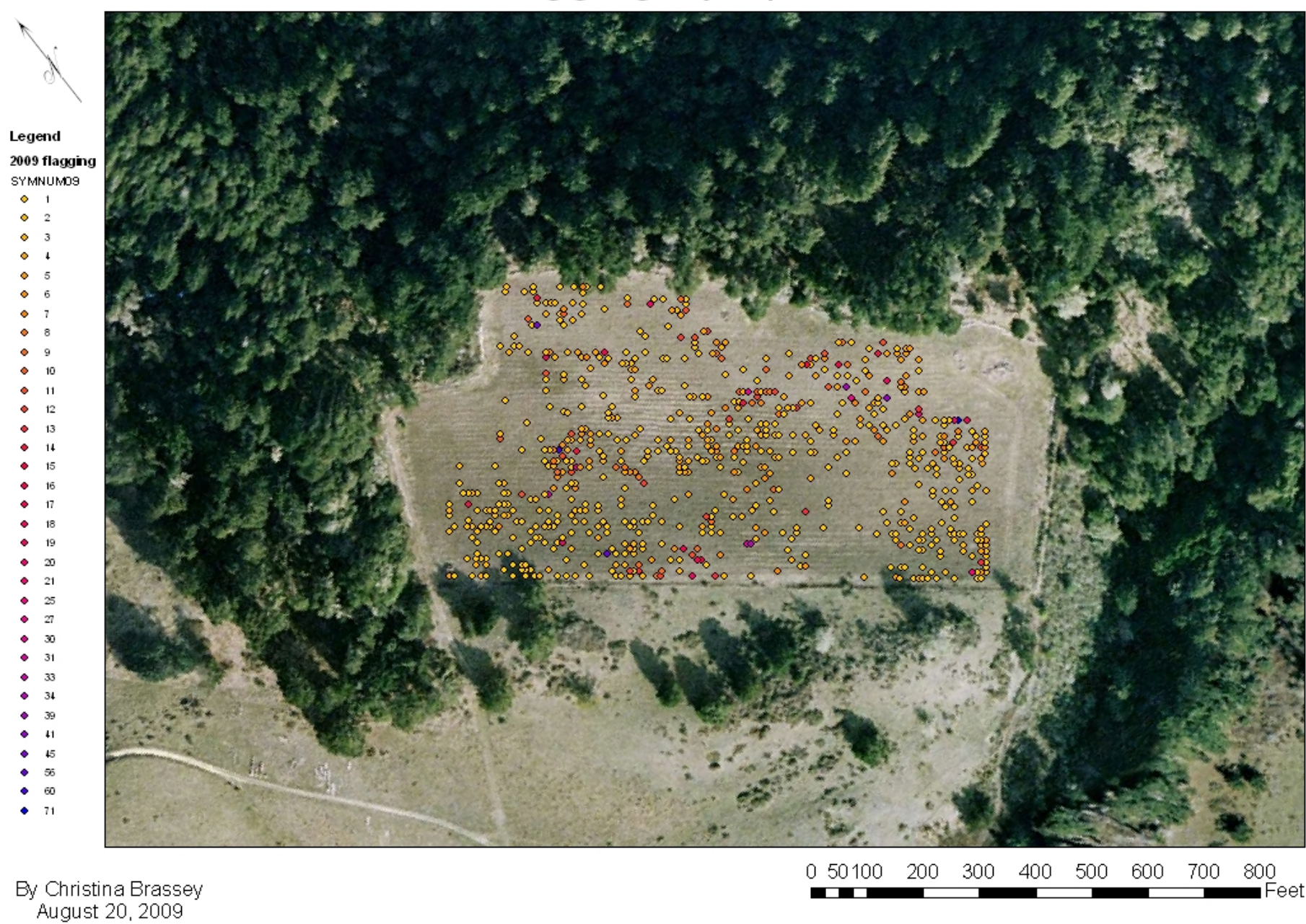

Fig. 34. Distribution of trees with flagging symptoms in 2009. Circles symbolize symptomatic trees, and the color indicates relative number of symptoms per tree. 


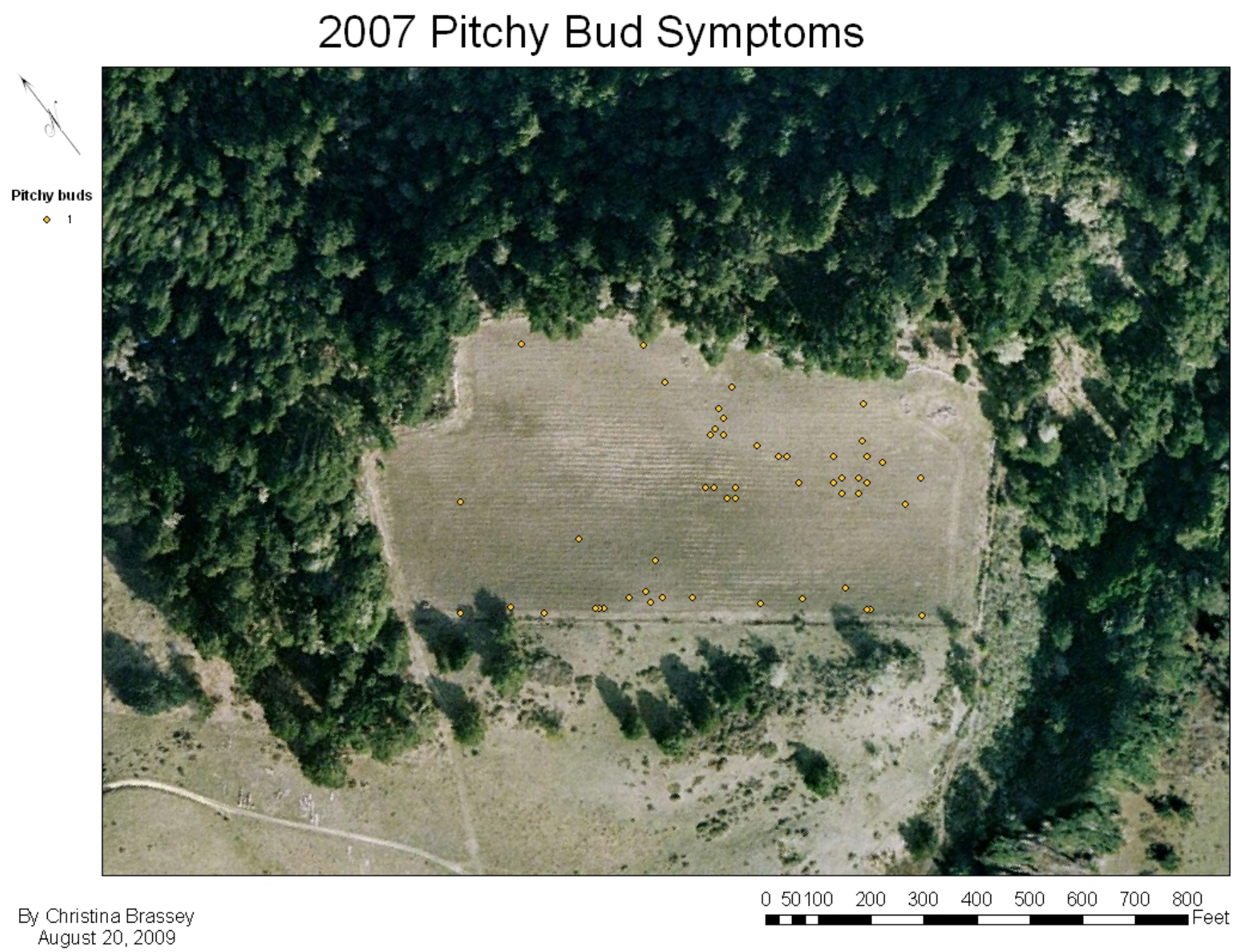

Fig. 35. Distribution of trees with pitchy bud symptoms in 2007. Circles symbolize symptomatic trees, and the color indicates relative number of symptoms per tree. 


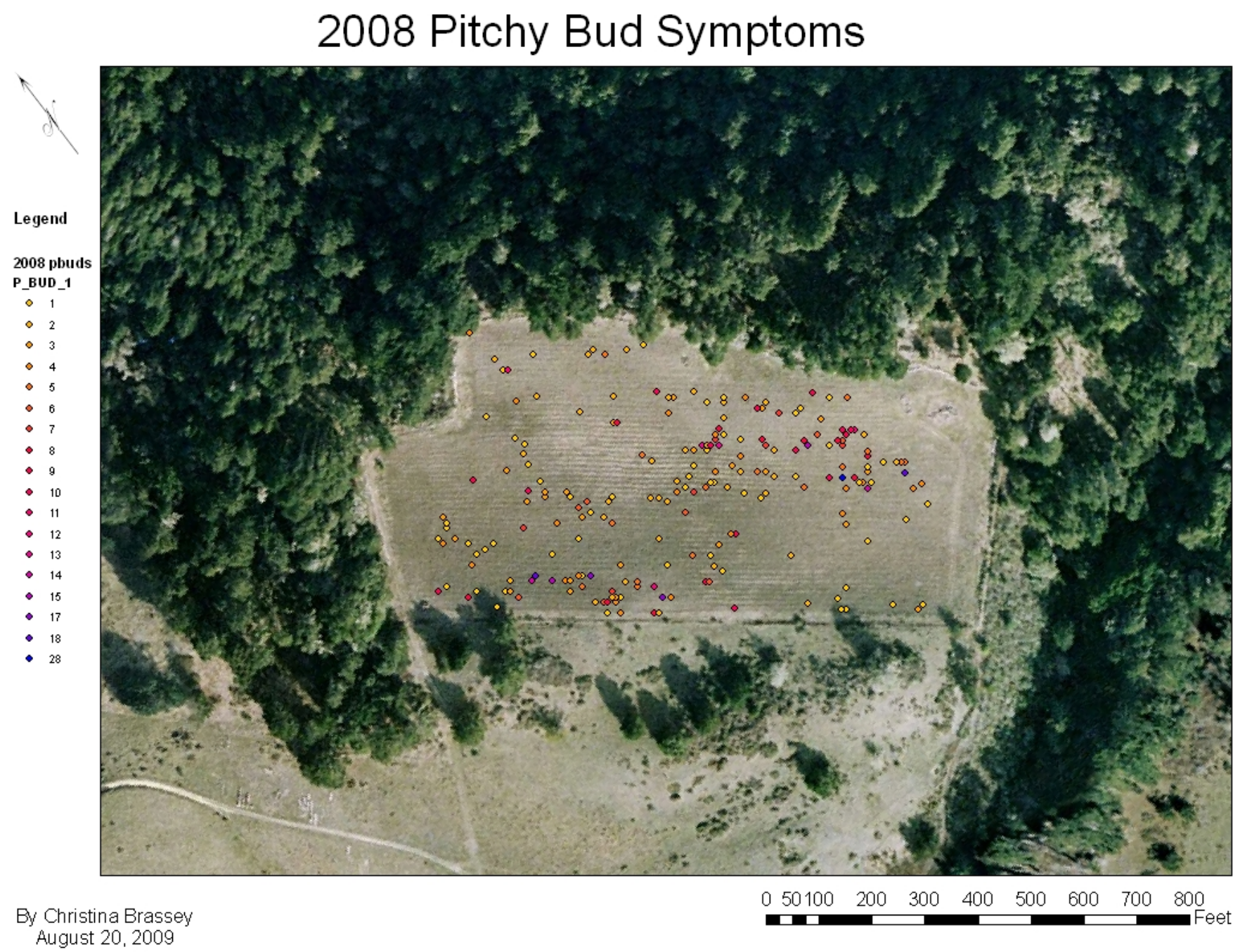

Fig. 36. Distribution of trees with pitchy bud symptoms in 2008. Circles symbolize symptomatic trees, and the color indicates relative number of symptoms per tree. 


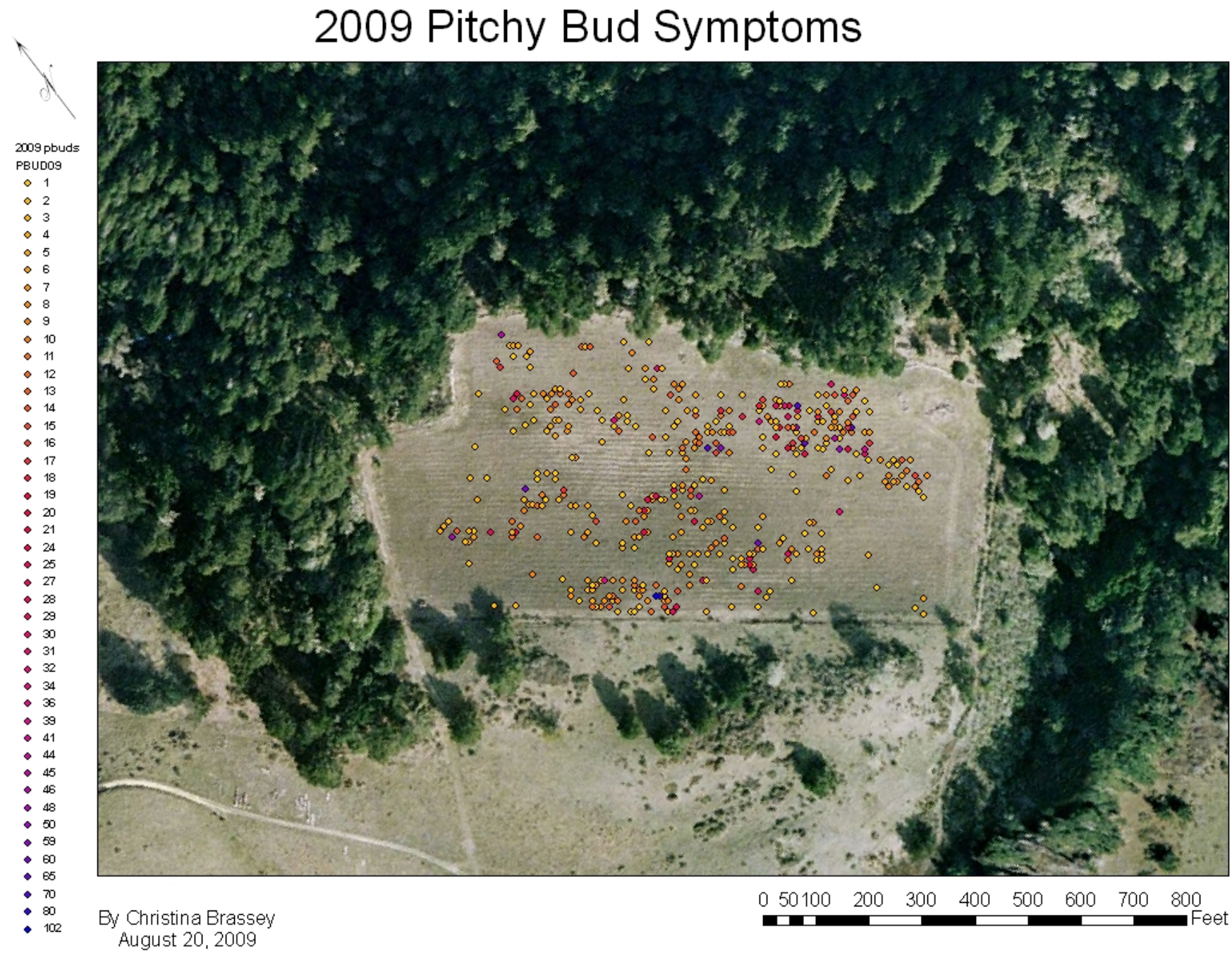

Fig. 37. Distribution of trees with pitchy bud symptoms in 2009. Circles symbolize symptomatic trees, and the color indicates relative number of symptoms per tree. 


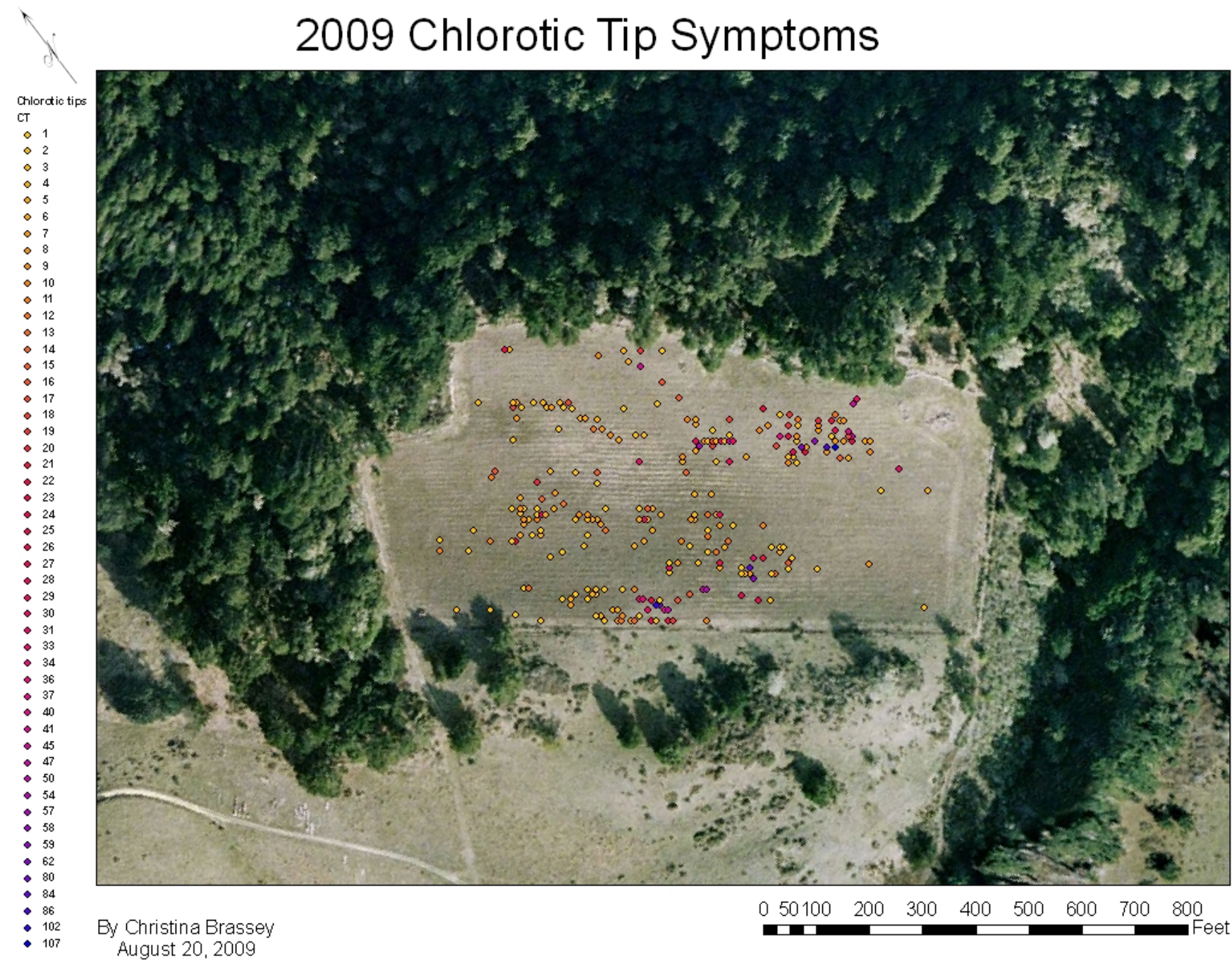

Fig. 38. Distribution of trees with pitchy bud symptoms in 2009. Circles symbolize symptomatic trees, and the color indicates relative number of symptoms per tree. 


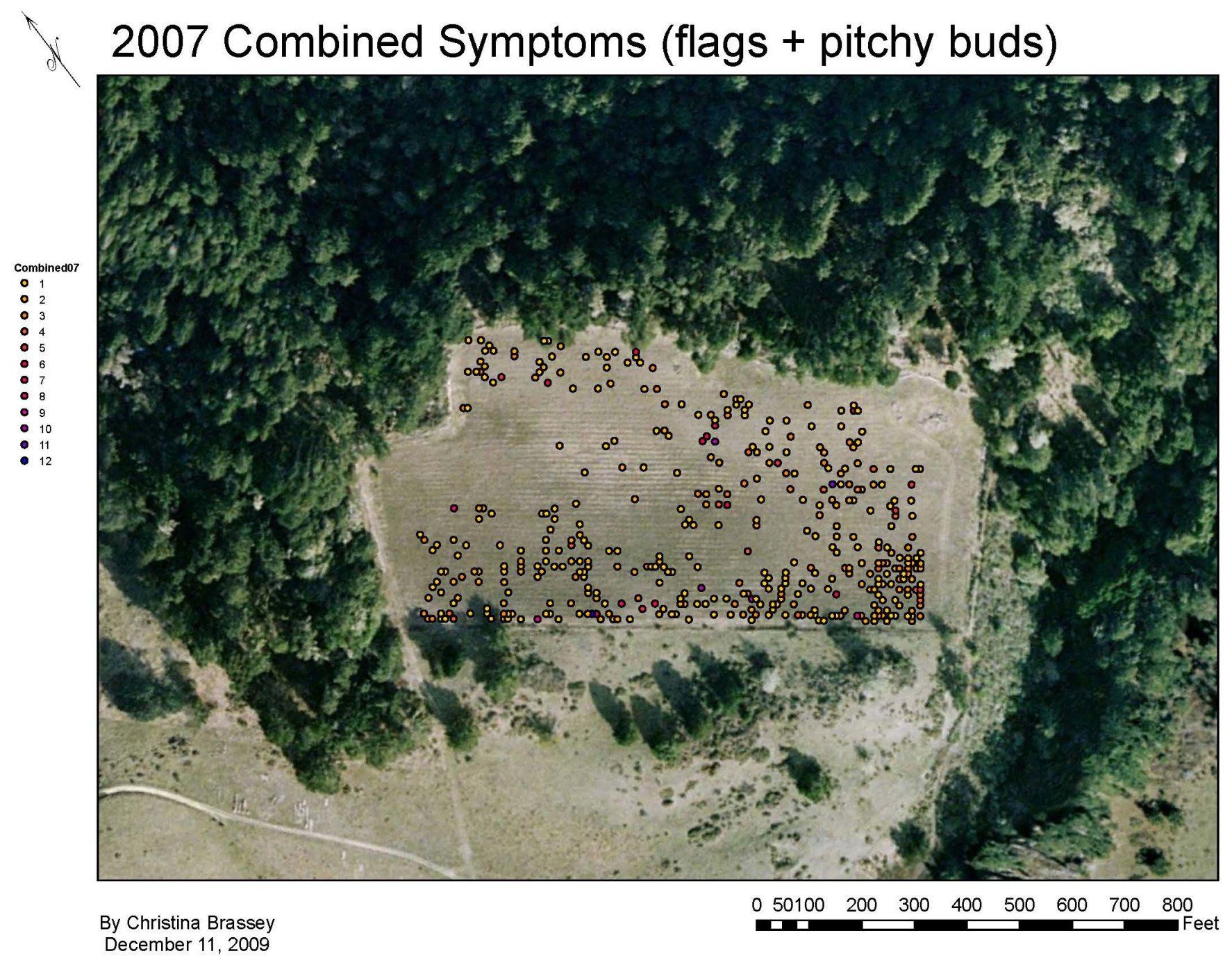

Fig. 39. Symptom distribution in 2007, combined for flagging and pitchy buds. Circles symbolize symptomatic trees, and the color indicates relative number of symptoms per tree. 


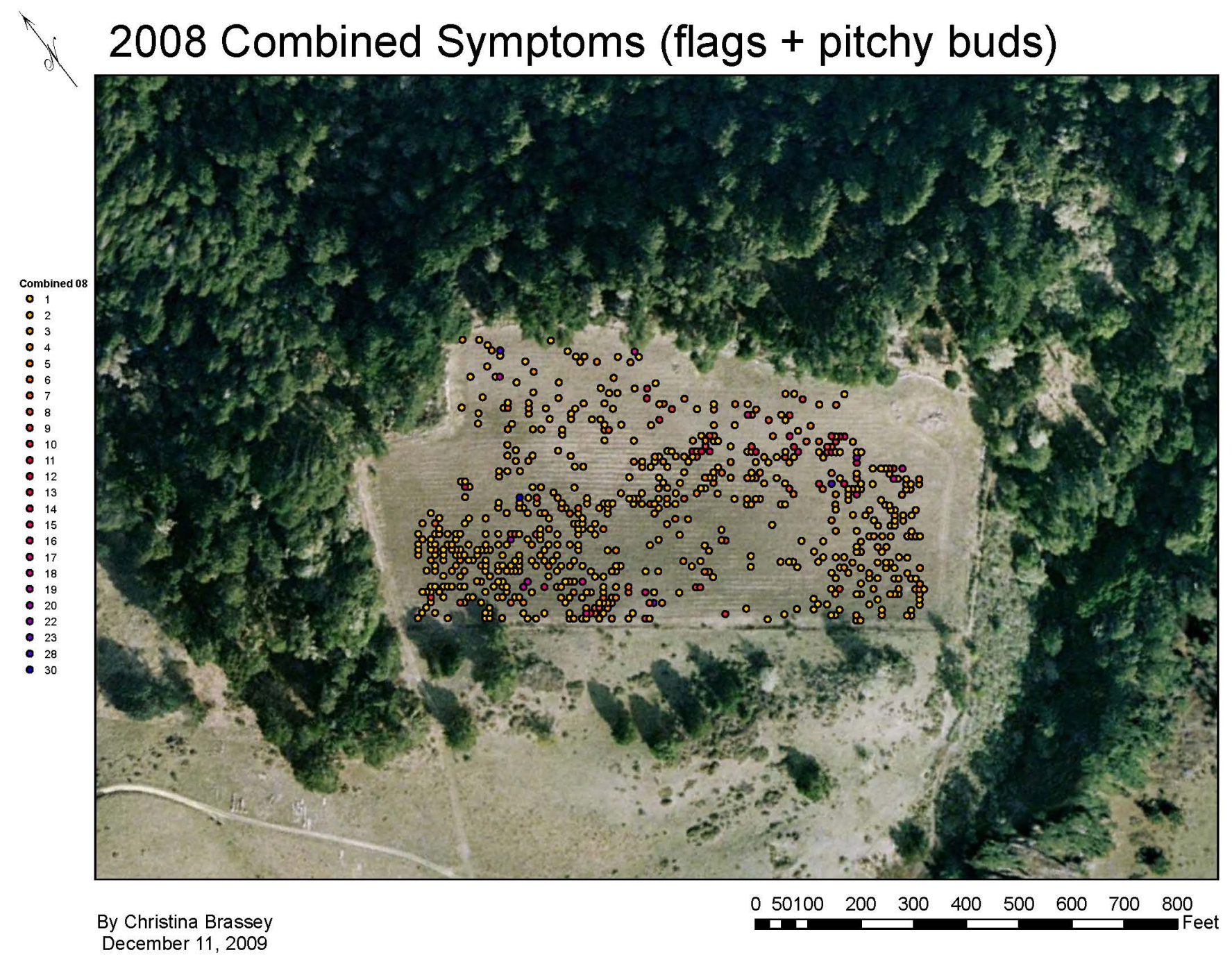

Fig. 40. Symptom distribution in 2008, combined for flagging and pitchy buds. Circles symbolize symptomatic trees, and the color indicates relative number of symptoms per tree. 


\section{Combined Symptoms (flags + pitchy buds)}

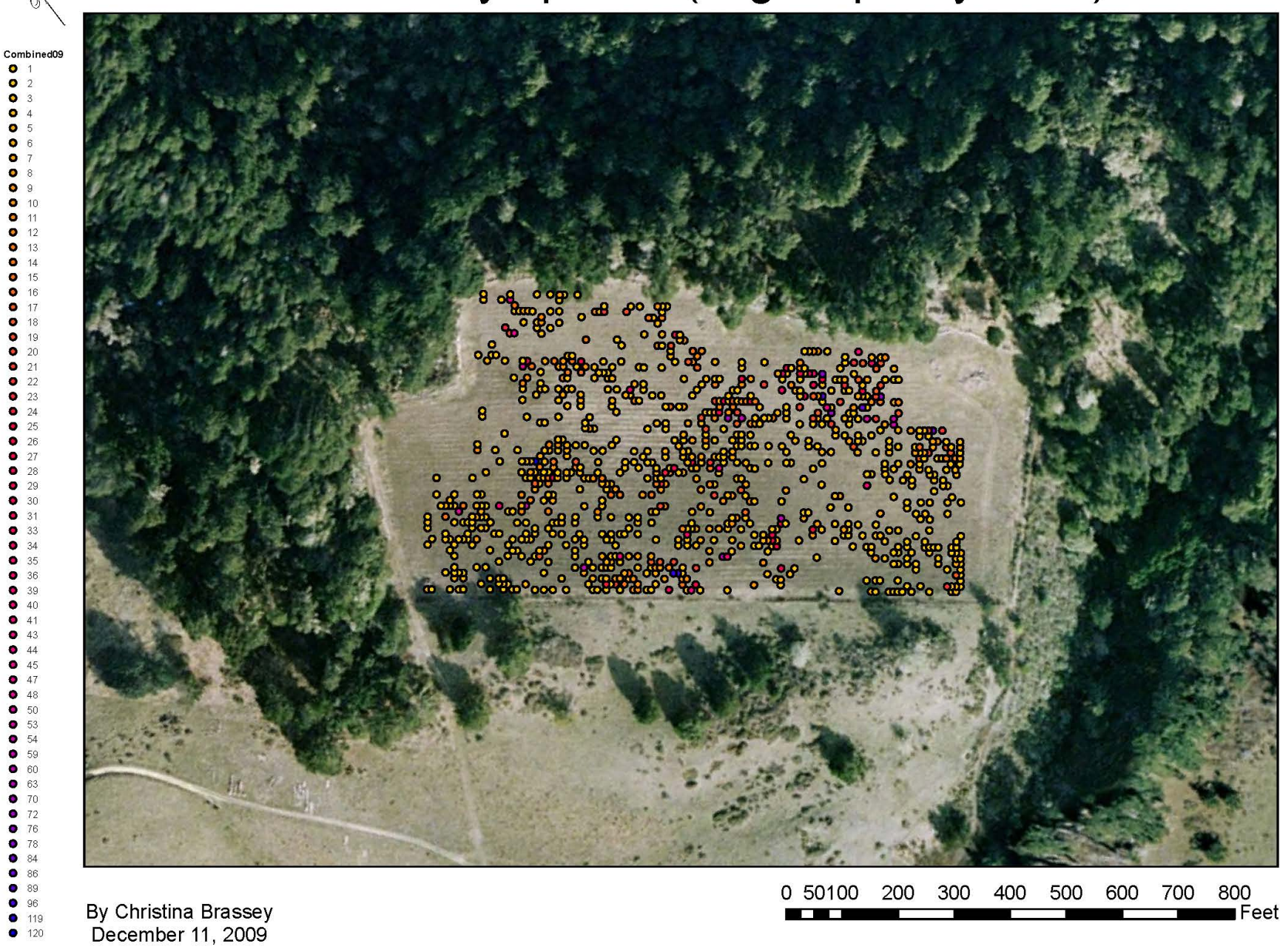

Fig. 41. Symptom distribution in 2009, combined for flagging and pitchy buds. Circles symbolize symptomatic trees, and the color indicates relative number of symptoms per tree. 


\section{DISCUSSION \& CONCLUSIONS}

Plantation field trials face a unique set of challenges that are not present in the more controlled environments of laboratories and greenhouses. Performing a study in this kind of environment can reveal important variables that were unexpected and unplanned for when the experiment was designed. While this can impact or even confound the original direction of the experiment, such discoveries are no less important and can be even more informative, given that the environmental setting more closely resembles the natural conditions of the organism of interest. In this case we were looking at the performance of Monterey pine seed stock from Australia, New Zealand, and Chile in a field trial in coastal California.

Intending to test the seed stocks for variation in resistance to pitch canker, we instead found that diplodia blight was also prevalent in the area, and that it manifested much more quickly than pitch canker. Over three years we collected data on the development of diplodia blight in the plantation, which started with branch tip flagging in the first year, followed by an abundance of pitchy buds in the second year, and then branch tips with chlorotic needles in the third year. This study will continue on for a final data collection in February 2010 to document the further progression of diplodia blight, as well as the beginning of pitch canker symptom manifestation. The fact that pitch canker is only now beginning to appear informs us of the necessary duration of such a trial, should it be repeated elsewhere in similar conditions. In this case a plantation planted in 2005 began to show diplodia blight symptoms in 2007 and pitch canker symptoms in 2009. Weather conditions during these years very likely influenced the 
development and severity of the disease each year in the plantation, and would be an informative area of further research.

In addition to the genetics of each seedstock, the location of each tree in the plantation was also found to have an important influence on development of disease. Certain replications were found to have significantly different numbers of disease symptoms, which was probably related to the proximity of certain replications to inoculum sources. The epidemiology of diplodia blight in Monterey pine in its native habitat is another opportunity for further research. In this experiment symptomatic trees were found to have a significantly clustered distribution, which is consistent with rainsplash being the primary mechanism of spore dispersal in Diplodia pinea.

Analysis of the symptom data indicated that there was no correlation with the results of the greenhouse pitch canker trial, and we now know that this is because we were looking at a different disease. However, significant differences in diplodia blight symptom development were still observed among the seed stock tested. This means that the results of this experiment will yield important information to plantation managers regarding resistance of the stock to diplodia blight, a disease that can also cause economic damage. In particular, within the New Zealand seed stock there were significant differences in symptom development, as well as within three of the Chilean suborigins: Forestal Celco, Forestal Millalemu, and Forestal Mininco. The additional seed stocks labeled C5/C6 from Australia also had significant differences among them. A list of the seed stocks from each country and suborigin with corresponding 2009 symptom data is included in Appendix B. The mean number of symptoms for each stock is listed in descending order, with the most susceptible stock listed first. Notably, there 
are a few stocks from each country that did not experience any symptoms over the three years of the trial. Managers can use this list as a quick reference for seed stock performance in the trial.

The benefit of hindsight allows for improvement of similar studies in the future. Field trials that are to be naturally infected from an adjacent stand of trees should include a comprehensive disease survey of the stand assumed to be providing the inoculum. Data and samples for this type of survey should be collected, and the results of the isolations recorded.

Another important issue to address with resistance field trials is how to deal with escapes (i.e. trees that avoided infection for reasons other than resistance level). As the GIS analysis showed, many trees avoided infection due to their location in the plantation, and blocking factor was just as significant as seedstock origin to symptom development. Replication and blocking were used to account for these spatial differences, as did the censoring feature in the survival analysis. In this particular study, it would have been a good idea to do some field inoculation of pitch canker. In the workshop minutes at the end of the 1998 IMPACT conference Mike Wingfield suggested having both inoculated and uninoculated trees in the trial to deal with escapes (Devey, Matheson, and Gordon, 1999).

In this study, what began as a resistance trial for pitch canker ended up providing important information about diplodia blight in California, and how symptoms manifest over three years in a pole stage Monterey pine forest. This outcome emphasizes the complexity and opportunities that can arise from research in the natural resource and ecological sciences. The data that was collected from each of the over 4,000 trees of 
known genetic origin provides us with the opportunity to enhance our understanding of the spatial, temporal and genetic relationships at work under such conditions, and contributes to the current state of knowledge on the subject. Through this, we enhance our ability to manage and protect our forest resources in a way that is sustainable, which is the primary goal of research in forest science. 


\section{LIST OF REFERENCES}

Aegerter, B. J., \& Gordon, T. R. (2006). Rates of pitch canker induced seedling mortality among Pinus radiata families varying in levels of genetic resistance to Gibberella circinata (anamorph Fusarium circinatum), For. Ecol. Manage. 235, 14-17.

Balocchi, C., Ahumada, R., \& Ramirez O. (1999). Present and future of radiata pine in Chile. In: Devey, M., C. Matheson, T. R. Gordon (Eds.). Current and potential impacts of pitch canker in radiata pine. Proc. IMPACT Monterey Workshop. Monterey, CA. 30 Nov.-3 Dec. 1998 (pp. 1-4). Australia: CSIRO.

Barrows-Broaddus, J., \& Dwinell, L. D. (1983). Histopathology of Fusarium moniliforme var. subglutinans in four species of southern pines, Phytopathology 73, 882-889.

Blakeslee, G. M., \& Rockwood, D. L. (1999). Variation in resistance to pitch canker in slash and loblolly pines. In: Devey, M., C. Matheson, T. R. Gordon (Eds.). Current and potential impacts of pitch canker in radiata pine. Proc. IMPACT Monterey Workshop. Monterey, CA. 30 Nov.-3 Dec. 1998 (pp. 70-75). Australia: CSIRO.

Blood, D. A. (2000). Mule and black-tailed deer in British Columbia: Ecology, conservation and management. Province of British Columbia. [Brochure, Electronic version] (Available at www.env.gov.bc.ca/wld/documents/muledeer.pdf)

Bonello, P., Gordon, T. R., \& Storer A. J. (2001). Systemic induced resistance in Monterey pine, For. Pathol., 31, 99-106.

Booth, C. (1971). The genus Fusarium. Kew, Surrey, England: Commonw. Mycol. Inst. 
$\mathrm{CAB}$ International $(\mathrm{CABI}) \&$ European and Mediterranean Plant Protection Organization (EPPO) (n.d.) Data sheets on quarantine organisms No. 11, Endocronartium harknessii. OEPP/EPPO Bulletin. Retrieved April 19, 2009, from http://www.eppo.org/QUARANTINE/fungi/Endocronartium_harknessii/ENDCH $\underline{\text { A ds.pdf }}$

Carlucci, A., Colatruglio, L., \& Frisullo, S. (2007). First report of pitch canker caused by Fusarium circinatum on Pinus halepensis and P. pinea in Apulia (Southern Italy), Plant Dis., 91, 1683.

Clark, S., \& Gordon, T. (1999). Susceptibility of eleven California conifers to pitch canker caused by Fusarium subglutinans f. sp. pini. In: Devey, M., C. Matheson, T. R. Gordon (Eds.). Current and potential impacts of pitch canker in radiata pine. Proc. IMPACT Monterey Workshop. Monterey, CA. 30 Nov.-3 Dec. 1998 (pp. 76-77). Australia: CSIRO.

Coleman, G. A. (1905). Report upon Monterey pine, made for the Pacific Improvement Company. Unpublished report, Pacific Southwest Forest and Range Experiment Station, Redding, CA.

Cook, D. C., \& Matheson, A. C. (2008). An estimate of the potential economic impact of pine pitch canker in Australia, Aust. For., 71(2), 107-112.

Cori, O., Valenzuela, P., Beytia, E., Yudelevich, A., Ruiz, F., Pino, A. et al. (1968). Biosynthesis of terpenes in Pinus radiata. Final Technical Report (Unpublished master's thesis). Universidad de Chile. Santiago, Chile.

Critchfield, W. B. (1967). Crossability and relationships of the California closed cone pines, Silvae Genet,, 16, 89-97. 
Cunningham, J. E., \& Pickard, M. A. (1985). Maltol, a metabolite of Scytalidium uredinicola which inhibits spore germination of Endocronartium harknessii, the western gall rust, Can. J. Microbiol., 31, 1051-1055.

Devey, M., Matheson, C., \& Gordon, T. R. (Eds.). Current and potential impacts of pitch canker in radiata pine. Proc. IMPACT Monterey Workshop. Monterey, CA. 30 Nov.-3 Dec. 1998 (pp. 35-39). Australia: CSIRO.

Dreistadt, S. H., \& Svihra, P. (2008). Pest notes: Sequoia pitch moth. UC ANR publication 7479. University of California Statewide IPM Program.

Dwinell, L. D. (1999). Association of the pitch canker fungus with cones and seeds of pines. In: Devey, M., C. Matheson, T. R. Gordon (Eds.). Current and potential impacts of pitch canker in radiata pine. Proc. IMPACT Monterey Workshop. Monterey, CA. 30 Nov.-3 Dec. 1998 (pp. 35-39). Australia: CSIRO.

Dwinell, L. D., Kuhlman, E. G., \& Blakeslee, G. M. (1981). Pitch canker of southern pines. In Nelson, P. E., Toussoun, T. A., \& Cook, R. J. (Eds.). Fusarium: Diseases, biology, and taxonomy (pp. 188-193). University Park, PA: Pennsylvania State Press.

Environmental Systems Research Institute, Inc. (ESRI). (n.d.). ArcGIS Desktop 9.3 Help. Retrieved from http://webhelp.esri.com/arcgisdesktop/9.3/index.cfm?id=2147\&pid=2146\&topicn $\underline{\text { ame=Average_Nearest_Neighbor_\%28Spatial_Statistics\%29 }}$.

Ganley, R. J. (2006). Pitch Canker: Risk of establishment in New Zealand based on a global perspective. Client Report No. 40217. Prepared for the Forest Biosecurity Research Council. Rotorua, New Zealand: ENSIS. 
Garbelotto, M., Smith, T., \& Schweigkofler, W. (2008). Variation in rates of spore deposition of Fusarium circinatum, the causal agent of pine pitch canker, over a 12-month-period at two locations in northern California, Phytopathology, 98, 137143.

Gill, R. M. A. (1992). A review of damage by mammals in north temperate forests: 1. Deer, Forestry, 65(2), 145-169.

Gordon, T. R., Storer, A. J., \& Wood, D. L. (2001). The pitch canker epidemic in California, Plant Dis., 85(11), 1128-1139.

Gordon, T. R., Okamoto, D., Storer, A. J., \& Wood, D. L. (1998). Susceptibility of five landscape pines to pitch canker disease, caused by Fusarium subglutinans f. sp. pini, HortScience. 33(5), 868-871.

The Gymnosperm Database. (2009). Pinus radiata. Earle, C. J. \& Frankis, M. P. (Eds.). Retrieved December 23, 2009, from http://www.conifers.org/pi/pin/radiata.htm Hepting, G. H., \& Roth, E. R. (1946). Pitch canker, a new disease of some southern pines, J. For., 44, 742-744.

Hodge, G. (1999). Screening of Mexican pines for pitch canker resistance. In: Devey, M., C. Matheson, T. R. Gordon (Eds.). Current and potential impacts of pitch canker in radiata pine. Proc. IMPACT Monterey Workshop. Monterey, CA. 30 Nov.-3 Dec. 1998 (pp. 90-94). Australia: CSIRO.

Hodge, G.R., \& Dvorak, W.S. (2000). Differential responses of Central American and Mexican pine species and Pinus radiata to infection by the pitch canker fungus, New Forests, 19, 241-258. 
Hodge, G. R., \& Dvorak, W. S. (2007). Variation in pitch canker resistance among provenances of Pinus patula and Pinus tecunumanii from Mexico and Central America, New Forests, 33, 193-206.

Hood, J. V., \& Libby, W. J. (1980). A clonal study of intraspecific variability in radiata pine. I. Cold and animal damage, Aust. For. Res., 10, 9-20.

Hoover, K., Wood, D. L., Fox, J. W., \& Bros, W. E. (1995). Quantitative and seasonal association of the pitch canker fungus, Fusarium subglutinans $\mathrm{f}$. sp. pini, with Conophthorus radiatae (Coleoptera: Scolytidae) and Ernobius punctulatus (Coleoptera: Anobiidae) which infest Pinus radiata, Can. Entomol., 127, 79-91. Inman, A. R., Kirkpatrick, S. C., Gordon, T. R., Shaw, D.V. (2008). Limiting effects of low temperature on growth and spore germination in Gibberella circinata, the cause of pitch canker in pine species, Plant Dis., 92(4), 542-545.

Kayihan, G. C., Huber, D. A., Morse, A. M., White, T. L., \& Davis, J. M. (2005). Genetic dissection of fusiform rust and pitch canker disease traits in loblolly pine, Theor Appl Genet., 110, 948-958.

Kim, Y. S., Woo, K. S., Koo, Y. B., \& Yeo, J. K. (2008). Variation in susceptibility of six pine species and hybrids to pitch canker caused by Fusarium circinatum, For. Path., 38, 419-428.

Lee, J. K., Lee, S. H., Yang, S. I., \& Lee, Y. W. (2000). First report of pitch canker disease on Pinus rigida in Korea, Plant Pathol. J., 16(1), 52-54.

Linhart, Y. B. (1978). Maintenance of variation in cone morphology in California closedcone pines: The role of fire, squirrels, and seed output, Southwest Nat., 23, 29-40. 
Lopez-Zamora, I., Bliss, C., Jokela, E. J., Comerford, N. B., Grunwald, S., Barnard, E., et al. (2007). Spatial relationships between nitrogen status and pitch canker disease in slash pine planted adjacent to a poultry operation, Environ. Pollut., 147, 101111.

Matheson, A. C., Devey, M. E., Gordon, T. L., Werner, W., Nogler, D. R., Balocchi, C., et al. (2006). Heritability of response to inoculation by pine pitch canker of seedlings of radiata pine. Aust. For. 69:101-106.

McCain, A. H., Koehler, C. S., \& Tjosvold, S. A. (1987). Pitch canker threatens California pines, Calif. Agric., 41, 22-23.

McDonald, P. M., \& Laacke, R. J. (1990). Pinus radiata D. Don. In: Silvics of North America: Conifers (pp. 433-441). USDA Forest Service Handbook No. 654.

Old, K. M., Libby, W. J., \& Russell, J. H. (1986). Genetic variability in susceptibility of Pinus radiata to western gall rust. Silvae Genetica, 35(4), 145-149.

Owen, D., \& Adams, D. (1999). Overview of pitch canker in California. In: Devey, M., C. Matheson, T. R. Gordon (Eds.). Current and potential impacts of pitch canker in radiata pine. Proc. IMPACT Monterey Workshop. Monterey, CA. 30 Nov.-3 Dec. 1998 (pp. 21-24). Australia: CSIRO.

Peterson, G. W. (1981). Diplodia blight of pines. For. Insect \& Dis. Leafl. 161. Washington. DC: U.S. Department of Agriculture. Forest Service.

Peterson, G. W., \& Nicholls, T. H. (1989). Diplodia blight. In Cordell, C. E., Anderson, R. L., Hoffard, W. H., Landis, T. D., Smith, R. S. Jr., \& Toko, H. V. (Eds.) Forest Nursery Pests. USDA Forest Service, Agriculture Handbook No. 680. 
Ramos, J. A., Bugalho, M. N., Cortez, P., \& Iason, G. R. (2006). Selection of trees for rubbing by red and roe deer in forest plantations, For. Ecol. Manage., 222, 39-45.

Rogers, D. L. (2002). In situ genetic conservation of Monterey pine (Pinus radiata D. Don): Information and recommendations. Report No. 26. University of California Division of Agriculture and Natural Resources, Genetic Resources Conservation Program, Davis, CA.

Roux, J., Eisenberg, B., Kanzler, A., Nel, A., Coetzee, V., Kietzka, E., et al. (2007). Testing of selected South African Pinus hybrids and families for tolerance to the pitch canker pathogen, Fusarium circinatum, New Forests., 33, 109-123.

SAS Institute Inc. (2008). SAS/STAT®9.2 User’s Guide. Cary, NC: SAS Institute Inc.

Sammon, S., Adams, D., Gordon, T., Frankel, S., \& Ringnes, D. (1999). Early results of screening for pitch canker resistance in the cambria population of Monterey pine (Pinus radiata). In: Devey, M., C. Matheson, T. R. Gordon (Eds.). Current and potential impacts of pitch canker in radiata pine. Proc. IMPACT Monterey Workshop. Monterey, CA. 30 Nov.-3 Dec. 1998 (pp. 95-97). Australia: CSIRO.

Shaw, D. C., Chen, J., Freeman, E. A., \& Braun, D. M. (2005). Spatial and population characteristics of dwarf mistletoe infected trees in an old-growth Douglas-firwestern hemlock forest, Can. J. For. Res., 35, 990-1001.

Sinclair, W. A., Lyon, H. H., \& Johnson, W. T. (1987). Diseases of trees and shrubs. Ithaca, NY: Cornell University Press.

Smith, W. H. (1970). Tree pathology: a short introduction. New York, NY: Academic Press, Inc. 
Storer, A. J., Gordon, T. R., Dallara, P. L., \& Wood, D. L. (1994). Pitch canker kills pines, spreads to new species and regions, Calif. Agric., 48(6), 9-13.

Storer, A. J., Wood, D. L., Wikler, K. R., \& Gordon T. R. (1998). Association between a native spittlebug (Homoptera:Cercopidae) on Monterey pine and an introduced tree pathogen which causes pitch canker disease, Can. Entomol., 130, 783-792.

Storer, A. J., Bonello, P., Gordon, T. R., \& Wood, D. L. (1999). Evidence of resistance to the pitch canker pathogen (Fusarium circinatum) in native stands of Monterey pine (Pinus radiata), For. Sci., 45(4), 500-505.

Sutton, W. R. J. (1995). Plantation forests protect our biodiversity. NZ For., 40, 2-5. van de Hoef, L. (2003). Radiata pine for farm forestry. Agriculture Notes AG0810 (State of Victoria, Department of Primary Industries).

Van der Kamp, B. J. (1994). Lodgepole pine stem diseases and management of stand density in the British Columbia interior, For. Chron., 70, 773-779.

Vogler, D., \& Kinloch, B. (1999). Variation in the radiata pine-western gall rust pathosystem: natural vs controlled inoculations. In: Devey, M., C. Matheson, T. R. Gordon (Eds.). Current and potential impacts of pitch canker in radiata pine. Proc. IMPACT Monterey Workshop. Monterey, CA. 30 Nov.-3 Dec. 1998 (pp. 98-99). Australia: CSIRO.

Welch, D., Staines, B. W., Scott, D., \& Catt, D. C. (1987). Bark stripping damage by red deer in a Sitka spruce forest in western Scotland. I. Incidence, Forestry, 60(2), 249-262. 
Welch, D., Staines, B. W., Scott, D., \& Catt, D. C. (1988). Bark stripping damage by red deer in a Sitka spruce forest in western Scotland. II. Wound size and position, Forestry, 61(3), 245-253.

Williamson, D., McLafferty, S., Goldsmith, V., Mollenkopf, J., \& McGuire, P. (1999, Jan-Mar). A better method to smooth crime incident data. ESRI ArcUser Magazine. Retrieved June 20, 2009 from http://www.esri.com/news/arcuser/0199/crimedata.html

Wingfield, M. J., Jacobs, A., Coutinho, T.A., Ahumada, R., \& Wingfield, B.D. (2002). First report of the pitch canker fungus, Fusarium circinatum, on pines in Chile, Plant Pathol., 51, 397.

Woo, K. S., Kim, Y. J., Kim, T. S., \& Lee, S. K. (2005). Selection of virulent isolates of Fusarium circinatum and investigation of pitch canker severity of Pinus rigida and P. rigida x P. taeda seed orchards in Jeju island, J. Korean For. Soc., 94, 402-409.

Zagory, D., \& Libby, W. J. (1985). Maturation-related resistance of Pinus radiata to western gall rust, Phytopathology, 75(12), 1443-1447. 


\section{APPENDICES}

Appendix A. List of seedstock tested, by country origin and suborigin.

Appendix B. Mean number of symptoms observed on each seedstock, by country origin.

Data is from 2009, with the most symptomatic stock listed first. 
Appendix A: List of seedstock tested, by country origin and suborigin. 


\begin{tabular}{|c|c|c|c|c|c|c|c|c|c|c|c|c|c|c|}
\hline \multicolumn{4}{|c|}{ AUSTRALIA } & $\begin{array}{c}\text { NEW } \\
\text { ZEALAND } \\
\text { NZ-XXX }\end{array}$ & \multicolumn{10}{|c|}{ CHILE } \\
\hline $\begin{array}{l}\text { C59XX } \\
\text { C6XXX }\end{array}$ & $\begin{array}{c}\text { CSIRO- } \\
\text { XXX }\end{array}$ & $\begin{array}{l}\text { CFTT- } \\
\text { XXX }\end{array}$ & $\begin{array}{c}\text { STBA- } \\
\text { XXX }\end{array}$ & NZ-XXX & $\begin{array}{c}\text { Bosques } \\
\text { Arauco } \\
\text { CPF1 } \\
\text { CPF3 } \\
\text { CPF4 } \\
\text { CPF5 } \\
\text { CPF6 } \\
\text { CPF37 } \\
\text { CPF42 } \\
\text { CPF43 } \\
\text { CPF47 } \\
\text { CPF53 } \\
\text { CPF61 }\end{array}$ & $\begin{array}{c}\text { Forestal } \\
\text { Celco } \\
\text { CPF12 } \\
\text { CPF13 } \\
\text { CPF14 } \\
\text { CPF15 } \\
\text { CPF79 } \\
\text { CPF80 } \\
\text { CPF81 } \\
\text { CPF85 } \\
\text { CPF87 } \\
\text { CPF89 } \\
\text { CPF90 } \\
\text { CPF91 } \\
\text { CPF92 } \\
\text { CPF93 } \\
\text { CPF96 } \\
\text { CPF97 } \\
\text { CPF98 } \\
\text { CPF100 } \\
\text { CPF10 }\end{array}$ & $\begin{array}{c}\text { Forestal } \\
\text { Bio bio } \\
\text { CPF8 } \\
\text { CPF9 }\end{array}$ & $\begin{array}{c}\text { Forestal } \\
\text { Cholguan } \\
\text { CPF16 } \\
\text { CPF17 } \\
\text { CPF102 } \\
\text { CPF103 } \\
\text { CPF104 } \\
\text { CPF105 } \\
\text { CPF107 }\end{array}$ & $\begin{array}{c}\text { Forestal } \\
\text { Millalemu } \\
\text { CPF18 } \\
\text { CPF19 } \\
\text { CPF20 } \\
\text { CPF108 } \\
\text { CPF109 } \\
\text { CPF110 } \\
\text { CPF112 } \\
\text { CPF115 } \\
\text { CPF116 } \\
\text { CPF117 }\end{array}$ & $\begin{array}{c}\text { Forestal } \\
\text { Mininco } \\
\text { CPF21 } \\
\text { CPF25 } \\
\text { CPF28 } \\
\text { CPF118 } \\
\text { CPF124 } \\
\text { CPF125 } \\
\text { CPF126 } \\
\text { CPF127 } \\
\text { CPF128 } \\
\text { CPF129 } \\
\text { CPF133 } \\
\text { CPF134 } \\
\text { CPF135 } \\
\text { CPF137 } \\
\text { CPF138 } \\
\text { CPF143 } \\
\text { CPF146 } \\
\text { CPF147 } \\
\text { CPF148 } \\
\text { CPF150 } \\
\text { CPF151 } \\
\text { CPF152 }\end{array}$ & $\begin{array}{l}\text { Tornagaleones } \\
\text { CPF31 }\end{array}$ & $\begin{array}{l}\text { Forestal } \\
\text { Valdivia } \\
\text { CPF32 } \\
\text { CPF33 } \\
\text { CPF34 } \\
\text { CPF35 } \\
\text { CPF161 } \\
\text { CPF162 } \\
\text { CPF163 } \\
\text { CPF165 } \\
\text { CPF166 }\end{array}$ & $\begin{array}{l}\text { Bosques } \\
\text { de Chile } \\
\text { CPF7 }\end{array}$ & $\begin{array}{c}\text { Cementos } \\
\text { Bio bio } \\
\text { CPF11 } \\
\text { CPF66 } \\
\text { CPF67 }\end{array}$ \\
\hline
\end{tabular}

Suborigin \#

\begin{tabular}{|lllllllllllllll}
\hline 1 & 2 & 3 & 4 & 5 & 6 & 7 & 8 & 9 & 10 & 11 & 12 & 13 & 14 \\
\hline
\end{tabular}


Appendix B: Mean number of symptoms observed on each seedstock, by country origin. Data is from 2009, with the most symptomatic stock listed first. 


\begin{tabular}{|c|c|c|c|c|}
\hline $\begin{array}{l}\text { AUSTRALIA } \\
\text { STOCK }\end{array}$ & Branch flags & Pitchy Buds & $\begin{array}{l}\text { Chlorotic } \\
\text { branch tips }\end{array}$ & Total \\
\hline C6176 & 11.8 & 2.4 & 3.1 & 17.3 \\
\hline CFTT019 & 7.4 & 9.2 & 0.5 & 17.1 \\
\hline C6003 & 0.7 & 6 & 4.3 & 11 \\
\hline STBA069 & 2.9 & 1.6 & 6.3 & 10.8 \\
\hline CSIRO143 & 2.5 & 6.2 & 1.4 & 10.1 \\
\hline C5986 & 1.7 & 8 & 0.1 & 9.8 \\
\hline CSIRO148 & 0.5 & 1.8 & 6.3 & 8.6 \\
\hline CSIRO123 & 0.9 & 1.1 & 5.8 & 7.8 \\
\hline C6004 & 1 & 6.1 & 0 & 7.1 \\
\hline C5993 & 0.8 & 3 & 3 & 6.8 \\
\hline C6159 & 2.8 & 2 & 1.8 & 6.6 \\
\hline STBA092 & 0.7 & 1.7 & 3.7 & 6.1 \\
\hline C6037 & 0.9 & 3.3 & 1.4 & 5.6 \\
\hline STBA057 & 1.9 & 1 & 2.6 & 5.5 \\
\hline C5973 & 0 & 4.2 & 1.2 & 5.4 \\
\hline C6073 & 1.5 & 2.5 & 1.2 & 5.2 \\
\hline C6141 & 1.7 & 2.4 & 1.1 & 5.2 \\
\hline C6149 & 0.2 & 2.6 & 2.2 & 5 \\
\hline C5972 & 2.7 & 2.1 & 0 & 4.8 \\
\hline STBA090 & 0.6 & 2.8 & 1.3 & 4.7 \\
\hline C5938 & 0.4 & 1 & 2.8 & 4.2 \\
\hline C6142 & 1 & 0.8 & 2.3 & 4.1 \\
\hline CFTT026 & 0.8 & 0 & 3.1 & 3.9 \\
\hline C6155 & 1 & 0.8 & 2 & 3.8 \\
\hline C6008 & 0.3 & 0.6 & 2.7 & 3.6 \\
\hline C6090 & 0.4 & 0.7 & 2.1 & 3.2 \\
\hline CSIRO136 & 1.5 & 1.7 & 0 & 3.2 \\
\hline C5922 & 1.7 & 1.3 & 0.1 & 3.1 \\
\hline CSIRO119 & 0.5 & 0.4 & 2.2 & 3.1 \\
\hline CSIRO125 & 0.1 & 2.3 & 0.5 & 2.9 \\
\hline C6013 & 1.1 & 0.3 & 1.4 & 2.8 \\
\hline C6027 & 0.7 & 1.1 & 0.8 & 2.6 \\
\hline C6071 & 0 & 2 & 0.6 & 2.6 \\
\hline C6244 & 1.1 & 0 & 1.5 & 2.6 \\
\hline CSIRO186 & 1.2 & 0.7 & 0.7 & 2.6 \\
\hline C6300 & 0.7 & 1.6 & 0.1 & 2.4 \\
\hline CSIRO155 & 0.2 & 1 & 1.2 & 2.4 \\
\hline CSIR0187 & 1 & 1.3 & 0.1 & 2.4 \\
\hline STBA061 & 0.6 & 1.4 & 0.4 & 2.4 \\
\hline C6158 & 0.2 & 0.4 & 1.6 & 2.2 \\
\hline C6241 & 1.1 & 1 & 0.1 & 2.2 \\
\hline
\end{tabular}




\begin{tabular}{|c|c|c|c|c|}
\hline C5937 & 0.4 & 0.8 & 0.9 & 2.1 \\
\hline C6010 & 0.7 & 1.1 & 0.1 & 1.9 \\
\hline C6146 & 1.1 & 0.8 & 0 & 1.9 \\
\hline C6156 & 1 & 0.8 & 0.1 & 1.9 \\
\hline STBA094 & 0.2 & 0.4 & 1.3 & 1.9 \\
\hline C6157 & 0.4 & 1.1 & 0.3 & 1.8 \\
\hline C6143 & 0.4 & 1.3 & 0 & 1.7 \\
\hline C5996 & 0.6 & 0.6 & 0.4 & 1.6 \\
\hline C6145 & 0.3 & 0.8 & 0.5 & 1.6 \\
\hline C6152 & 0.5 & 0.4 & 0.7 & 1.6 \\
\hline C6183 & 1 & 0.5 & 0.1 & 1.6 \\
\hline C6031 & 0.8 & 0.6 & 0.2 & 1.6 \\
\hline C5998 & 0.2 & 1.3 & 0 & 1.5 \\
\hline C6162 & 0 & 0.1 & 1.4 & 1.5 \\
\hline CFTT027 & 1.4 & 0.1 & 0 & 1.5 \\
\hline C6138 & 1.2 & 0.1 & 0.1 & 1.4 \\
\hline C6144 & 0.4 & 0.7 & 0.3 & 1.4 \\
\hline C6150 & 1.2 & 0.1 & 0.1 & 1.4 \\
\hline CSIR0140 & 0.3 & 0.8 & 0.3 & 1.4 \\
\hline C5992 & 0.7 & 0.6 & 0 & 1.3 \\
\hline C6044 & 0.7 & 0.1 & 0.5 & 1.3 \\
\hline C6114 & 0.5 & 0.6 & 0.1 & 1.2 \\
\hline C6009 & 0.3 & 0.4 & 0.5 & 1.2 \\
\hline C6139 & 0.3 & 0.3 & 0.6 & 1.2 \\
\hline C5944 & 0.7 & 0 & 0.4 & 1.1 \\
\hline C6005 & 0.6 & 0.3 & 0.2 & 1.1 \\
\hline C5982 & 0.9 & 0.1 & 0 & 1 \\
\hline C6102 & 0.4 & 0.6 & 0 & 1 \\
\hline CFTT014 & 0.2 & 0.5 & 0.3 & 1 \\
\hline C6148 & 0.8 & 0.1 & 0 & 0.9 \\
\hline C6030 & 0.4 & 0.3 & 0.2 & 0.9 \\
\hline CFTT017 & 0.4 & 0.1 & 0.3 & 0.8 \\
\hline C6161 & 0.5 & 0.2 & 0.1 & 0.8 \\
\hline C5989 & 0.1 & 0.6 & 0 & 0.7 \\
\hline C6055 & 0.5 & 0.2 & 0 & 0.7 \\
\hline C6006 & 0.4 & 0.1 & 0.1 & 0.6 \\
\hline C6062 & 0.6 & 0 & 0 & 0.6 \\
\hline C6063 & 0.3 & 0.3 & 0 & 0.6 \\
\hline C6276 & 0.3 & 0.2 & 0.1 & 0.6 \\
\hline CSIRO211 & 0.6 & 0 & 0 & 0.6 \\
\hline C6101 & 0.2 & 0.1 & 0.2 & 0.5 \\
\hline C6166 & 0.1 & 0.1 & 0.3 & 0.5 \\
\hline C5997 & 0.3 & 0.1 & 0 & 0.4 \\
\hline C6298 & 0.1 & 0 & 0.3 & 0.4 \\
\hline C6036 & 0.2 & 0 & 0.1 & 0.3 \\
\hline C6043 & 0.2 & 0 & 0.1 & 0.3 \\
\hline C6164 & 0.3 & 0 & 0 & 0.3 \\
\hline STBA053 & 0.3 & 0 & 0 & 0.3 \\
\hline C6109 & 0.1 & 0.1 & 0 & 0.2 \\
\hline
\end{tabular}




$\begin{array}{lllll}\text { C6116 } & 0.2 & 0 & 0 & 0.2 \\ \text { C6137 } & 0.1 & 0 & 0.1 & 0.2 \\ \text { CSIRO218 } & 0.1 & 0.1 & 0 & 0.2 \\ \text { STBA079 } & 0.1 & 0 & 0.1 & 0.2 \\ \text { CSIRO150 } & 0.1 & 0 & 0 & 0.1 \\ \text { C5964 } & 0 & 0 & 0 & 0 \\ \text { C6021 } & 0 & 0 & 0 & 0\end{array}$




\begin{tabular}{|c|c|c|c|c|}
\hline $\begin{array}{l}\text { NEW ZEALAND } \\
\text { STOCK }\end{array}$ & $\begin{array}{l}\text { Branch } \\
\text { flags }\end{array}$ & Pitchy Buds & $\begin{array}{l}\text { Chlorotic } \\
\text { branch tips }\end{array}$ & Total \\
\hline NZ139 & 2.6 & 3.1 & 11.4 & 17.1 \\
\hline NZ100 & 2.6 & 3.5 & 10 & 16.1 \\
\hline NZ79 & 1.5 & 6.4 & 6.4 & 14.3 \\
\hline NZ131 & 4 & 2.9 & 6.8 & 13.7 \\
\hline NZ39 & 2.5 & 6 & 5.1 & 13.6 \\
\hline NZ30 & 3.7 & 4.3 & 1.9 & 9.9 \\
\hline NZ133 & 0.7 & 5 & 1.8 & 7.5 \\
\hline NZ135 & 3 & 1.2 & 3.1 & 7.3 \\
\hline NZ124 & 0.2 & 1.9 & 3.9 & 6 \\
\hline NZ26 & 0.1 & 5.6 & 0.1 & 5.8 \\
\hline NZ2 & 0.3 & 3.2 & 2.2 & 5.7 \\
\hline NZ16 & 0.9 & 1.9 & 2.8 & 5.6 \\
\hline NZ41 & 1 & 1.7 & 2.5 & 5.2 \\
\hline NZ5 & 1.7 & 2.2 & 1.3 & 5.2 \\
\hline NZ86 & 1.2 & 0.8 & 3.1 & 5.1 \\
\hline NZ36 & 1.5 & 1.1 & 2.4 & 5 \\
\hline NZ48 & 0.4 & 3.6 & 1 & 5 \\
\hline NZ21 & 1.1 & 3.8 & 0 & 4.9 \\
\hline NZ132 & 2.3 & 0.2 & 2.3 & 4.8 \\
\hline NZ11 & 0.9 & 1.5 & 2.3 & 4.7 \\
\hline NZ123 & 0.8 & 2.6 & 1.2 & 4.6 \\
\hline NZ55 & 2.1 & 0.9 & 1.6 & 4.6 \\
\hline NZ71 & 1.4 & 1.1 & 2.1 & 4.6 \\
\hline NZ110 & 0.2 & 0.6 & 3.4 & 4.2 \\
\hline NZ44 & 0.1 & 4 & 0 & 4.1 \\
\hline NZ62 & 1.6 & 0.7 & 1.6 & 3.9 \\
\hline NZ104 & 0.6 & 2.9 & 0.3 & 3.8 \\
\hline NZ51 & 1.4 & 0.8 & 1.5 & 3.7 \\
\hline NZ1 & 0.4 & 0.8 & 2.4 & 3.6 \\
\hline NZ136 & 1.7 & 0.2 & 1.4 & 3.3 \\
\hline NZ28 & 0.4 & 1.5 & 1.2 & 3.1 \\
\hline NZ67 & 0.1 & 1.7 & 1.2 & 3 \\
\hline NZ95 & 1.2 & 0.4 & 1.2 & 2.8 \\
\hline NZ12 & 1.1 & 1 & 0.6 & 2.7 \\
\hline NZ58 & 1.9 & 0.6 & 0.1 & 2.6 \\
\hline NZ6 & 0.9 & 0.9 & 0.8 & 2.6 \\
\hline NZ119 & 0.4 & 1.7 & 0.3 & 2.4 \\
\hline NZ70 & 0.4 & 1.6 & 0.2 & 2.2 \\
\hline NZ8 & 1.3 & 0.1 & 0.8 & 2.2 \\
\hline NZ94 & 0.1 & 2 & 0.1 & 2.2 \\
\hline NZ82 & 0.8 & 0.6 & 0.7 & 2.1 \\
\hline NZ47 & 0.7 & 0.4 & 0.9 & 2 \\
\hline NZ103 & 0.7 & 0.9 & 0.3 & 1.9 \\
\hline NZ43 & 0 & 1.6 & 0.3 & 1.9 \\
\hline NZ7 & 0.8 & 0.9 & 0.1 & 1.8 \\
\hline
\end{tabular}




\begin{tabular}{|c|c|c|c|c|}
\hline NZ33 & 0.2 & 1.3 & 0.2 & 1.7 \\
\hline NZ66 & 0.8 & 0.6 & 0.3 & 1.7 \\
\hline NZ40 & 0.2 & 0.5 & 0.9 & 1.6 \\
\hline NZ74 & 0.1 & 0.5 & 1 & 1.6 \\
\hline NZ92 & 0.2 & 1.1 & 0.3 & 1.6 \\
\hline NZ106 & 0.4 & 0.7 & 0.4 & 1.5 \\
\hline NZ109 & 0 & 1.3 & 0.1 & 1.4 \\
\hline NZ17 & 0.2 & 0 & 1.2 & 1.4 \\
\hline NZ31 & 1.4 & 0 & 0 & 1.4 \\
\hline NZ4 & 0.9 & 0.1 & 0.4 & 1.4 \\
\hline NZ120 & 0.4 & 0.4 & 0.5 & 1.3 \\
\hline NZ19 & 0.8 & 0 & 0.4 & 1.2 \\
\hline NZ63 & 0 & 0.8 & 0.4 & 1.2 \\
\hline NZ23 & 0.3 & 0.1 & 0.6 & 1 \\
\hline NZ45 & 0.6 & 0 & 0.4 & 1 \\
\hline NZ105 & 0.4 & 0.5 & 0 & 0.9 \\
\hline NZ142 & 0.4 & 0.2 & 0.1 & 0.7 \\
\hline NZ3 & 0.4 & 0 & 0.3 & 0.7 \\
\hline NZ93 & 0.3 & 0.1 & 0.3 & 0.7 \\
\hline NZ35 & 0.5 & 0.1 & 0 & 0.6 \\
\hline NZ107 & 0.1 & 0.3 & 0.1 & 0.5 \\
\hline NZ112 & 0.1 & 0.3 & 0 & 0.4 \\
\hline NZ140 & 0.3 & 0.1 & 0 & 0.4 \\
\hline NZ52 & 0.4 & 0 & 0 & 0.4 \\
\hline NZ78 & 0.2 & 0.1 & 0.1 & 0.4 \\
\hline NZ75 & 0.1 & 0.1 & 0.1 & 0.3 \\
\hline NZ97 & 0.2 & 0.1 & 0 & 0.3 \\
\hline NZ27 & 0.3 & 0 & 0 & 0.3 \\
\hline NZ134 & 0.1 & 0.1 & 0 & 0.2 \\
\hline NZ29 & 0.2 & 0 & 0 & 0.2 \\
\hline NZ37 & 0.2 & 0 & 0 & 0.2 \\
\hline NZ42 & 0.2 & 0 & 0 & 0.2 \\
\hline NZ60 & 0.1 & 0 & 0.1 & 0.2 \\
\hline NZ121 & 0.1 & 0 & 0 & 0.1 \\
\hline NZ18 & 0.1 & 0 & 0 & 0.1 \\
\hline NZ143 & 0 & 0 & 0 & 0 \\
\hline
\end{tabular}




\begin{tabular}{|c|c|c|c|c|}
\hline $\begin{array}{l}\text { CHILE } \\
\text { STOCK }\end{array}$ & $\begin{array}{l}\text { Branch } \\
\text { flags }\end{array}$ & Pitchy Buds & $\begin{array}{l}\text { Chlorotic } \\
\text { branch tips }\end{array}$ & Total \\
\hline CPF66 & 0.9 & 6.2 & 7.1 & 14.2 \\
\hline CPF53 & 1.6 & 6.5 & 2.3 & 10.4 \\
\hline CPF161 & 5.5 & 4.1 & 0 & 9.6 \\
\hline CPF87 & 0.4 & 4.2 & 3 & 7.6 \\
\hline CPF162 & 5 & 0.8 & 0.6 & 6.4 \\
\hline CPF34 & 0.8 & 2.1 & 2.5 & 5.4 \\
\hline CPF3 & 0.6 & 2.2 & 2.2 & 5 \\
\hline CPF80 & 1.1 & 2.8 & 1.1 & 5 \\
\hline CPF133 & 0.4 & 0.4 & 3.9 & 4.7 \\
\hline CPF98 & 1.4 & 1.3 & 2 & 4.7 \\
\hline CPF6 & 0.1 & 4.2 & 0 & 4.3 \\
\hline CPF33 & 1.1 & 1.7 & 0.4 & 3.2 \\
\hline CPF61 & 0.9 & 0.6 & 1.6 & 3.1 \\
\hline CPF146 & 0.1 & 2.7 & 0.1 & 2.9 \\
\hline CPF96 & 0.2 & 1.9 & 0.8 & 2.9 \\
\hline CPF81 & 1.3 & 0.9 & 0.6 & 2.8 \\
\hline CPF79 & 1.7 & 0 & 1.1 & 2.8 \\
\hline CPF37 & 1.4 & 0.7 & 0.5 & 2.6 \\
\hline CPF17 & 1 & 0.9 & 0.6 & 2.5 \\
\hline CPF18 & 0.7 & 0.9 & 0.8 & 2.4 \\
\hline CPF21 & 0.8 & 1.1 & 0.4 & 2.3 \\
\hline CPF102 & 0.6 & 0.6 & 1.1 & 2.3 \\
\hline CPF85 & 0.5 & 1.3 & 0.5 & 2.3 \\
\hline CPF25 & 0.1 & 1.1 & 1 & 2.2 \\
\hline CPF31 & 0.1 & 1.3 & 0.7 & 2.1 \\
\hline CPF147 & 0.2 & 0.7 & 1.2 & 2.1 \\
\hline CPF28 & 0.6 & 0.8 & 0.6 & 2 \\
\hline CPF92 & 0.9 & 1.1 & 0 & 2 \\
\hline CPF32 & 0.9 & 0 & 0.9 & 1.8 \\
\hline CPF135 & 0.4 & 1.4 & 0 & 1.8 \\
\hline CPF42 & 0.8 & 0.7 & 0.2 & 1.7 \\
\hline CPF97 & 0.1 & 0.9 & 0.7 & 1.7 \\
\hline CPF117 & 0.8 & 0.8 & 0 & 1.6 \\
\hline CPF35 & 0.3 & 1.1 & 0.2 & 1.6 \\
\hline CPF47 & 0.4 & 0.8 & 0.1 & 1.3 \\
\hline CPF15 & 0.4 & 0.9 & 0 & 1.3 \\
\hline CPF125 & 0.1 & 0.6 & 0.6 & 1.3 \\
\hline CPF93 & 0.6 & 0.6 & 0 & 1.2 \\
\hline CPF143 & 0.6 & 0.5 & 0 & 1.1 \\
\hline CPF43 & 0.8 & 0.1 & 0.2 & 1.1 \\
\hline CPF9 & 0.2 & 0 & 0.9 & 1.1 \\
\hline CPF112 & 0.8 & 0 & 0.2 & 1 \\
\hline CPF150 & 0.9 & 0.1 & 0 & 1 \\
\hline CPF4 & 0 & 0.9 & 0.1 & 1 \\
\hline CPF5 & 0.1 & 0.8 & 0.1 & 1 \\
\hline
\end{tabular}




\begin{tabular}{|c|c|c|c|c|}
\hline CPF148 & 0.4 & 0.3 & 0.2 & 0.9 \\
\hline CPF115 & 0.4 & 0.4 & 0 & 0.8 \\
\hline CPF19 & 0 & 0.4 & 0.4 & 0.8 \\
\hline CPF12 & 0.2 & 0.5 & 0.1 & 0.8 \\
\hline CPF128 & 0.7 & 0.1 & 0 & 0.8 \\
\hline CPF1 & 0.4 & 0.1 & 0.2 & 0.7 \\
\hline CPF13 & 0.2 & 0.3 & 0.2 & 0.7 \\
\hline CPF163 & 0.1 & 0.6 & 0 & 0.7 \\
\hline CPF166 & 0.7 & 0 & 0 & 0.7 \\
\hline CPF107 & 0.4 & 0 & 0.2 & 0.6 \\
\hline CPF151 & 0.4 & 0.2 & 0 & 0.6 \\
\hline CPF103 & 0.1 & 0.5 & 0 & 0.6 \\
\hline CPF104 & 0.5 & 0.1 & 0 & 0.6 \\
\hline CPF124 & 0.6 & 0 & 0 & 0.6 \\
\hline CPF127 & 0 & 0.5 & 0.1 & 0.6 \\
\hline CPF67 & 0.4 & 0.1 & 0.1 & 0.6 \\
\hline CPF134 & 0 & 0.4 & 0.1 & 0.5 \\
\hline CPF14 & 0.3 & 0.1 & 0.1 & 0.5 \\
\hline CPF7 & 0.1 & 0.3 & 0.1 & 0.5 \\
\hline CPF89 & 0.4 & 0 & 0.1 & 0.5 \\
\hline CPF110 & 0.2 & 0.1 & 0.1 & 0.4 \\
\hline CPF11 & 0.2 & 0 & 0.1 & 0.3 \\
\hline CPF129 & 0.1 & 0.1 & 0.1 & 0.3 \\
\hline CPF116 & 0.3 & 0 & 0 & 0.3 \\
\hline CPF118 & 0.3 & 0 & 0 & 0.3 \\
\hline CPF10 & 0.1 & 0 & 0.1 & 0.2 \\
\hline CPF100 & 0.2 & 0 & 0 & 0.2 \\
\hline CPF105 & 0.1 & 0 & 0.1 & 0.2 \\
\hline CPF126 & 0.1 & 0 & 0.1 & 0.2 \\
\hline CPF138 & 0.2 & 0 & 0 & 0.2 \\
\hline CPF152 & 0 & 0.2 & 0 & 0.2 \\
\hline CPF91 & 0.2 & 0 & 0 & 0.2 \\
\hline CPF109 & 0.1 & 0 & 0 & 0.1 \\
\hline CPF16 & 0.1 & 0 & 0 & 0.1 \\
\hline CPF20 & 0 & 0.1 & 0 & 0.1 \\
\hline CPF108 & 0 & 0 & 0 & 0 \\
\hline CPF137 & 0 & 0 & 0 & 0 \\
\hline CPF165 & 0 & 0 & 0 & 0 \\
\hline CPF8 & 0 & 0 & 0 & 0 \\
\hline
\end{tabular}

